Cochrane Database of Systematic Reviews

\title{
One-to-one oral hygiene advice provided in a dental setting for oral health (Review)
}

Soldani FA, Lamont T, Jones K, Young L, Walsh T, Lala R, Clarkson JE

Soldani FA, Lamont T, Jones K, Young L, Walsh T, Lala R, Clarkson JE.

One-to-one oral hygiene advice provided in a dental setting for oral health.

Cochrane Database of Systematic Reviews 2018, Issue 10. Art. No.: CD007447.

DOI: 10.1002/14651858.CD007447.pub2.

www.cochranelibrary.com 
TABLE OF CONTENTS

ABSTRACT

PLAIN LANGUAGE SUMMARY

SUMMARY OF FINDINGS

BACKGROUND

OBJECTIVES

METHODS

RESULTS

Figure 1.

Figure 2.

Figure 3.

DISCUSSION

AUTHORS' CONCLUSIONS

ACKNOWLEDGEMENTS

REFERENCES

CHARACTERISTICS OF STUDIES

ADDITIONAL TABLES

APPENDICES

CONTRIBUTIONS OF AUTHORS

DECLARATIONS OF INTEREST

SOURCES OF SUPPORT

DIFFERENCES BETWEEN PROTOCOL AND REVIEW

INDEX TERMS 
[Intervention Review]

\section{One-to-one oral hygiene advice provided in a dental setting for oral health}

Francesca A Soldani ${ }^{1}$, Thomas Lamont ${ }^{2}$, Kate Jones ${ }^{3}$, Linda Young 4 , Tanya Walsh ${ }^{5}$, Rizwana Lala6, Janet E Clarkson?

1Community Dental Service, Bradford District Care NHS Foundation Trust, Bradford, UK. 2University of Dundee, Dental School \& Hospital, Dundee, UK. ${ }^{3}$ Public Health England, London, UK. ${ }^{4}$ Scottish Dental Clinical Effectiveness Programme, NHS Education for Scotland, Dundee, UK. ${ }^{5}$ Division of Dentistry, School of Medical Sciences, Faculty of Biology, Medicine and Health, The University of Manchester, Manchester, UK. 6Unit of Dental Public Health, School of Clinical Dentistry, University of Sheffield, Sheffield, UK. ${ }^{7}$ Division of Oral Health Sciences, Dundee Dental School, University of Dundee, Dundee, UK

Contact: Francesca A Soldani, Community Dental Service, Bradford District Care NHS Foundation Trust, Bradford, UK. frankie.soldani@bdct.nhs.uk.

Editorial group: Cochrane Oral Health Group.

Publication status and date: New, published in Issue 10, 2018.

Citation: Soldani FA, Lamont T, Jones K, Young L, Walsh T, Lala R, Clarkson JE. One-to-one oral hygiene advice provided in a dental setting for oral health. Cochrane Database of Systematic Reviews 2018, Issue 10. Art. No.: CD007447. DOI: 10.1002/14651858.CD007447.pub2.

Copyright @ 2018 The Cochrane Collaboration. Published by John Wiley \& Sons, Ltd.

\section{A B S T R A C T}

\section{Background}

Effective oral hygiene measures carried out on a regular basis are vital to maintain good oral health. One-to-one oral hygiene advice (OHA) within the dental setting is often provided as a means to motivate individuals and to help achieve improved levels of oral health. However, it is unclear if one-to-one OHA in a dental setting is effective in improving oral health and what method(s) might be most effective and efficient.

\section{Objectives}

To assess the effects of one-to-one OHA, provided by a member of the dental team within the dental setting, on patients' oral health, hygiene, behaviour, and attitudes compared to no advice or advice in a different format.

\section{Search methods}

Cochrane Oral Health's Information Specialist searched the following databases: Cochrane Oral Health's Trials Register (to 10 November 2017); the Cochrane Central Register of Controlled Trials (CENTRAL; 2017, Issue 10) in the Cochrane Library (searched 10 November 2017); MEDLINE Ovid (1946 to 10 November 2017); and Embase Ovid (1980 to 10 November 2017). The US National Institutes of Health Ongoing Trials Register (ClinicalTrials.gov) and the World Health Organization International Clinical Trials Registry Platform were also searched for ongoing trials (10 November 2017). No restrictions were placed on the language or date of publication when searching the electronic databases. Reference lists of relevant articles and previously published systematic reviews were handsearched. The authors of eligible trials were contacted, where feasible, to identify any unpublished work.

\section{Selection criteria}

We included randomised controlled trials assessing the effects of one-to-one OHA delivered by a dental care professional in a dental care setting with a minimum of 8 weeks follow-up. We included healthy participants or participants who had a well-defined medical condition.

\section{Data collection and analysis}

At least two review authors carried out selection of studies, data extraction and risk of bias independently and in duplicate. Consensus was achieved by discussion, or involvement of a third review author if required. 


\section{Main results}

Nineteen studies met the criteria for inclusion in the review with data available for a total of 4232 participants. The included studies reported a wide variety of interventions, study populations, clinical outcomes and outcome measures. There was substantial clinical heterogeneity amongst the studies and it was not deemed appropriate to pool data in a meta-analysis. We summarised data by categorising similar interventions into comparison groups.

\section{Comparison 1: Any form of one-to-one OHA versus no OHA}

Four studies compared any form of one-to-one OHA versus no OHA.

Two studies reported the outcome of gingivitis. Although one small study had contradictory results at 3 months and 6 months, the other study showed very low-quality evidence of a benefit for OHA at all time points (very low-quality evidence).

The same two studies reported the outcome of plaque. There was low-quality evidence that these interventions showed a benefit for OHA in plaque reduction at all time points.

Two studies reported the outcome of dental caries at 6 months and 12 months respectively. There was very low-quality evidence of a benefit for $\mathrm{OHA}$ at 12 months.

\section{Comparison 2: Personalised one-to-one OHA versus routine one-to-one OHA}

Four studies compared personalised OHA versus routine $\mathrm{OHA}$.

There was little evidence available that any of these interventions demonstrated a difference on the outcomes of gingivitis, plaque or dental caries (very low quality).

\section{Comparison 3: Self-management versus professional OHA}

Five trials compared some form of self-management with some form of professional OHA.

There was little evidence available that any of these interventions demonstrated a difference on the outcomes of gingivitis or plaque (very low quality). None of the studies measured dental caries.

\section{Comparison 4: Enhanced one-to-one OHA versus one-to-one OHA}

Seven trials compared some form of enhanced $\mathrm{OHA}$ with some form of routine $\mathrm{OHA}$.

There was little evidence available that any of these interventions demonstrated a difference on the outcomes of gingivitis, plaque or dental caries (very low quality).

\section{Authors' conclusions}

There was insufficient high-quality evidence to recommend any specific one-to-one OHA method as being effective in improving oral health or being more effective than any other method. Further high-quality randomised controlled trials are required to determine the most effective, efficient method of one-to-one OHA for oral health maintenance and improvement. The design of such trials should be cognisant of the limitations of the available evidence presented in this Cochrane Review.

\section{PLAIN LANGUAGE SUMMARY}

\section{One-to-one oral hygiene advice for oral health}

\section{Review question}

The aim of this review was to assess the effects of one-to-one oral hygiene advice, provided by a member of the dental team within the dental setting, on patients' oral health, hygiene, behaviour, and attitudes compared to no advice or advice in a different format.

\section{Background}

Poor oral hygiene habits are known to be associated with high rates of dental decay and gum disease. The dental team routinely assess oral hygiene methods, frequency and effectiveness or otherwise of oral hygiene routines carried out by their patients; one-to-one oral hygiene advice is regularly provided by members of the dental team with the aim of motivating individuals and improving their oral health. The most effective method of delivering one-to-one advice in the dental setting is unclear. This review's aim is to determine if providing patients with one-to-one oral hygiene advice in the dental setting is effective and if so what is the best way to deliver this advice.

\section{Study characteristics}


Authors from Cochrane Oral Health carried out this review and the evidence is up to date to 10 November 2017. We included research where individual patients received oral hygiene advice from a dental care professional on a one-to-one basis in a dental clinic setting with a minimum of 8 weeks follow-up.

In total, within the identified 19 studies, oral hygiene advice was provided by a hygienist in eight studies, dentist in four studies, dental nurse in one study, dentist or hygienist in one study, dental nurse and hygienist in one study, and dental nurse oral hygiene advice to the control group with further self-administration of the intervention in one study. It was unclear in three of the studies which member of the dental team carried out the intervention. Over half of the studies (10 of the 19) were conducted in a hospital setting, with only five studies conducted in a general dental practice setting (where oral hygiene advice is largely delivered).

\section{Key results}

Overall we found insufficient evidence to recommend any specific method of one- to-one oral hygiene advice as being more effective than another in maintaining or improving oral health.

The studies we found varied considerably in how the oral hygiene advice was delivered, by whom and what outcomes were looked at. Due to this it was difficult to readily compare these studies and further well designed studies should be conducted to give a more accurate conclusion as to the most effective method of maintaining or improving oral health through one-to-one oral hygiene advice delivered by a dental care professional in a dental setting.

\section{Quality of the evidence}

We judged the quality of the evidence to be very low due to problems with the design of the studies. 


\section{SUMMARY OF FINDINGS}

\section{Summary of findings for the main comparison. Summary of findings - Any form of one-to-one oral hygiene advice (OHA) versus no OHA}

\section{Any form of 1-to-1 OHA versus no OHA in a dental setting for oral health}

Patient or population: children or adults

Settings: dental surgery/office setting

Intervention: any form of 1-to-1 OHA

Comparison: no OHA

\begin{tabular}{|c|c|c|c|}
\hline Outcomes & $\begin{array}{l}\text { Number of partici- } \\
\text { pants } \\
\text { (studies) }\end{array}$ & $\begin{array}{l}\text { Quality of the evi- } \\
\text { dence } \\
\text { (GRADE) }\end{array}$ & Comments \\
\hline $\begin{array}{l}\text { Periodontal health: } \\
\text { gingivitis }\end{array}$ & $\begin{array}{l}477 \text { participants ( } 2 \\
\text { studies); follow-up: } 235 \\
\text { participants }\end{array}$ & $\begin{array}{l}\oplus \odot \odot \odot \\
\text { very low } 1\end{array}$ & $\begin{array}{l}1 \text { small study in adults had contradictory results at } 3 \\
\text { months and } 6 \text { months } \\
\text { The other study in adults showed evidence of a benefit for } \\
\text { OHA at all time points of } 12 \text { months, } 24 \text { months, and } 36 \\
\text { months }\end{array}$ \\
\hline $\begin{array}{l}\text { Periodontal health: } \\
\text { plaque levels }\end{array}$ & $\begin{array}{l}477 \text { participants ( } 2 \\
\text { studies); follow-up: } 235 \\
\text { participants }\end{array}$ & $\begin{array}{l}\oplus \oplus \Theta \Theta \\
\text { low } 2\end{array}$ & $\begin{array}{l}\text { Both studies at all time points consistently showed a bene- } \\
\text { fit in plaque reduction for OHA }\end{array}$ \\
\hline Dental caries & $\begin{array}{l}377 \text { participants ( } 2 \\
\text { studies); follow- up: } 244 \\
\text { participants }\end{array}$ & $\begin{array}{l}\oplus \odot \odot \odot \\
\text { very low } 3\end{array}$ & $\begin{array}{l}1 \text { study in adults reported only "small and statistically in- } \\
\text { significant changes" but no usable data reported } \\
\text { The other study on infants provided very low-quality evi- } \\
\text { dence of a benefit for OHA at } 8 \text { months and } 12 \text { months, but } \\
\text { not at } 4 \text { months }\end{array}$ \\
\hline
\end{tabular}

GRADE Working Group grades of evidence

High quality: further research is very unlikely to change our confidence in the estimate of effect

Moderate quality: further research is likely to have an important impact on our confidence in the estimate of effect and may change the estimate

Low quality: further research is very likely to have an important impact on our confidence in the estimate of effect and is likely to change the estimate

Very low quality: we are very uncertain about the estimate

11 study at high risk and 1 at unclear risk of bias. 1 study small with contradictory results. Inconsistency between studies, unable to pool data. The number of appointments and intensity of the interventions would not be applicable in routine dental practice. Downgraded for risk of bias, inconsistency and indirectness.

21 study at high risk and 1 at unclear risk of bias. The number of appointments and intensity of the interventions would not be applicable in routine dental practice. Downgraded for risk of bias and indirectness.

32 unclear risk of bias studies. Inconsistency between studies, unable to pool data. The number of appointments and intensity of the interventions would not be applicable in routine dental practice. Downgraded for risk of bias and inconsistency and indirectness.

\section{Summary of findings 2. Summary of findings - Personalised one-to-one OHA versus routine one-to-one OHA}

\section{Personalised 1-to-1 OHA versus routine 1-to-1 OHA in a dental setting for oral heath}

Patient or population: children or adults 
Settings: dental surgery/office setting

Intervention: personalised 1-to-1 OHA in a dental setting

Comparison: routine 1-to-1 OHA in a dental setting

\begin{tabular}{|c|c|c|c|}
\hline Outcomes & $\begin{array}{l}\text { Number of partici- } \\
\text { pants } \\
\text { (studies) }\end{array}$ & $\begin{array}{l}\text { Quality of the evi- } \\
\text { dence } \\
\text { (GRADE) }\end{array}$ & Comments \\
\hline $\begin{array}{l}\text { Periodontal health: } \\
\text { gingivitis }\end{array}$ & $\begin{array}{l}2209 \text { participants ( } 4 \\
\text { studies); follow-up: } \\
1635 \text { participants }\end{array}$ & $\begin{array}{l}\oplus \odot \odot \odot \\
\text { very low } 1\end{array}$ & $\begin{array}{l}1 \text { large study in adults showed little or no difference between } \\
\text { groups at } 36 \text { months } \\
1 \text { study in adults showed evidence of a benefit for personalised } \\
\text { OHA at } 3 \text { months and } 12 \text { months } \\
1 \text { study in children reported "statistically significant }(P<0.05) \\
\text { improvement" for personalised OHA but did not report usable } \\
\text { data } \\
1 \text { study showed little or no difference between groups at } 3 \\
\text { months }\end{array}$ \\
\hline $\begin{array}{l}\text { Periodontal health: } \\
\text { plaque levels }\end{array}$ & $\begin{array}{l}332 \text { participants ( } 3 \\
\text { studies); follow-up: } \\
308 \text { participants }\end{array}$ & $\begin{array}{l}\oplus \odot \Theta \odot \\
\text { very low } 2\end{array}$ & $\begin{array}{l}1 \text { study in adults showed evidence of a benefit for personalised } \\
\text { OHA at } 3 \text { months and } 12 \text { months } \\
1 \text { study in children reported "statistically significant }(P<0.05) \\
\text { improvement" for personalised OHA but did not report usable } \\
\text { data } \\
1 \text { study showed little or no difference between groups at } 3 \\
\text { months }\end{array}$ \\
\hline Dental caries & $\begin{array}{l}69 \text { participants ( } 1 \\
\text { study); follow- up: } \\
69 \text { participants }\end{array}$ & $\begin{array}{l}\oplus \odot \Theta \odot \\
\text { very low } 3\end{array}$ & $\begin{array}{l}1 \text { study in children between the ages of } 1 \text { year and } 6 \text { years old } \\
\text { reported "statistically significant }(P<0.05) \text { improvement" for } \\
\text { personalised OHA but did not report usable data }\end{array}$ \\
\hline
\end{tabular}

GRADE Working Group grades of evidence

High quality: further research is very unlikely to change our confidence in the estimate of effect

Moderate quality: further research is likely to have an important impact on our confidence in the estimate of effect and may change the estimate

Low quality: further research is very likely to have an important impact on our confidence in the estimate of effect and is likely to change the estimate

Very low quality: we are very uncertain about the estimate

14 unclear risk of bias studies. Inconsistency between studies, unable to pool data. Setting of 3 studies is secondary care, and intervention in 1 study (number of appointments and/or intensity required) is not applicable to routine dental practice. Downgraded for risk of bias, inconsistency and indirectness.

23 unclear risk of bias studies. Inconsistency between studies, unable to pool data. Setting of 3 studies is secondary care, and intervention in 1 study (number of appointments and/or intensity required) is not applicable to routine dental practice. Downgraded for risk of bias, inconsistency and indirectness.

31 unclear risk of bias study. No usable data. Setting not applicable to routine dental practice, so downgraded for indirectness.

\section{Summary of findings 3. Summary of findings - Self-management versus professional OHA}

\section{Self-management versus professional OHA in a dental setting for oral heath}

Patient or population: children or adults

Settings: dental surgery/office setting 
Intervention: self-management

Comparison: professional OHA in a dental setting

\begin{tabular}{|c|c|c|c|}
\hline Outcomes & $\begin{array}{l}\text { Number of partici- } \\
\text { pants } \\
\text { (studies) }\end{array}$ & $\begin{array}{l}\text { Quality of the evi- } \\
\text { dence } \\
\text { (GRADE) }\end{array}$ & Comments \\
\hline $\begin{array}{l}\text { Periodontal health: } \\
\text { gingivitis }\end{array}$ & $\begin{array}{l}185 \text { participants ( } 4 \\
\text { studies); follow-up: } \\
181 \text { participants }\end{array}$ & $\begin{array}{l}\oplus \odot \odot \odot \\
\text { very low } 1\end{array}$ & $\begin{array}{l}1 \text { study in adults reported "significant differences between } \\
\text { groups at each observation were not found" but no usable data } \\
\text { reported } \\
1 \text { study in adults reported "no statistically significant differ- } \\
\text { ences in gingival bleeding scores were found between the } 2 \\
\text { treatment groups at any of the } 3 \text { examinations" but no usable } \\
\text { data reported } \\
1 \text { study in adults showed little or no difference between groups } \\
\text { at } 3 \text { months } \\
1 \text { study in adults with hyposalivation provided weak evidence } \\
\text { of a benefit in gingivitis for professional OHA at } 2 \text { months }\end{array}$ \\
\hline $\begin{array}{l}\text { Periodontal health: } \\
\text { plaque levels }\end{array}$ & $\begin{array}{l}185 \text { participants ( } 4 \\
\text { studies); follow-up: } \\
181 \text { participants }\end{array}$ & $\begin{array}{l}\oplus \odot \odot \odot \\
\text { very low } 1\end{array}$ & $\begin{array}{l}1 \text { study in adults reported "mean plaque scores did not differ } \\
\text { significantly between groups" but no usable data reported } \\
1 \text { study in adults reported "no statistically significant differ- } \\
\text { ences were found between the } 2 \text { groups at any of the examina- } \\
\text { tion times" but no usable data reported } \\
1 \text { study in adults provided weak evidence of a benefit in plaque } \\
\text { reduction at } 3 \text { months for self-management } \\
1 \text { study in adults with hyposalivation provided very weak evi- } \\
\text { dence of a benefit in plaque reduction for professional OHA at } 2 \\
\text { months }\end{array}$ \\
\hline Dental caries & Nos & & aries \\
\hline
\end{tabular}

GRADE Working Group grades of evidence

High quality: further research is very unlikely to change our confidence in the estimate of effect

Moderate quality: further research is likely to have an important impact on our confidence in the estimate of effect and may change the estimate

Low quality: further research is very likely to have an important impact on our confidence in the estimate of effect and is likely to change the estimate

Very low quality: we are very uncertain about the estimate

14 unclear risk of bias studies. Inconsistency between studies, unable to pool data. 3 studies were in secondary care and 3 of the interventions of 3 trials (number of appointments and/or intensity required) are not applicable to routine dental practice therefore we also downgraded for indirectness.

\section{Summary of findings 4. Summary of findings - Enhanced one-to-one OHA versus one-to-one OHA}

Enhanced 1-to-1 OHA versus 1-to-1 OHA in a dental setting for oral heath

Patient or population: children or adults

Settings: dental surgery/office setting

Intervention: enhanced 1-to-1 OHA in a dental setting 
Comparison: 1-to-1 OHA in a dental setting

\begin{tabular}{|c|c|c|c|}
\hline Outcomes & $\begin{array}{l}\text { Number of partici- } \\
\text { pants } \\
\text { (studies) }\end{array}$ & $\begin{array}{l}\text { Quality of the evi- } \\
\text { dence } \\
\text { (GRADE) }\end{array}$ & Comments \\
\hline $\begin{array}{l}\text { Periodontal health: } \\
\text { gingivitis }\end{array}$ & $\begin{array}{l}782 \text { participants ( } 5 \\
\text { studies); follow-up: } \\
430 \text { participants }\end{array}$ & $\begin{array}{l}\oplus \odot \odot \odot \\
\text { very low } 1\end{array}$ & $\begin{array}{l}2 \text { studies in adults did not report usable data } \\
1 \text { study in adults provided low-quality evidence of a benefit in } \\
\text { gingivitis reduction at } 5.5 \text { months for enhanced OHA } \\
3 \text { studies found little or no difference between groups across } \\
\text { all time points }\end{array}$ \\
\hline $\begin{array}{l}\text { Periodontal health: } \\
\text { plaque levels }\end{array}$ & $\begin{array}{l}802 \text { participants ( } 6 \\
\text { studies); follow-up: } \\
440 \text { participants }\end{array}$ & $\begin{array}{l}\oplus \ominus \odot \odot \\
\text { very low } 2\end{array}$ & $\begin{array}{l}2 \text { studies in adults did not report usable data } \\
1 \text { study in adults provided low-quality evidence of a benefit in } \\
\text { plaque reduction at } 5.5 \text { months for enhanced OHA } \\
1 \text { study in adults found little or no difference between groups } \\
\text { at } 3 \text { months } \\
1 \text { study in adults found little or no difference between groups } \\
\text { across all time points } \\
1 \text { study in adults provided weak evidence of a benefit in } \\
\text { plaque reduction for } 1 \text { of the enhanced OHA at } 2 \text { months }\end{array}$ \\
\hline Dental caries & $\begin{array}{l}121 \text { participants ( } 1 \\
\text { study); follow- up: } 70 \\
\text { participants }\end{array}$ & $\begin{array}{l}\oplus \odot \odot \odot \\
\text { very low } 3\end{array}$ & 1 study in adults did not report usable data \\
\hline
\end{tabular}

GRADE Working Group grades of evidence

High quality: further research is very unlikely to change our confidence in the estimate of effect

Moderate quality: further research is likely to have an important impact on our confidence in the estimate of effect and may change the estimate

Low quality: further research is very likely to have an important impact on our confidence in the estimate of effect and is likely to change the estimate

Very low quality: we are very uncertain about the estimate

11 study at high and 4 at unclear risk of bias. Unable to pool data. 2 of the included studies were in secondary care. Interventions of 4 trials (number of appointments and/or intensity) are not applicable in routine dental practice. Downgraded for risk of bias, inconsistency and indirectness.

21 study at high and 5 at unclear risk of bias. Unable to pool data. 2 of the included studies were in secondary care. Interventions of 5 trials (number of appointments and/or intensity) are not applicable in routine dental practice. Downgraded for risk of bias, inconsistency and indirectness.

31 high risk of bias study. Did not report usable data. Setting and intervention not applicable to routine dental care, therefore also downgraded for indirectness. 


\section{B A C K G R O U N D}

\section{Description of the condition}

Dental caries and periodontal disease are the two most prevalent dental conditions globally; both are largely preventable. The accumulation of dental plaque, a microbial biofilm on the tooth surface is a primary aetiological factor in both diseases (Löe 1965; Löe 1972).

When the microbial biofilm is exposed to carbohydrate sources via the host's diet it can lead to the localised lowering of the $\mathrm{pH}$ which results in the chemical dissolution of the tooth surface (Sheiham 2015). If this process goes undisturbed the caries process can lead to a lesion or 'cavity' in the exposed tooth. Although the affected carious tooth often remains asymptomatic in the early stages of the disease, the longer term consequences can be toothache, sepsis or ultimately tooth loss. Estimates of the prevalence of caries varies worldwide but the 2010 global burden of disease study estimated that untreated caries in permanent teeth was the most prevalent condition worldwide affecting an estimated 2.4 billion people (Kassebaum 2015). Self-care prevention strategies include: reducing free sugars intake; disruption of plaque biofilm (toothbrushing and interdental cleaning aids); using a fluoride dentifrice or fluoride mouthwash or both (Marinho 2003; Marinho 2004a; Marinho 2004b; Marinho 2016). Self-care strategies can be supplemented by professional interventions including fluoride gels and varnishes (Marinho 2003; Marinho 2004a; Marinho 2004b).

The accumulation of dental plaque also results in the inflammation of the periodontium (supporting structures) of the teeth. The undisturbed plaque biofilm initially causes swelling, loss of texture, characteristic redness of the gingiva and liability to gingival bleeding (gingivitis). At this early stage the disease is reversible by the disruption of the dysbiotic pathogenic biofilm allowing a return to healthy periodontal tissues. Periodontal disease, like dental caries often goes unnoticed by patients at its earliest stages. If left undisturbed in susceptible patients, gingival inflammation can lead to the irreversible loss of supporting structures (periodontitis), which can present as gingival recession, sensitivity of the exposed root, tooth mobility, drifting of the teeth or ultimately tooth loss. Studies suggest that $50 \%$ to $90 \%$ of adults in the UK and USA have gingivitis. The global burden of disease study estimated that severe periodontitis affects approximately $11 \%$ of the global population or 743 million people worldwide (Kassebaum 2014).

Oral self-care prevention involves disruption of the plaque biofilm (toothbrushing and interdental cleaning aids) (Poklepovic 2013; Yaacob 2014) and control of systemic risk factors (e.g. smoking) (Tonetti 2017). There is evidence to suggest effective dental plaque control sustained over the longer term can achieve reduced experience of periodontal disease, dental caries and ultimately tooth mortality rates (Axelsson 2004).

\section{Description of the intervention}

The patient's own oral self-care is a crucial component of the prevention strategies for dental caries and periodontal disease. Ultimately the aim of oral hygiene advice $(\mathrm{OHA})$ is to enable a patient to improve their own oral self-care and consequently their oral health. To improve a patient's oral self-care, OHA can be delivered in a variety of formats by any appropriately trained member of the dental team. The content of OHA can include: toothbrushing and toothpaste advice, interdental cleaning advice, mouthwash advice, denture hygiene advice and/or orthodontic fixed/removable appliance hygiene advice.

\section{How the intervention might work}

OHA may work through improving patient knowledge, attitudes, and behaviours. Helping patients to understand their disease process and the preventative actions required may motivate them to change their oral self-care behaviours thus reducing their risk of oral disease. In addition, OHA may improve patients' confidence in carrying out oral self-care and/or highlight barriers and enablers to facilitate improved oral self-care. Adequate oral hygiene regimens help prevent dental caries and periodontal disease.

\section{Why it is important to do this review}

Current clinical guidance recommends that OHA should be reinforced regularly and tailored to individual patients' needs to attain sustainable benefits (NICE 2015). Advice or information regarding toothbrushing is currently not uniformly provided to all patients. In England in 2009, 78\% of adults reported receiving advice on cleaning their teeth and gums, an increase from $63 \%$ in 1998 (Chadwick 2011). Within the child population, oral health advice varies widely in both content and to whom it is provided (Tickle 2003) with younger children being less likely to receive advice than older children (Tsakos 2015).

Although OHA is taught as an obligatory part of the undergraduate dental curriculum (given OHA frequently forms part of routine dental care), there remains uncertainty as to how, where and by whom OHA should be provided to be effective. Previously, the main focus of preventing oral disease has been to increase patient knowledge and awareness regarding oral health, with the hope that this would lead to improved oral health status (Towner 1993). This has been superceded by oral health promotion, which aims not only to increase public knowledge, but also to utilise a multidisciplinary approach aimed at the underlying determinants of oral health (WHO 1986; WHO 2003). A systematic review of oral health promotion concluded that the evidence for long-term reduction in plaque and gingival bleeding outcomes, based on mainly short-term interventions, was limited. There were also conflicting conclusions regarding the relative effectiveness of different types/styles of educational interventions employed (Watt 2005). A recent systematic review of psychological approaches to behaviour change for improved plaque control in periodontal management concluded that interventions based on the use of goal setting, self-monitoring and planning are effective in improving oral health-related behaviours as assessed by oral health status (Newton 2015), although these conclusions were based upon observational studies as well as randomised controlled trials.

Although there are a variety of healthcare professionals who may be involved in the delivery of $\mathrm{OHA}$, both within the dental surgery and within the wider community setting, there does not appear to be any systematic reviews published previously which assess the effect of the individual providing OHA.

\section{O B JECT IVES}

To assess the effects of one-to-one oral hygiene advice, provided by a member of the dental team within the dental setting, on patients' oral health, hygiene, behaviour, and attitudes compared to no advice or advice in a different format. 


\section{METHODS}

\section{Criteria for considering studies for this review}

\section{Types of studies}

We included all randomised controlled trials (RCTs) in which participants who were provided with one-to-one oral hygiene advice $(\mathrm{OHA})$ by a member of the dental team in the dental setting were compared to participants not provided with OHA. We also included RCTs which compared different formats (e.g. DVD, leaflet, video, etc.) of one-to-one OHA provided within the dental setting or $\mathrm{OHA}$ provided by different members of the dental team within the dental setting. We only included studies with a minimum follow-up period of 8 weeks. The unit of randomisation could be individual participants, clusters of individuals, or dental setting.

\section{Types of participants}

We included studies that involved children (with or without guardian/parent) or adult participants who were fit and healthy or groups of individuals who had well defined medical conditions. Studies involving participants who wore a removable prosthesis or orthodontic appliance of any kind were excluded.

\section{Types of interventions}

We included studies that involved $\mathrm{OHA}$ being provided by any member of the dental team within the dental setting environment (i.e. within a general dental practice, community dental setting or dental hospital setting) on a one-to-one basis in which the comparator was no advice or advice in an alternative format or advice from a different member of the dental team. Dental team members included dentist, dental nurse, dental hygienist and dental therapist. Studies were included if the OHA took place alongside an intervention aiming to change dietary behaviour or smoking behaviour, although these multi-intervention studies were planned to be subjected to a subgroup analysis if any such studies had met the inclusion criteria.

We excluded any studies where additional measures were provided to the intervention group but not the control group (e.g. dental prophylaxis, dental scaling, application or provision of fluoride containing products, provision of toothbrushes, etc.).

\section{Types of outcome measures}

Outcome measures considered in this review included clinical status, patient-centred and economic factors. The outcome measure must have been assessed at least 8 weeks following the intervention.

\section{Primary outcomes}

\section{Clinical status factors}

- Periodontal health (e.g. plaque levels, gingivitis, and probing depths).

- Caries (e.g. dmft/DMFT or other indices).

\section{Secondary outcomes}

Patient-centred factors

- Patient-reported behaviour changes (e.g. toothbrushing/ flossing/mouthwash use).

- Patient satisfaction with advice provided.
- Patient-reported changes in knowledge, attitudes, and quality of life.

Economic factors

- Cost effectiveness.

Other outcomes

- Any adverse events due to $\mathrm{OHA}$ reported in the included trials.

\section{Search methods for identification of studies}

Cochrane Oral Health's Information Specialist conducted systematic searches in the following databases for RCTs and controlled clinical trials. There were no language, publication year or publication status restrictions:

- Cochrane Oral Health's Trials Register (searched 10 November 2017) (Appendix 1);

- Cochrane Central Register of Controlled Trials (CENTRAL; 2017, Issue 10) in the Cochrane Library (searched 10 November 2017) (Appendix 2);

- MEDLINE Ovid (1946 to 10 November 2017) (Appendix 3);

- Embase Ovid (1980 to 10 November 2017) (Appendix 4).

Subject strategies were modelled on the search strategy designed for MEDLINE Ovid. Where appropriate, they were combined with subject strategy adaptations of the highly sensitive search strategy designed by Cochrane for identifying randomised controlled trials and controlled clinical trials as described in the Cochrane Handbook for Systematic Reviews of Interventions Chapter 6 (Lefebvre 2011).

\section{Searching other resources}

The following trial registries were searched for ongoing studies:

- US National Institutes of Health Ongoing Trials Register ClinicalTrials.gov (clinicaltrials.gov; searched 10 November 2017) (Appendix 5);

- World Health Organization International Clinical Trials Registry Platform (apps.who.int/trialsearch; searched 10 November 2017) (Appendix 6).

Bibliographic references of identified RCTs and articles identified as relevant to the review retrieved in the electronic search were also searched (e.g. review articles and systematic reviews). In addition, emails were sent to authors of identified potentially eligible RCTs asking them for other known unpublished or ongoing research. Relevant sections of the reports were translated of non-English publications identified from title, abstract, or keyword, to be of interest.

\section{Data collection and analysis}

\section{Selection of studies}

The search was designed to be sensitive and included controlled clinical trials, these were filtered out early in the selection process if they were not randomised.

At least two review authors reviewed and analysed independently all reports identified by the search on the basis of title, keywords, and abstract (where this was available) to see if the study was likely to be relevant. Where it was not possible to classify an article based on title, keywords and abstract, we obtained the full article. The full 
report was obtained of all potentially eligible studies, and also of studies where the title/abstract provided insufficient information to make a decision on eligibility.

The review authors were not blinded with respect to report authors, journals, date of publication, sources of financial support, or results. The inclusion criteria, as outlined above, were applied and those studies deemed suitable for inclusion by at least two review authors were included. We contacted study authors for missing information or clarity regarding methods, results, etc. where required and feasible. We linked multiple publications of the same study under one single study title. Those studies excluded are cited with reasons for exclusion reported.

Two review authors independently and in duplicate assessed the eligibility of the non-English language reports. Relevant sections of the reports were translated with the assistance of Cochrane Oral Health and non-English reports that met the inclusion criteria had data extraction and risk of bias completed.

\section{Data extraction and management}

A data extraction form was designed and piloted prior to full use. At least two review authors independently extracted data from each of the potentially eligible studies; any disagreements between the two review authors undertaking data extraction was resolved by discussion and if necessary the involvement of a third review author. If necessary we contacted the study author, where possible, to clarify any unclear or inadequate characteristics before a final decision on inclusion was made. Data recorded included the following:

- general study information: authors, title, year research completed, year research published, country, ethics and consent process, financial support and conflicts of interest, country, contact address;

- methods: research objective, sample size calculation, allocation procedures, follow-up period, degree of blindness in outcome assessment;

- participants: inclusion/exclusion criteria, age, medical factors, baseline periodontal health/caries status/behaviours/ knowledge/attitudes/quality of life;

- intervention and comparators: type of OHA, format of OHA, advice duration, advice frequency, personnel providing advice;

- outcomes: primary and secondary outcomes and outcome measures.

\section{Assessment of risk of bias in included studies}

The risk of bias of included trials for the seven domains of random sequence generation, allocation concealment, blinding of participants and personnel, blinding of outcome assessment, incomplete outcome data, selective reporting, and other potential sources for bias was undertaken independently and in duplicate by at least two review authors as part of the data extraction process and in accordance with the guidelines in theCochrane Handbook for Systematic Reviews of Interventions 5.1.0 (Higgins 2011). Where possible, we contacted study authors for missing information or clarification of their study methods. Any disagreements were resolved by discussion between the review authors with Cochrane Oral Health being consulted where there was continuing disagreement.
We allocated the level of bias for each domain as high or low as per the criteria below; for those domains where insufficient information was available or not described in sufficient detail to allow a definitive judgement then the level of bias was recorded as unclear.

\section{- Random sequence generation}

- Low: the investigators describe a random component in the sequence generation process such as referring to a random number table, using a computer random number generator, etc.

- High: the investigators describe a non-random component in the sequence generation process. Usually, the description would involve some systematic, non-random approach, (e.g. sequence generated by odd or even date of birth, etc.).

- Allocation concealment

- Low: participants and investigators enrolling participants could not foresee assignment because an appropriate method was used to conceal allocation (e.g. central allocation, etc.).

- High: participants or investigators enrolling participants could possibly foresee assignments and thus introduce selection bias, such as allocation based on using an open random allocation schedule, etc..

- Blinding of participants and personnel

- Low: no blinding or incomplete blinding, but the review authors judge that the outcome is not likely to be influenced by lack of blinding.

- High: no blinding or incomplete blinding, and the outcome is likely to be influenced by lack of blinding.

- Blinding of outcome assessment

- Low: no blinding of outcome assessment, but the review authors judge that the outcome measurement is not likely to be influenced by lack of blinding; blinding of outcome assessment ensured, and unlikely that the blinding could have been broken.

- High: no blinding of outcome assessment, and the outcome measurement is likely to be influenced by lack of blinding; blinding of outcome assessment, but likely that the blinding could have been broken, and the outcome measurement is likely to be influenced by lack of blinding.

- Incomplete outcome data

- Low: no missing outcome data; reasons for missing outcome data unlikely to be related to true outcome (for survival data, censoring unlikely to be introducing bias); missing outcome data balanced in numbers across intervention groups, with similar reasons for missing data across groups; for dichotomous outcome data, the proportion of missing outcomes compared with observed event risk not enough to have a clinically relevant impact on the intervention effect estimate; for continuous outcome data, plausible effect size (difference in means or standardized difference in means) among missing outcomes not enough to have a clinically relevant impact on observed effect size; missing data have been imputed using appropriate methods.

- High: reason for missing outcome data likely to be related to true outcome, with either imbalance in numbers or reasons for missing data across intervention groups; for dichotomous outcome data, the proportion of missing 
outcomes compared with observed event risk enough to induce clinically relevant bias in intervention effect estimate; for continuous outcome data, plausible effect size (difference in means or standardized difference in means) among missing outcomes enough to induce clinically relevant bias in observed effect size; 'as-treated' analysis done with substantial departure of the intervention received from that assigned at randomisation; potentially inappropriate application of simple imputation.

- Selective reporting

- Low: the study protocol is available and all of the study's pre-specified (primary and secondary) outcomes that are of interest in the review have been reported in the pre-specified way.

- High: not all of this study's pre-specified primary outcomes have been reported; one or more primary outcomes is reported using measurements, analysis methods or subsets of the data (e.g. subscales) that were not pre-specified; one or more reported primary outcomes were not pre-specified (unless clear justification for their reporting is provided, such as an unexpected adverse effect); one or more outcomes of interest in the review are reported incompletely so that they cannot be entered in a meta-analysis; the study report fails to include results for a key outcome that would be expected to have been reported for such a study.

- Other potential sources for bias

- Low: the study appears to be free of other sources of bias.

- High: there is as least one important risk of bias, for example a potential source of bias related to the specific study design used.

We summarised the risk of bias as follows.

\begin{tabular}{lll}
\hline Risk of bias & In outcome & In included studies \\
\hline Low risk of bias & Low risk of bias in all key domains & Most information is from studies at low risk of bias \\
\hline Unclear risk of bias & $\begin{array}{l}\text { Unclear risk of bias for one or more } \\
\text { key domains }\end{array}$ & Most information is from studies at low or unclear risk of bias \\
\hline High risk of bias & $\begin{array}{l}\text { High risk of bias for one or more key } \\
\text { domains }\end{array}$ & $\begin{array}{l}\text { The proportion of information from studies at high risk is suffi- } \\
\text { cient to affect the interpretation of results }\end{array}$ \\
\hline
\end{tabular}

\section{Measures of treatment effect}

For continuous outcomes (e.g. plaque/gingivitis scores), where studies used the same scale, we used the mean values and standard deviations reported in the studies in order to express the estimate of effect of the intervention as mean difference (MD) with 95\% confidence interval $(\mathrm{Cl})$. Where different scales were used, we expressed the treatment effect as standardised mean difference (SMD) and 95\% Cl.

For dichotomous outcomes (e.g. attachment loss/no attachment loss), we expressed the estimate of effect as a risk ratio (RR) with $95 \% \mathrm{Cl}$. Had we included any cross-over studies, we would have extracted appropriate data following the methods outlined by Elbourne 2002, and would have used the generic inverse variance method to enter log RRs or MD/SMD and standard error into Review Manager 5 (Review Manager 2014).

\section{Unit of analysis issues}

The participant was the unit of analysis. Had we included any crossover studies, these should have analysed data using a paired t-test, or other appropriate statistical test, to take into account the paired nature of the data. Cluster-RCTs should have analysed results taking account of the clustering present in the data, otherwise we would have used the methods outlined in Section 16.3.4 of the Cochrane Handbook for Systematic Reviews of Interventions in order to perform an approximately correct analysis (Higgins 2011).

\section{Dealing with missing data}

We attempted, where feasible, to contact the author(s) of studies to obtain missing data or for clarification. We did not use any further statistical methods or carry out any further imputation to account for missing data.

\section{Assessment of heterogeneity}

Heterogeneity was assessed by examining the types of participants, interventions and outcomes in each study. It was agreed in advance that meta-analysis would only be attempted if studies of similar comparisons reporting the same outcome measures were included in the review.

If it had been appropriate to perform meta-analysis, we would have assessed the possible presence of heterogeneity visually by inspecting the point estimates and Cls on the forest plots; if the Cls had poor overlap then heterogeneity would have been considered to be present. We would also have assessed heterogeneity statistically using a $\mathrm{Chi}^{2}$ test, where a $\mathrm{P}$ value $<0.1$ would have been considered to indicate statistically significant heterogeneity. Furthermore, we would have quantified heterogeneity using the 12 statistic. A guide to interpretation of the 12 statistic given in Section 9.5.2 of the Cochrane Handbook for Systematic Reviews of Interventions is as follows (Higgins 2011):

- $0 \%$ to $40 \%$ : might not be important;

- $30 \%$ to $60 \%$ : may represent moderate heterogeneity;

- $50 \%$ to $90 \%$ : may represent substantial heterogeneity;

- $75 \%$ to $100 \%$ : considerable heterogeneity.

\section{Assessment of reporting biases}

Assessment of reporting bias within studies has already been described in the section Assessment of risk of bias in included 
studies. Reporting biases can occur when reporting (or not reporting) research findings is related to the results of the research (e.g. a study that did not find a statistically significant difference/ result may not be published). Reporting bias can also occur if ongoing studies are missed (but that may be published by the time the systematic review is published), or if multiple reports of the same study are published, or if studies are not included in a systematic review due to not being reported in the language of the review authors. If there had been more than 10 studies included in a meta-analysis, we would have assessed the possible presence of reporting bias by testing for asymmetry in a funnel plot. If present, we would have carried out statistical analysis using the methods described by Egger 1997 for continuous outcomes and Rücker 2008 for dichotomous outcomes. However, we did attempt to limit reporting bias in the first instance by conducting a detailed, sensitive search, including searching for ongoing studies, and any studies not reported in English were translated by a member of Cochrane Oral Health.

\section{Data synthesis}

We would only have carried out a meta-analysis where studies of similar comparisons reported the same outcomes. We would have combined MDs (we would have used SMD where studies had used different scales) for continuous outcomes, and would have combined RRs for dichotomous outcomes, using a fixed-effect model if there were only two or three studies, or a random-effects model if there were four or more studies.

We would have used the generic inverse variance method to include data from cross-over studies in meta-analyses as described in Section 16.4 of the Cochrane Handbook for Systematic Reviews of Interventions (Elbourne 2002; Higgins 2011). Where appropriate, we would have combined the results from cross-over studies with parallel group studies, using the methods described by Elbourne 2002.

\section{Subgroup analysis and investigation of heterogeneity}

If it had been required, subgroup analyses would have been undertaken where OHA had taken place alongside an intervention aiming to change dietary behaviour or smoking behaviour, personnel providing advice and frequency of advice.

If there had been a number of similar studies, sensitivity analysis would have been considered to determine whether conclusions reached would be affected by different inclusion criteria. However, given the heterogeneity of studies included this was not required.

\section{Presentation of main results}

We produced a 'Summary of findings' table for each comparison. We included gingivitis, plaque and dental caries. We used GRADE methods (GRADE 2004), and the GRADEpro GDT online tool for developing 'Summary of findings' tables (www.guidelinedevelopment.org). We assessed the quality of the body of evidence for each comparison and outcome by considering the overall risk of bias of the included studies, the directness of the evidence, the inconsistency of the results, the precision of the estimates, and the risk of publication bias. We categorised the quality of each body of evidence as high, moderate, low, or very low.

\section{RES U L T S}

\section{Description of studies}

See Characteristics of included studies; Characteristics of excluded studies; Characteristics of studies awaiting classification; Characteristics of ongoing studies.

\section{Results of the search}

The literature search resulted in 15,188 references following deduplication. In addition, we also handsearched the references of seven relevant systematic reviews (Harris 2012; Kay 1998; Kay 2016a; Kay 2016b; Khokhar 2016; Newton 2015; Yevlahova 2009) and two reviews (Pastagia 2006; Watt 2005), identifying two further studies (Hetland 1982; Little 1997). Four review authors screened the titles and abstracts against the inclusion criteria for this review, independently and in duplicate, and 15,076 references were found to be ineligible for this review (including four potentially eligible references but they had abstracts-only published with no further information regarding the study available). Full-text copies of the remaining references were obtained and examined independently and in duplicate, excluding 84 studies at this stage. Two studies are awaiting classification and four are ongoing. Nineteen studies reported in 24 papers met the inclusion criteria for this review. Handsearching of the references of included studies and correspondence from authors identified no further studies for inclusion. This process is illustrated in Figure 1 PRISMA flow diagram. 
Figure 1. Study flow diagram.

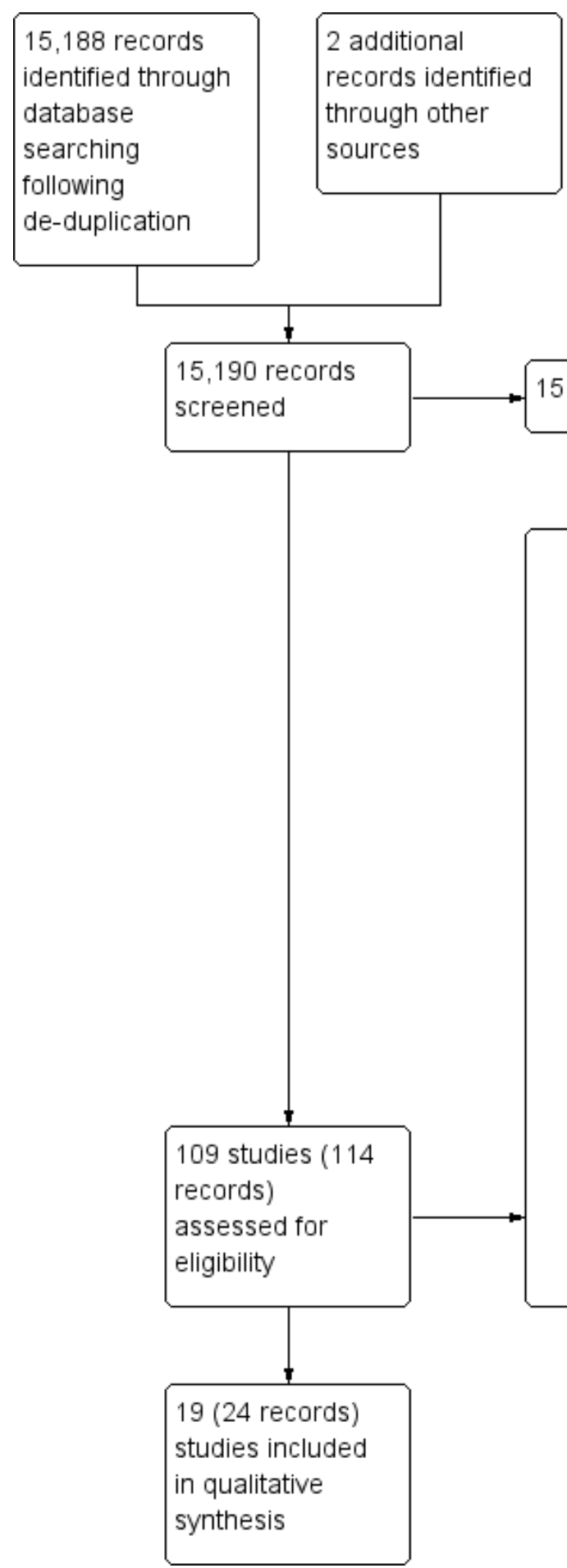

\section{Included studies}

\section{Characteristics of trial design and setting}

Nineteen studies met the inclusion criteria of the review and were included (Characteristics of included studies). All 19 studies were of parallel-group design, 10 of which had two trial arms (Aljafari 2017; Baab 1986; Bali 1999; Glavind 1985; Jönsson 2006; Jönsson 2009; Lepore 2011; López-Jornet 2014; Münster Halvari 2012; Tedesco
84 full-text articles excluded, with reasons including (some studies were excluded for more than 1 reason):

o 36 studies did not take place in a dental setting

011 studies were not a randomised controlled trial

09 studies the intervention was not delivered by a member of the dental team

08 studies had less than 8 weeks follow-up

07 studies did not deliver the intervention on a 1-to-1 basis

011 studies had an additional intervention included in the intervention group but not the control group (e.g. fluoride application, prophylaxis, provision of an electric toothbrush)

03 studies had no oral hygiene advice (OHA) provided or no OHA comparator

01 tested a model of behaviour only, 1 compared manual versus powered toothbrushes, 1 was not related to oral health education, 1 no pre-treatment measures were completed

2 studies awaiting classification

4 ongoing studies 
Ten of the included studies were conducted in hospital/graduate clinics (Aljafari 2017; Baab 1986; Bali 1999; Jönsson 2006; Jönsson 2009; Lepore 2011; López-Jornet 2014; Schmalz 2018; Söderholm 1982; Van Leeuwen 2017), four in a dental practice setting (Glavind 1985; Hoogstraten 1983; Münster Halvari 2012; Ramsay 2018), one in public healthcare settings (Memarpour 2016), one study involved one clinic in a public dental setting and the other a general dental practice (Hugoson 2007), one was in a factory which had two dental units and chairs installed for the purpose of the study (Hetland 1982), and two trials did not specify which dental setting they were conducted in (Tedesco 1992; Weinstein 1996).

Fifteen of the studies were single centre with one study reporting two centres (Hugoson 2007), one study with three centres (Glavind 1985), one study with five centres (Memarpour 2016), and one study with 63 centres (Ramsay 2018).

Four studies were conducted in Sweden (Hugoson 2007; Jönsson 2006; Jönsson 2009; Söderholm 1982), three in the USA (Baab 1986; Lepore 2011; Tedesco 1992), two in the Netherlands (Hoogstraten 1983; Van Leeuwen 2017), two in Norway (Hetland 1982; Münster Halvari 2012), one in Germany (Schmalz 2018), and one in Denmark (Glavind 1985), Spain (López-Jornet 2014), Italy (Weinstein 1996), England (Aljafari 2017), Austria (Bali 1999), Iran (Memarpour 2016), and one study across the United Kingdom in Scotland and North East England (Ramsay 2018).

Only seven studies mentioned sample size calculations (Aljafari 2017; Jönsson 2009; Memarpour 2016; Münster Halvari 2012; Ramsay 2018; Schmalz 2018; Van Leeuwen 2017). Four of these studies achieved their sample sizes and had the required number of participants at follow-up (Memarpour 2016; Münster Halvari 2012; Ramsay 2018; Schmalz 2018). Jönsson 2009 reported their sample size calculation but noted that they did not recruit or follow up this number of participants; the original examiner could not continue to complete recruitment and a second examiner could not be recruited in time. The authors also noted that the original power analysis was based on an intervention that was less effective than the intervention investigated in their study. Aljafari 2017 reported that only $55 \%$ of the recruited sample completed the telephone follow-up 3 months after the child's dental care under general anaesthetic; the authors recommended the results be interpreted with caution given the sample size calculation deemed a sample of 45 participants in each group would have been required to provide $80 \%$ power, at the $5 \%$ significance level, to detect effects of 0.6 and above. At 3-month follow-up there were 28 patients and 31 patients available from the intervention and control group, respectively (Aljafari 2017). Van Leeuwen 2017 achieved their sample size in five of the six groups at 13 months such that the recruitment target was achieved at the 4-month review for all groups, but not thereafter.

Eleven studies reported their funding source with six having received some form of public funding (Aljafari 2017; Baab 1986; Hugoson 2007; Münster Halvari 2012; Ramsay 2018; Tedesco 1992), one with dental association research funds (Glavind 1985), one with national health research and development funding (Van Leeuwen 2017 ), one with a university grant (Memarpour 2016), and one study reported joint funding sources between research council, public funding and the Pfizer oral care award (Jönsson 2009). One study acknowledged Philips GmbH (Hamburg, Germany), CP GABA (GmbH, Hamburg, Germany), and GlaxoSmithKline Oral Health Care $\mathrm{GmbH}$ (Brühl, Germany) for providing materials for the study (Schmalz 2018).

\section{Characteristics of the participants}

A total of 4232 participants were recruited, with numbers included in each trial ranging from 33 to 1877 . Three studies investigated children with a mean age of 20 months, 3 years and six years old and age ranges from 1 year to 10 years old (Aljafari 2017; Lepore 2011; Memarpour 2016). In the remaining adult population studies, the age range of the sample was reported in 15 studies with the mean age of adults ranging from 20 years to 58 years old and age range from 15 years to 91 years old (Baab 1986; Bali 1999; Glavind 1985; Hetland 1982; Hoogstraten 1983; Jönsson 2006; Jönsson 2009; López-Jornet 2014; Münster Halvari 2012; Ramsay 2018; Schmalz 2018; Söderholm 1982; Tedesco 1992; Van Leeuwen 2017; Weinstein 1996).

Two studies restricted their inclusion criteria to participants who were known to have a specific medical condition: diabetes (Bali 1999) and hyposalivation (López-Jornet 2014).

The dental condition pre-treatment required participants to be caries free in three studies (Memarpour 2016; Schmalz 2018; Van Leeuwen 2017) and only those with caries were included in another study (Aljafari 2017). Eight studies reported that the included individuals were only those with plaque present (Glavind 1985) or those who had active or previously treated periodontal disease patients (Baab 1986; Glavind 1985; Jönsson 2006; Jönsson 2009; Tedesco 1992; Van Leeuwen 2017; Weinstein 1996). One study reported including those individuals with healthy periodontal status, gingivitis or moderate periodontal disease (Ramsay 2018). One study specified that there were to be no periodontal pockets $\geq 4.0 \mathrm{~mm}$, as measured by a pocket probe, and/or serious bone loss visualized by digital $X$ rays during the dental examination (Münster Halvari 2012), and another specified there to be no periodontal attachment loss greater than $1.5 \mathrm{~mm}$, radiographic evidence of bone loss greater than 25\% (anterior/ posterior bite-wing radiographs or periapical radiographs), or previous periodontal therapy (Tedesco 1992); another specified there to be no pockets of $4 \mathrm{~mm}$ to $5 \mathrm{~mm}$ in combination with gingival recession or pockets of $\geq 6 \mathrm{~mm}$, as assessed according to the Dutch Periodontal Screening Index (DPSI) scores $3+$ and 4 (Van Leeuwen 2017).

\section{Characteristics of the interventions}

\section{Intervention type}

A variety of interventions were used in the included studies, none of which were entirely identical.

- Two studies used self-inspection/instruction manuals (Baab 1986; Glavind 1985) with a further incorporating self-assessment as part of the intervention (Weinstein 1996).

- One study reported participants received one-to-one advice on toothbrushing technique (Schmalz 2018).

- One used a computer game (Aljafari 2017), one included instruction and viewing of an educational film (Hoogstraten 1983), and another included showing patients a phase-contrast slide of their own subgingival flora on a video monitor (Tedesco 1992).

- One study reported the intervention group receiving onceonly professional individual oral hygiene instruction (Van Leeuwen 2017), one with a three-visit oral hygiene instruction program delivered on a once a week basis (Hetland 1982), one with intensive patient education in oral hygiene with 
additional control examinations (Bali 1999), another providing oral hygiene instruction in addition to a pamphlet and toothbrush (Memarpour 2016), or similar instruction at a variable number of appointments (Söderholm 1982).

- One study reported a motivational-behavioural skills protocol designed following principles of self-efficacy theory (LópezJornet 2014).

- Six studies provided information tailored to the patients needs (Bali 1999; Hugoson 2007; Jönsson 2009; Lepore 2011; Ramsay 2018; Weinstein 1996), one of which was with the addition of cognitive behavioural therapy (Jönsson 2009), another including Social Cognitive Theory and Implementation Intention Theory (Ramsay 2018) and another with the inclusion of positive social reinforcement (Weinstein 1996).

- A negotiation and self-selected goals method described as Client Self-Care Commitment Model was reported in one study (Jönsson 2006).

- A competency enhancing intervention in addition to standard autonomy-supportive treatment was described in one study (Münster Halvari 2012).

\section{Member of dental team delivering intervention}

It was unclear in three of the studies which member of the dental team carried out the intervention (Bali 1999; López-Jornet 2014; Weinstein 1996) but after reviewing the text the review authors were confident the intervention was undertaken by a member of the dental team. In the remainder of the studies the interventions were delivered by various members of the dental team.

- A hygienist delivered the intervention in eight of the studies (Baab 1986; Hoogstraten 1983; Hugoson 2007; Jönsson 2006; Jönsson 2009; Münster Halvari 2012; Tedesco 1992; Van Leeuwen 2017).

- A dentist delivered the intervention in four studies (Glavind 1985; Lepore 2011; Memarpour 2016; Schmalz 2018).

- A dentist or hygienist delivered the intervention in one study (Ramsay 2018).

- A hygienist and dental nurse delivered the intervention in one study (Söderholm 1982).

- A dental nurse delivered the intervention in one study (Hetland 1982) and control OHA in another study (Aljafari 2017).

- Further self-administration of the intervention at home took place in one study (Aljafari 2017).

\section{Frequency of intervention}

The frequency of the intervention varied with three studies reporting the intervention to be delivered on a one-off basis (Lepore 2011; Schmalz 2018; Van Leeuwen 2017).The remaining studies reported various intervention frequencies other than one study being unclear (Hoogstraten 1983).

- Two studies reported two intervention visits (Glavind 1985; Memarpour 2016).

- Two studies reported three intervention visits (Hetland 1982; Jönsson 2006).

- Four studies reported four intervention visits (Bali 1999; LópezJornet 2014; Münster Halvari 2012; Tedesco 1992).

- Two studies reported five intervention visits (Baab 1986; Söderholm 1982).
- One study reported three or six intervention visits (Hugoson 2007).

One intervention was initially delivered in the clinic and then used at home as per the patients wishes (Aljafari 2017), one study reported a median of nine intervention visits (Jönsson 2009), and one reported reinforcement of $\mathrm{OHA}$ was provided at the discretion of the dentist/hygienist during the trial and recorded (Ramsay 2018). The study by Weinstein 1996 varied in the frequency of intervention from three clinical visits with twice weekly phone call to periodontist to report self-evaluated plaque score, 16 visits with OHA (twice weekly examinations by periodontist) or 16 visits with $\mathrm{OHA}$ (twice weekly examinations by periodontist) and daily completion of an oral hygiene task checklist.

\section{Intensity of intervention}

The intensity of the intervention was not reported in nine studies (Baab 1986; Bali 1999; Jönsson 2006; Lepore 2011; Ramsay 2018; Schmalz 2018; Tedesco 1992; Weinstein 1996; Van Leeuwen 2017), two were largely administered at home (Aljafari 2017; Glavind 1985), one remained unclear (López-Jornet 2014), and one varied between patients (Jönsson 2009).

For those studies who did report the intensity of the intervention, the intensity varied considerably.

- Approximately 30 minutes to 40 minutes intervention noted in one study (Hoogstraten 1983).

- Two intervention appointments of 30 minutes to 40 minutes each in one study (Memarpour 2016).

- Forty-five minutes for the first intervention visit, 30 minutes for the second intervention visit and 15 minutes for the third intervention visit in one study (Hetland 1982).

- Approximately 45 minutes intervention was noted in one study (Münster Halvari 2012).

- Between 120 minutes and 150 minutes was reported in two studies (Hugoson 2007; Söderholm 1982).

\section{Prophylaxis as part of intervention}

Twelve studies reported some form of prophylactic measures at baseline (Baab 1986; Glavind 1985; Hetland 1982; Hoogstraten 1983; Hugoson 2007; Jönsson 2006; Lepore 2011; Münster Halvari 2012; Ramsay 2018; Schmalz 2018; Söderholm 1982; Tedesco 1992). One study reported prophylactic measures throughout (Jönsson 2009) and six did not report any prophylactic measures (Aljafari 2017; Bali 1999; López-Jornet 2014; Memarpour 2016; Van Leeuwen 2017; Weinstein 1996).

\section{Characterictics of the outcomes}

Primary outcomes - Clinical status

\section{Periodontal health}

\section{Gingivitis}

Fifteen studies reported on the presence of gingivitis (Baab 1986; Bali 1999; Glavind 1985; Hetland 1982; Hugoson 2007; Jönsson 2006; Jönsson 2009; Lepore 2011; López-Jornet 2014; Münster Halvari 2012; Ramsay 2018; Schmalz 2018; Söderholm 1982; Tedesco 1992; Van Leeuwen 2017).

Of these studies: 
- the gingival index by Löe and Sillness was used by seven studies (Hetland 1982; Hugoson 2007; Jönsson 2006; Jönsson 2009; Münster Halvari 2012; Schmalz 2018; Tedesco 1992);

- bleeding on probing was reported in five studies (Baab 1986; Bali 1999; Glavind 1985; Ramsay 2018; Söderholm 1982);

- gingival inflammation evaluated using the Papilla Bleeding Index (PBI) (Lange 1977) was reported in one study (Schmalz 2018);

- one study (Van Leeuwen 2017) reported that gingival health was assessed at six sites (mesio-buccal, mid-buccal, distobuccal, mesio-lingual, mid-lingual and disto-lingual) around the selected quadrants by scoring bleeding on marginal probing (BOMP) on a scale of 0 to 2 (Lie 1998; Van der Weijden 1994);

- one study reported that gingival health was recorded but did not specify what scoring system was employed (Lepore 2011);

- one study reported a bleeding index was recorded but did not specify what scoring system was employed (López-Jornet 2014).

\section{Probing depth}

Four studies reported on probing depths (Bali 1999; Jönsson 2006; Jönsson 2009; Ramsay 2018). One study reported on Community Periodontal Index of Treatment Needs (CPITN) score (López-Jornet 2014) with an additional study only reporting pocket depths of $>5$ $\mathrm{mm}$ (Söderholm 1982), and a further study only reporting on pocket depths $>4 \mathrm{~mm}$ (Hetland 1982).

\section{Plaque levels}

Fifteen studies reported on plaque levels using various plaque indices (Baab 1986; Bali 1999; Glavind 1985; Hetland 1982; Hugoson 2007; Jönsson 2006; Jönsson 2009; Lepore 2011; López-Jornet 2014; Münster Halvari 2012; Schmalz 2018; Söderholm 1982; Tedesco 1992; Van Leeuwen 2017; Weinstein 1996).

Of these studies:

- three studies (Hugoson 2007; Münster Halvari 2012; Tedesco 1992) used the Löe and Sillness plaque index (Löe 1963; Löe 1967) with a further two studies (Jönsson 2006; Jönsson 2009) reporting the accumulation of plaque being recorded using Silness and Löe (Silness 1964);

- one study (López-Jornet 2014) reported a plaque extension index (PEI) following plaque disclosure using a $2 \%$ aqueous erythrosine solution. After rinsing once with water, plaque deposits were assessed using the Quigley and Hein index, modified by Turesky et al (Turesky 1970), with scores from 0 to 5 with another study (Van Leeuwen 2017) reporting a similar process by measuring plaque at six sites after disclosing with Mira-2-Ton ${ }^{\circledR}$ with scores also based on the modified Quigley and Hein (Quigley 1962) plaque index (QHPI) with a scale of 0 to 5. One study reported a similar method with plaque extension evaluated using the plaque index by Quigley and Hein (QHI) modified by Turesky et al after using a plaque disclosing agent (Mira-2-Ton ${ }^{\circledR}$, Hager score 5 = plaque extending to the coronal third) in addition to recording the Marginal Plaque Index (MPI) by Deinzer et al to differentiate plaque extension at the gingival margin (Deinzer 2014) (Schmalz 2018). A further study also reported using the Turesky hygiene index (Bali 1999);

- two studies (Baab 1986; Weinstein 1996) reported on presence or absence of disclosed plaque at the gingival margin (O'Leary 1972);
- two studies reported on the presence of disclosed plaque; one did not refer to a specific index (Glavind 1985) and the other reported the percentage of tooth surfaces (mesial, buccal, distal and lingual) with plaque (Söderholm 1982);

- two studies reported that a plaque score was recorded but did not specify what scoring system was employed (Hetland 1982; Lepore 2011).

\section{Dental caries}

Two studies reported on DMFT (number of decayed, missing or filled permanent teeth) (Bali 1999; Hetland 1982). One study reported on dmft (number of decayed, missing or filled primary teeth) (Memarpour 2016), and a further study reported on dental caries but appeared to use the terms DMFS (number of decayed, missing or filled permanent surfaces) and dmft interchangeably within the text of the primary paper (Lepore 2011).

\section{Secondary outcomes - Patient-centred factors}

\section{Patient-reported behaviour changes}

Five studies reported on patient-reported behaviour change regarding:

- time spent brushing and the number of oral hygiene aids used (Baab 1986);

- child's dietary habits, and the child's self-reported snacking and toothbrushing practices (Aljafari 2017);

- oral health behaviour (Ramsay 2018);

- oral self-care habits (Jönsson 2006);

- self-reported brushing and flossing behaviours and self-efficacy assessed via Oral Health Behavior Expectation Scale (Tedesco 1992).

One of the studies specifically reported on patient-reported health indices:

- the General Oral Health Assessment Index (GOHAI) and selfrated oral health (Jönsson 2009).

\section{Patient satisfaction with advice provided}

One study reported on patient satisfaction with provider of advice and patient satisfaction with advice format:

- parent and child satisfaction with their educational intervention (Aljafari 2017).

\section{Patient-reported changes in knowledge, attitudes and quality of life}

Five studies reported on patient-reported changes in knowledge, attitudes and quality of life following provision of advice:

- child's dietary knowledge (Aljafari 2017);

- dental knowledge, attitude, behaviour, and fear of dental treatment (Hoogstraten 1983; Jönsson 2009);

- patient-related dental quality of life and confidence in oral hygiene self-efficacy (Slade 1997) (Ramsay 2018);

- parents' knowledge and performance regarding oral health (Memarpour 2016);

- oral health-related quality of life measure (OHQoL-UK) (Jönsson 2009). 
One study used multiple psychological outcome measures including (Münster Halvari 2012):

- autonomy orientation (Dental Care Autonomy Orientation Scale) adapted in the present study from the Exercise Causality Orientations Scale (Rose 2001) and the General Causality Orientations Scale (Deci 1985);

- perceived autonomy support (6-item version of the Health Care Climate Questionnaire (Williams 1996));

- autonomous motivation for the dental project (Evaluation of Dental Project Scale (Halvari 2006));

- autonomous motivation for dental home care (a 3-item identified subscale of the Self-Regulation for Dental Home Care Questionnaire (Halvari 2012));

- perceived dental competence (Dental Coping Beliefs Scale (Wolfe 1996)) using the five items with the best factor loadings (Halvari 2006) and two added items from a previous study (Halvari 2010);

- dental health behaviour assessed by a 4-item formative composite scale (Halvari 2010).

A further study (Tedesco 1992) reported on the theory of reasoned action variables assessed via Theory of Reasoned Action Oral Health Scale (Fishbein 1980).

\section{Secondary outcome - Economic factors}

Only one study reported on economic net benefits of OHA (Ramsay 2018).

\section{Other outcomes}

No adverse events due to OHA were reported in the included trials.

\section{Excluded studies}

We excluded 84 studies from the review (see Characteristics of excluded studies). Below is a summary of the reasons for excluding these studies (some studies were excluded for more than one reason).

- Thirty-six studies did not take place in a dental setting.

- Eleven studies were not a randomised controlled trial.

- Nine studies the intervention was not delivered by a member of the dental team.

- Eight studies had less than 8 weeks follow-up.

- Seven studies did not deliver the intervention on a one-to-one basis.

- Eleven studies had an additional intervention included in the intervention group but not the control group (e.g. fluoride application, prophylaxis, provision of an electric toothbrush).

- Three studies had no OHA provided or no OHA comparator.

- One study tested a model of behaviour only.

- One study compared manual versus powered toothbrushes.

- One study was not related to oral health education.

- In one study no pre-treatment measures were completed.

\section{Awaiting classification studies}

The authors of two published trial protocols were contacted for further information but no reply was received (Gao 2013; IRCT2014062618248N1).

\section{Ongoing studies}

The author of one ongoing trial confirmed that data collection was completed but data analysis was not complete at the current time (ACTRN12605000607673).

\section{Risk of bias in included studies}

We assessed risk of bias based on the information reported in the included studies in the first instance. We subsequently contacted authors for further information for missing information or clarification. Two authors replied and provided information for two studies (Aljafari 2017; Schmalz 2018).

\section{Allocation \\ Random sequence generation}

We assessed nine studies to be at low risk of bias for this domain (Aljafari 2017; Baab 1986; Hugoson 2007; Jönsson 2006; Jönsson 2009; López-Jornet 2014; Memarpour 2016; Ramsay 2018; Van Leeuwen 2017). There were 10 studies that had insufficient information to make a judgement and we assessed them as at unclear risk of bias (Bali 1999; Glavind 1985; Hetland 1982; Hoogstraten 1983; Lepore 2011; Münster Halvari 2012; Schmalz 2018; Söderholm 1982; Tedesco 1992; Weinstein 1996).

\section{Allocation concealment}

We assessed four studies to be at low risk of bias for this domain (Aljafari 2017; Jönsson 2009; Ramsay 2018; Van Leeuwen 2017). None of the studies assessed were deemed to be at high risk of bias for this domain. There were 15 studies that had insufficient information to make a judgement and we assessed them as at unclear risk of bias (Baab 1986; Bali 1999; Glavind 1985; Hetland 1982; Hoogstraten 1983; Hugoson 2007; Jönsson 2006; Lepore 2011; López-Jornet 2014; Memarpour 2016; Münster Halvari 2012; Schmalz 2018; Söderholm 1982; Tedesco 1992; Weinstein 1996).

\section{Blinding}

\section{Blinding of participants and personnel (performance bias)}

We assessed all 19 studies to be at unclear risk of bias for this domain (Aljafari 2017; Baab 1986; Bali 1999; Glavind 1985; Hetland 1982; Hoogstraten 1983; Hugoson 2007; Jönsson 2006; Jönsson 2009; Lepore 2011; López-Jornet 2014; Memarpour 2016; Münster Halvari 2012; Ramsay 2018; Schmalz 2018; Söderholm 1982; Tedesco 1992; Van Leeuwen 2017; Weinstein 1996). It is not possible to blind participants to this intervention and it is unclear the influence this would have on the risk of bias for this domain.

\section{Blinding of outcome assessment (detection bias)}

We assessed 13 studies to be at low risk of bias for this domain (Aljafari 2017; Baab 1986; Hetland 1982; Hoogstraten 1983; Hugoson 2007; Jönsson 2006; Jönsson 2009; López-Jornet 2014; Münster Halvari 2012; Ramsay 2018; Schmalz 2018; Söderholm 1982; Van Leeuwen 2017). There were six studies that had insufficient information to make a judgement and we assessed them as at unclear risk of bias (Bali 1999; Glavind 1985; Lepore 2011; Memarpour 2016; Tedesco 1992; Weinstein 1996).

\section{Incomplete outcome data}

We assessed 11 studies to be at low risk of bias for this domain (Glavind 1985; Jönsson 2006; Jönsson 2009; López-Jornet 2014; 
Memarpour 2016; Münster Halvari 2012; Ramsay 2018; Schmalz 2018; Söderholm 1982; Tedesco 1992; Van Leeuwen 2017). We assessed two studies at high risk of bias for this domain (Aljafari 2017; Bali 1999). There were six studies that had insufficient information to make a judgement and we assessed them as at unclear risk of bias (Baab 1986; Hetland 1982; Hoogstraten 1983; Hugoson 2007; Lepore 2011; Weinstein 1996).

\section{Selective reporting}

We assessed 16 studies to be at low risk of bias for this domain (Aljafari 2017; Baab 1986; Glavind 1985; Hetland 1982; Hoogstraten 1983; Jönsson 2009; Lepore 2011; López-Jornet 2014; Memarpour 2016; Münster Halvari 2012; Ramsay 2018; Schmalz 2018; Söderholm 1982; Tedesco 1992; Van Leeuwen 2017; Weinstein 1996). We assessed one study at high risk of bias for this domain (Hugoson 2007). There were two studies that had insufficient information to make a judgement and we assessed them as at unclear risk of bias (Bali 1999; Jönsson 2006).

\section{Other potential sources of bias}

We assessed 16 studies to be at low risk of bias for this domain (Aljafari 2017; Bali 1999; Glavind 1985; Hetland 1982; Hugoson 2007; Jönsson 2006; Jönsson 2009; López-Jornet 2014; Memarpour 2016;
Münster Halvari 2012; Ramsay 2018; Schmalz 2018; Söderholm 1982; Tedesco 1992; Van Leeuwen 2017; Weinstein 1996). There were three studies that had insufficient information to make a judgement and we assessed them as at unclear risk of bias (Baab 1986; Hoogstraten 1983; Lepore 2011).

\section{Overall risk of bias}

- We assessed none of the studies as being at low risk of bias.

- We assessed three studies as being at high risk of bias. These studies had at least one domain assessed as high risk of bias (Aljafari 2017; Bali 1999; Hugoson 2007).

- We assessed 16 studies as being at unclear risk of bias. These studies had at least one domain judged to be at unclear risk of bias, but no domains judged to be at high risk of bias (Baab 1986; Glavind 1985; Hetland 1982; Hoogstraten 1983; Jönsson 2006; Jönsson 2009; Lepore 2011; López-Jornet 2014; Memarpour 2016; Münster Halvari 2012; Ramsay 2018; Schmalz 2018; Söderholm 1982; Tedesco 1992; Van Leeuwen 2017; Weinstein 1996).

The results of the risk of bias assessments are presented graphically in Figure 2 and Figure 3. 
Figure 2. Risk of bias summary: review authors' judgements about each risk of bias item for each included study.

\begin{tabular}{|c|c|c|c|c|c|c|c|}
\hline & 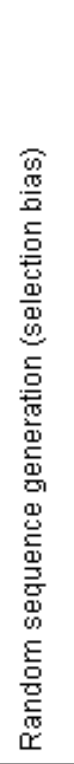 & 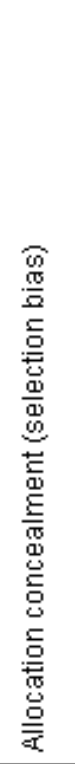 & 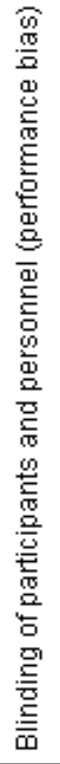 & 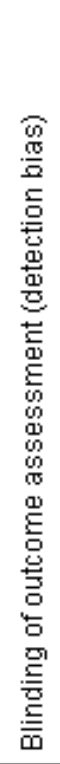 & 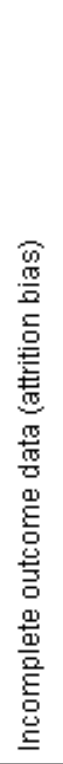 & 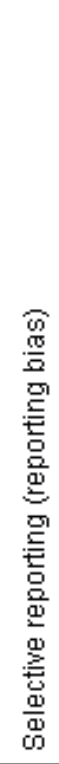 & 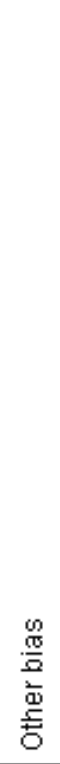 \\
\hline Aljafari 2017 & $\odot$ & $\odot$ & $?$ & + & $\odot$ & + & + \\
\hline Baab 1986 & + & $?$ & $?$ & $\oplus$ & $?$ & + & $?$ \\
\hline Bali 1999 & $?$ & $?$ & $?$ & $?$ & $\odot$ & ? & + \\
\hline Glavind 1985 & $?$ & ? & $?$ & ? & $\odot$ & $\odot$ & + \\
\hline Hetland 1982 & $?$ & $?$ & $?$ & + & $?$ & + & + \\
\hline Hoogstraten 1983 & $?$ & $?$ & $?$ & + & $?$ & + & $?$ \\
\hline Hugoson 2007 & $\odot$ & $?$ & $?$ & + & ? & $\Theta$ & + \\
\hline Jönsson 2006 & $\odot$ & $?$ & $?$ & + & $\odot$ & ? & + \\
\hline Jönsson 2009 & + & + & $?$ & + & + & + & + \\
\hline Lepore 2011 & $?$ & $?$ & $?$ & $?$ & $?$ & + & $?$ \\
\hline López-Jornet 2014 & $\odot$ & $?$ & $?$ & + & $\odot$ & + & + \\
\hline Memarpour 2016 & + & ? & ? & ? & $\odot$ & + & + \\
\hline Münster Halvari 2012 & $?$ & $?$ & $?$ & + & + & $\odot$ & + \\
\hline Ramsay 2018 & $\odot$ & $\odot$ & $?$ & + & $\odot$ & + & + \\
\hline Schmalz 2018 & $?$ & $?$ & $?$ & + & + & $\odot$ & + \\
\hline Söderholm 1982 & $?$ & $?$ & ? & + & + & + & + \\
\hline Tedesco 1992 & ? & ? & ? & ? & + & + & + \\
\hline Van Leeuwen 2017 & + & + & $?$ & + & $\odot$ & + & + \\
\hline Weinstein 1996 & $?$ & ? & ? & ? & ? & + & + \\
\hline
\end{tabular}


Figure 3. Risk of bias graph: review authors' judgements about each risk of bias item presented as percentages across all included studies.

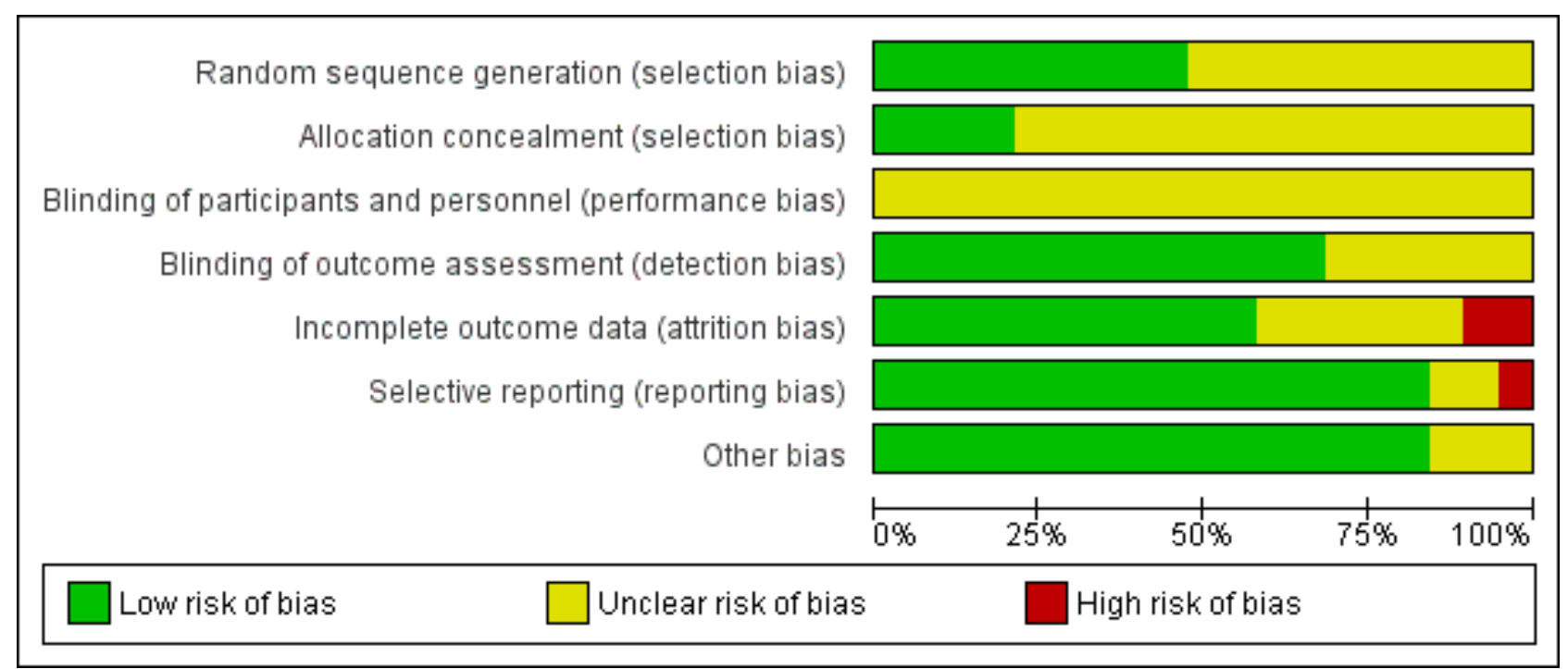

\section{Effects of interventions}

See: Summary of findings for the main comparison Summary of findings - Any form of one-to-one oral hygiene advice (OHA) versus no OHA; Summary of findings 2 Summary of findings - Personalised one-to-one OHA versus routine one-to-one OHA; Summary of findings 3 Summary of findings - Self-management versus professional OHA; Summary of findings 4 Summary of findings - Enhanced one-to-one OHA versus one-to-one OHA

We have included 19 studies that investigated various forms and delivery methods of one-to one oral hygiene advice (OHA) in a dental setting.

We have summarised data in additional tables, categorising trials to similar interventions groups where possible (Table 1; Table 2; Table 3; Table 4).

\section{Comparison 1: Any form of one-to-one OHA versus no OHA}

Four studies compared any form of one-to-one OHA versus no OHA (Hetland 1982; Hoogstraten 1983; Hugoson 2007; Memarpour 2016). Two of these studies reported outcomes of gingivitis and plaque levels (Hetland 1982; Hugoson 2007). Two studies reported dental caries (Hetland 1982; Memarpour 2016). The remaining study did not include clinical outcomes (Hoogstraten 1983). Outcomes were reported up to 6 months in Hetland 1982, 36 months in Hugoson 2007, and 12 months in Hoogstraten 1983 and Memarpour 2016.

\section{Gingivitis}

The Hetland 1982 was a small study in adults that had contradictory results (very weak evidence) at 3 months and 6 months. There was a small difference favouring the control arm of no OHA at 3 months: mean difference (MD) 0.25 , 95\% confidence interval $(\mathrm{Cl}) 0.05$ to 0.45 . At 6 months the small difference favoured the OHA intervention: MD $-0.38,95 \% \mathrm{Cl}-0.62$ to -0.14 .

The Hugoson 2007 study in adults showed very low-quality evidence of a benefit for OHA at 12 months: MD $-8.0,95 \% \mathrm{Cl}-12.86$ to $-3.14 ; 24$ months: $\mathrm{MD}-7.70,95 \% \mathrm{Cl}-12.77$ to -2.63 ; and 36 months: MD $-9.10,95 \% \mathrm{Cl}-14.03$ to -4.17 .

\section{Plaque levels}

Both studies at all time points consistently showed low-quality evidence of a benefit in plaque reduction for OHA. The Hetland 1982 showed a benefit of: MD $-0.44,95 \% \mathrm{Cl}-0.56$ to -0.32 at 6 months; at 36 months the Hugoson 2007 study demonstrated a benefit of MD $-13.10,95 \% \mathrm{Cl}-19.97$ to -6.23 .

\section{Dental caries}

The Hetland 1982 study did not provide summary statistics or effect estimates, reporting only "small and statistically insignificant changes" between groups. The Memarpour 2016 study provided weak evidence of a benefit for $\mathrm{OHA}$ at 8 months: risk ratio (RR) 0.20 , $95 \% \mathrm{Cl} 0.06$ to 0.67 ; and 12 months: RR $0.14,95 \% \mathrm{Cl} 0.05$ to 0.39 (173 participants), but not at 4 months: RR $0.66,95 \% \mathrm{Cl} 0.11$ to 3.86. Overall, the evidence for dental caries was graded as very lowquality evidence.

\section{Comparison 2: Personalised one-to-one OHA versus routine one-to-one OHA}

Four studies compared personalised OHA versus routine OHA (Jönsson 2009; Lepore 2011; Ramsay 2018; Schmalz 2018). All four studies reported gingivitis as an outcome (Jönsson 2009; Lepore 2011; Ramsay 2018; Schmalz 2018). Three of the studies that reported gingivitis also reported plaque levels as an outcome (Jönsson 2009; Lepore 2011; Schmalz 2018). Only one of the studies reported dental caries (Lepore 2011). Outcomes were reported up to 2 months (Lepore 2011), 3 months (Schmalz 2018), 12 months (Jönsson 2009), and 36 months (Ramsay 2018).

\section{Gingivitis}

The large Ramsay 2018 study in adults showed little or no difference between groups at 36 months: $\mathrm{MD}-2.50,95 \% \mathrm{Cl}-8.30$ to 3.30 . 
The Jönsson 2009 study in adults showed weak evidence of a benefit for personalised OHA at 3 months: MD $-0.25,95 \% \mathrm{Cl}-0.31$ to -0.19 and 12 months: MD $-0.29,95 \% \mathrm{Cl}-0.35$ to -0.23 .

The Lepore 2011 study in children reported "statistically significant $(\mathrm{P}<0.05)$ improvement" for personalised OHA at 2 months but did not report usable data.

The Schmalz 2018 study showed little or no difference between groups at 3 months: MD $-0.03,95 \% \mathrm{Cl}-0.06$ to 0.01 .

Overall, the evidence for gingivitis was graded as very low-quality evidence.

\section{Plaque levels}

The Jönsson 2009 study in adults showed weak evidence of a benefit for personalised OHA at 3 months: MD $-0.15,95 \% \mathrm{Cl}-0.21$ to -0.09 and 12 months: MD $-0.17,95 \% \mathrm{Cl}-0.22$ to -0.12 .

The Lepore 2011 study in children reported "statistically significant $(P<0.05)$ improvement" for personalised OHA but did not report usable data.

The Schmalz 2018 study showed little or no difference between groups at 3 months: MD $-0.04,95 \% \mathrm{Cl}-0.15$ to 0.08 .

Overall, the evidence for plaque levels was graded as very lowquality evidence.

\section{Dental caries}

The Lepore 2011 study in children between the ages of 1 year and 6 years old reported "statistically significant $(P<0.05)$ improvement" for personalised OHA but did not report usable data. Overall, the evidence for dental caries was graded as very low-quality evidence.

\section{Comparison 3: Self-management versus professional OHA}

Five trials compared some form of self-management with some form of professional OHA (Aljafari 2017; Baab 1986; Glavind 1985; Jönsson 2006; López-Jornet 2014). Four studies reported gingivitis and plaque levels (Baab 1986; Glavind 1985; Jönsson 2006; LópezJornet 2014). None of the studies reported dental caries. Outcomes were reported up to 2 months (López-Jornet 2014), 3 months (Jönsson 2006), and 6 months (Baab 1986; Glavind 1985).

\section{Gingivitis}

The Baab 1986 study in adults reported "significant differences between groups at each observation were not found" but no usable data reported.

The Glavind 1985 study in adults reported "no statistically significant differences in gingival bleeding scores were found between the two treatment groups at any of the three examinations" but no usable data reported.

The Jönsson 2006 study in adults showed little or no difference between groups at 3 months: MD $-0.01,95 \% \mathrm{Cl}-0.12$ to 0.10 .

The López-Jornet 2014 study in adults with hyposalivation showed a benefit in gingivitis for professional OHA at 2 months: MD 12.30 $95 \% \mathrm{Cl} 1.90$ to 22.70 .

Overall, the evidence for gingivitis was graded as very low quality.

\section{Plaque levels}

The Baab 1986 study in adults reported "mean plaque scores did not differ significantly between groups" but no usable data reported.

The Glavind 1985 study in adults reported "no statistically significant differences were found between the two groups at any of the examination times" but no usable data reported.

The Jönsson 2006 study in adults showed a benefit in plaque reduction at 3 months for self-management: MD $-0.08,95 \% \mathrm{Cl}-0.15$ to -0.01 .

The López-Jornet 2014 study in adults with hyposalivation showed a benefit in gingivitis for professional OHA at 2 months: MD -0.10 $95 \% \mathrm{Cl}-0.18$ to -0.02 .

Overall, the evidence for plaque levels was graded as very low quality.

\section{Dental caries}

No studies were found that looked at dental caries.

\section{Comparison 4: Enhanced one-to-one OHA versus one-to-one OHA}

Seven trials compared some form of enhanced OHA with some form of routine OHA (Bali 1999; Hoogstraten 1983; Münster Halvari 2012; Söderholm 1982; Tedesco 1992; Van Leeuwen 2017; Weinstein 1996). Five of the studies investigating enhanced $\mathrm{OHA}$ versus $\mathrm{OHA}$ reported gingivitis (Bali 1999; Münster Halvari 2012; Söderholm 1982; Tedesco 1992; Van Leeuwen 2017). Six of the studies investigating enhanced $\mathrm{OHA}$ versus routine $\mathrm{OHA}$ reported gingivitis (Bali 1999; Münster Halvari 2012; Söderholm 1982; Tedesco 1992; Van Leeuwen 2017; Weinstein 1996). Only the Bali 1999 study reported dental caries. Outcomes were reported up to 2 months (Weinstein 1996), 3 months (Söderholm 1982), 5.5 months (Münster Halvari 2012), 9 months (Tedesco 1992), and 12 months (Bali 1999; Hoogstraten 1983; Van Leeuwen 2017).

\section{Gingivitis}

Two studies in adults did not report usable data (Bali 1999; Tedesco 1992).

Three studies found little or no difference between groups across all time points (Münster Halvari 2012; Söderholm 1982; Van Leeuwen 2017).

The Münster Halvari 2012 study showed low-quality evidence of a benefit in reduction of gingivitis for enhanced $\mathrm{OHA}$ at 5.5 months: MD $-0.32,95 \% \mathrm{Cl}-0.36$ to -0.28 .

The Söderholm 1982 study reported little or no difference between groups at 3 months: MD $0.00,95 \% \mathrm{Cl}-3.34$ to 3.34 .

The Van Leeuwen 2017 study reported little or no difference between groups at 12 months: MD $-0.90,95 \% \mathrm{Cl}-7.47$ to 5.67 .

Overall, the evidence for gingivitis was graded as very low quality.

\section{Plaque levels}

Two studies (Bali 1999; Tedesco 1992) in adults did not report usable data. 
The Münster Halvari 2012 study in adults showed low-quality evidence of a benefit in plaque reduction for enhanced OHA at 5.5 months: $\mathrm{MD}-0.3995 \% \mathrm{Cl}-0.47$ to -0.31 .

The Söderholm 1982 study reported little or no difference between groups at 3 months: MD $-2.90,95 \% \mathrm{Cl}-11.56$ to 5.76 .

The Van Leeuwen 2017 study reported little or no difference between groups at all time points. The mean difference at 12 months was $0.03,95 \% \mathrm{Cl}-0.12$ to 0.18 .

The Weinstein 1996 study included three intervention groups of enhanced OHA compared with the control OHA. Only one of the intervention groups (intervention group 3 ) showed a small benefit in plaque reduction at 2 months: $\mathrm{MD}-0.23,95 \% \mathrm{Cl}-0.37$ to -0.09 .

Overall, the evidence for plaque levels was graded as very low quality.

\section{Dental caries}

The Bali 1999 study in adults investigated dental caries but did not report usable data.

\section{DISCUSSION}

\section{Summary of main results}

We have identified 19 studies suitable for inclusion to this review. A total of 4232 participants were recruited, with numbers included in each trial ranging from 33 to 1877 . The member of the dental team delivering the oral hygiene advice $(\mathrm{OHA})$ was a hygienist in eight studies, dentist in four studies, dental nurse in one study, dentist or hygienist in one study, dental nurse and hygienist in one study, and dental nurse OHA to the control group with further selfadministration of the intervention in one study. It was unclear in three of the studies which member of the dental team carried out the intervention.

Due to the heterogeneity of the studies with respect to participants, interventions, settings and outcome measures we were unable to pool the data. We summarised data by categorising similar interventions into comparison groups.

\section{Comparison 1: Any form of one-to-one OHA versus no OHA}

Four studies compared any form of one-to-one $\mathrm{OHA}$ versus no $\mathrm{OHA}$ and the results are summarised in Summary of findings for the main comparison.

Two studies reported the outcome of gingivitis. Although one small study in adults had contradictory results at 3 months and 6 months, the other study in adults showed very low-quality evidence of a benefit for OHA at all time points of 12 months, 24 months and 36 months.

The same two studies reported the outcome of plaque. There was low-quality evidence that these interventions showed a benefit for $\mathrm{OHA}$ in plaque reduction at all time points.

Two studies reported the outcome of dental caries at 6 months and 12 months respectively. There was very low-quality evidence of a benefit for $\mathrm{OHA}$ at 12 months.

\section{Comparison 2: Personalised one-to-one OHA versus routine} one-to-one OHA

Four studies compared personalised $\mathrm{OHA}$ versus routine $\mathrm{OHA}$ and the results are summarised in Summary of findings 2 .

There was little evidence available that any of these interventions demonstrated a difference on the outcomes of gingivitis, plaque or dental caries (very low quality).

\section{Comparison 3: Self-management versus professional OHA}

Five trials compared some form of self-management with some form of professional OHA and the results are summarised in Summary of findings 3.

There was little evidence available that any of these interventions demonstrated a difference on the outcomes of gingivitis or plaque (very low quality). None of the studies measured dental caries.

\section{Comparison 4: Enhanced one-to-one OHA versus one-to-one} OHA

Seven trials compared some form of enhanced OHA with some form of routine OHA and the results are presented in Summary of findings 4 .

There was little evidence available that any of these interventions demonstrated a difference on the outcomes of gingivitis, plaque or dental caries (very low quality).

\section{Overall completeness and applicability of evidence}

Our search strategy was wide and retrieved 15,188 studies with a further two studies identified by handsearching. We identified 19 studies for inclusion having also handsearched the references from systematic reviews, reviews and those papers included. As such we are confident that the actions completed have resulted in a robust review of the evidence currently available. Furthermore, the evidence identified studies carried out in a number of dental settings, different countries, different age populations and healthy patients or those with specified medical or oral health conditions. In addition, there was a variety of dental care professionals who delivered a mixture of different interventions over a variety of time frames and frequencies. The sample size and length of follow-up of included studies were also variable.

Regarding the applicability of the evidence, due to the heterogeneity of study design, study interventions and outcome measures it was not possible to carry out a meta-analysis to determine if any specific intervention was more effective in maintaining or improving oral health, hygiene, behaviour, and attitudes compared to no advice or advice in a different format. There was also a dearth of high-quality studies with low risk of bias. The majority of studies were carried out in secondary care, as such it may be difficult to extrapolate the evidence to the wider population as the majority of the general population access dental care in primary care. We also noted that the frequency and intensity of intervention varied significantly between studies with some reporting multiple intervention appointments, as many as median of nine (Jönsson 2009), and up to 150 minutes intervention time. The follow-up time was limited in most of the included studies. As such the applicability of the evidence is not largely generalisable. 


\section{Quality of the evidence}

The body of the evidence is very low quality as presented in Summary of findings for the main comparison; Summary of findings 2; Summary of findings 3; Summary of findings 4.

\section{Potential biases in the review process}

The search strategy produced a large number of results with very few additional studies found via handsearching. However, while this process was deemed robust, it is possible that some small studies were not identified though we are confident that all larger studies were found.

We were not blinded to the names of authors, publications, institutions, etc. of studies at the time of reviewing which may have introduced bias to the review with conflict of interests declared in advance of the review process; the primary author had no conflict of interest and those who did declare conflicts of interest were not involved in reviewing any of the related data (i.e. the IQuaD Study (Ramsay 2018)).

\section{Agreements and disagreements with other studies or reviews}

In agreement with our review, a number of previous reviews have noted the variety of oral health promotion interventions investigated and the resultant heterogeneity in studies (Kay 2016a; Kay 2016b; Watt 2005; Yevlahova 2009). Furthermore, due to the variable quality of studies and findings, it is not possible to estimate the intervention effect (Watt 2005). As a result, direct comparisons between studies is difficult due to the lack of standardised and validated outcome measurement tools (Kay 1998).

As previously stated, due to the variety of different outcomes and outcome measures used there is difficulty in assessing and summarizing the effect of interventions on plaque levels (Watt 2005). Watt et al also commented that in the short term, i.e. up to 6 months-post intervention, substantial reductions in plaque reduction can be expected following educational interventions but longer term studies are limited in number, so whether or not such short-term improvements are maintained is impossible to determine (Watt 2005) which has been echoed by others (Kay 2016b).

The systematic review by Kay et al, which focused on oral health promotion activities that could be delivered in the context of general dental practice, aimed to change individual's knowledge, attitudes or behaviours in order to influence their oral health, also noted that the quality of the studies were very variable. Furthermore, the authors similarly noted that "the outcome measures used to assess knowledge, behaviour and attitudes were ad-hoc measures and therefore only very rarely allowed direct comparisons between studies and entirely obviated the possibility of meta-analysing the data. Direct comparison between studies and/or meta-analysis would have only been possible for studies that measured the same clinical outcomes, and then only if the interventions had been the same. This required level of similarity between studies was not reached" (Kay 2016b). The authors note that this is similar to a previous publication by the same authors (Kay 2016a).

One review concluded that there was evidence to show that motivational interviewing "may be useful in the dental surgery setting and this application should be researched further" (Kay 2016b). The current systematic review only found two studies suitable for inclusion on this topic (López-Jornet 2014; Münster Halvari 2012) and we did not think the available evidence allowed adequate comparisons.

Regarding previous review findings regarding $\mathrm{OHA}$ and dental caries prevention, Kay et al reported that "there is still no evidence that caries can be prevented by oral health promotion although this apparent lack of effect may be due, in part, to the short follow-up (<3 years) in the majority of studies" (Kay 2016a).

\section{AUTHORS' CONCLUSIONS}

\section{Implications for practice}

There was insufficient high-quality evidence to recommend any specific one-to-one oral hygiene advice (OHA) method as being effective in improving oral health or being more effective than any other method.

\section{Implications for research}

The quality of study reporting was variable with the use of CONSORT recommended for future studies (www.consortstatement.org).

Many of the studies did not make the exact nature of the OHA intervention entirely clear; more detailed description of intervention(s) following the 'Criteria for Reporting the Development and Evaluation of Complex Interventions in health care: revised guideline (CReDECl 2)' (Möhler 2015) would be of benefit to facilitate easier comparison.

Researchers conducting future studies should ensure that methods of randomisation are adequate and clearly reported along with ensuring allocation concealment, appropriate blinding and sample size determined at design stage. In addition, appropriate and validated patient-centred outcome measures should be included in future studies along with the need to determine the cost effectiveness of interventions.

The vast majority of the studies had a short follow-up; longer follow-up periods would be beneficial to determine longer term effects of one-to-one OHA.

Given the vast majority of dental care is provided in a primary care environment, future studies within this environment that take into account the likely time and financial limitations such an environment are likely to impose (e.g. frequency and intensity of intervention), would be advantageous to allow future research to be applicable to the wider population with such interventions needing to be both clinically and financially effective and efficient.

\section{ACKNOWLEDGEMENTS}

We would like to extend our thanks to Anne Littlewood for completion of searches, and Luisa M Fernandez Mauleffinch for her editorial assistance and copy editing. We would also like to thank Anette Blümle, Dominic Lamont and Falk Schwendicke for their assistance with translation. Also, thanks to Craig Ramsay and Anne Marie Glenny for advice on thematic considerations, and Helen Worthington, Philip Riley, Paul Brocklehurst and Derek Richards for peer review comments. 


\section{R E F E R E N C E S}

\section{References to studies included in this review}

Aljafari 2017 \{published and unpublished data\}

* Aljafari A, Gallagher JE, Hosey MT. Can oral health education be delivered to high-caries-risk children and their parents using a computer game? - A randomised controlled trial. International Journal of Paediatric Dentistry 2017;27(6):476-85. [DOI: 10.1111/ ipd.12286]

Aljafari A, Rice C, Gallagher JE, Hosey MT. An oral health education video game for high caries risk children: study protocol for a randomized controlled trial. Trials 2015;16:237.

Baab 1986 \{published data only\}

Baab D, Weinstein P. Longitudinal evaluation of a self-inspection plaque index in periodontal recall patients. Journal of Clinical Periodontology 1986;13(4):313-8.

Bali 1999 \{published data only\}

Bali C, Gurdet C, Hauer G, Handler I, Fischer R. Evaluation of the effect of professional dental cleaning and education in dental hygiene in type 1 diabetic patients. Acta Medica Austriaca 1999;26(5):159-62.

\section{Glavind 1985 \{published data only\}}

Glavind L, Christensen H, Pedersen E, Rosendahl H, Attström R. Oral hygiene instruction in general dental practice by means of self-teaching manuals. Journal of Clinical Periodontology 1985;12(1):27-34.

\section{Hetland 1982 \{published data only\}}

Hetland L, Midtun N, Kristoffersen T. Effect of oral hygiene instructions given by paraprofessional personnel. Community Dentistry and Oral Epidemiology 1982;10(1):8-14.

\section{Hoogstraten 1983 \{published data only\}}

Hoogstraten J, Moltzer G. Effects of dental health care instruction on knowledge, attitude, behavior and fear. Community Dentistry and Oral Epidemiology 1983;11(5):278-82.

\section{Hugoson 2007 \{published data only\}}

* Hugoson A, Lundgren D, Asklöw B, Borgklint G. Effect of three different dental health preventive programmes on young adult individuals: a randomized, blinded, parallel group, controlled evaluation of oral hygiene behaviour on plaque and gingivitis. Journal of Clinical Periodontology 2007;34(5):407-15.

Hugoson A, Lundgren D, Asklöw B, Borgklint G. The effect of different dental health programmes on young adult individuals. A longitudinal evaluation of knowledge and behaviour including cost aspects. Swedish Dental Journal 2003;27(3):115-30.

\section{Jönsson 2006 \{published data only\}}

Jönsson B, Lindberg P, Oscarson N, Ohrn K. Improved compliance and self-care in patients with periodontitis - a randomized control trial. International Journal of Dental Hygiene 2006;4(2):77-83. [DOI: 10.1111/ j.1601-5037.2006.00175.x]
Jönsson 2009 \{published data only\}

Jönsson B, Ohrn K. Evaluation of the effect of non-surgical periodontal treatment on oral health-related quality of life: estimation of minimal important differences 1 year after treatment. Journal of Clinical Periodontology 2014;41(3):275-82.

Jönsson B, Ohrn K, Lindberg P, Oscarson N. Cost-effectiveness of an individually tailored oral health educational programme based on cognitive behavioural strategies in non-surgical periodontal treatment. Journal of Clinical Periodontology 2012;39(7):659-65. [DOI: 10.1111/j.1600-051X.2012.01898.x]

Jönsson B, Ohrn K, Lindberg P, Oscarson N. Evaluation of an individually tailored oral health educational programme on periodontal health. Journal of Clinical Periodontology 2010;37(10):912-9. [DOI: 10.1111/j.1600-051X.2010.01590.x]

* Jönsson B, Ohrn K, Oscarson N, Lindberg P. The effectiveness of an individually tailored oral health educational programme on oral hygiene behaviour in patients with periodontal disease: a blinded randomized-controlled clinical trial (one-year followup). Journal of Clinical Periodontology 2009;36(12):1025-34. [DOI: 10.1111/j.1600-051X.2009.01453.x]

\section{Lepore 2011 \{published data only\}}

Lepore LM, Yoon RK, Chinn CH, Chussid S. Evaluation of behavior change goal-setting action plan on oral health activity and status. New York State Dental Journal 2011;77(6):43-7. [PUBMED: 22338818]

\section{López-Jornet 2014 \{published data only\}}

López-Jornet P, Fabio CA, Consuelo RA, Paz AM. Effectiveness of a motivational-behavioural skills protocol for oral hygiene among patients with hyposalivation. Gerodontology 2014;31(4):288-95. [DOI: 10.1111/ger.12037]

\section{Memarpour 2016 \{published data only\}}

Memarpour M, Dadaein S, Fakhraei E, Vossoughi M. Comparison of oral health education and fluoride varnish to prevent early childhood caries: a randomized clinical trial. Caries Research 2016;50(5):433-42. [DOI: 10.1159/000446877]

\section{Münster Halvari 2012 \{published data only\}}

Münster Halvari AE, Halvari H, Bjørnebekk G, Deci EL. Selfdetermined motivational predictors of increases in dental behaviors, decreases in dental plaque, and improvement in oral health: a randomized clinical trial. Health Psychology 2012;31(6):777-88. [DOI: 10.1037/a0027062]

\section{Ramsay 2018 \{published data only\}}

Ramsay CR, Clarkson JE, Duncan A, Lamont TJ, Heasman PA, Boyers D, et al. Improving the Quality of Dentistry (IQuaD): a cluster factorial randomised controlled trial comparing the effectiveness and cost-benefit of oral hygiene advice and/ or periodontal instrumentation with routine care for the prevention and management of periodontal disease in dentate adults attending dental primary care. Health Technology Assessment 2018;22(38):1-144. [DOI: 10.3310/hta22380] 
Schmalz 2018 \{published data only\}

Schmalz G, Kiehl K, Schmickler J, Rinke S, Schmidt J, Krause F, et al. No difference between manual and different power toothbrushes with and without specific instructions in young, oral healthy adults - results of a randomized clinical trial. Clinical Oral Investigations 2018;22(3):1147-55. [DOI: 10.1007/ s00784-017-2200-5]

\section{Söderholm 1982 \{published data only\}}

Söderholm G, Nobréus N, Attström R, Egelberg J. Teaching plaque control. I. A five-visit versus a two-visit program. Journal of Clinical Periodontology 1982;9(3):203-13. [PUBMED: 6954162]

\section{Tedesco 1992 \{published data only\}}

Tedesco LA, Keffer MA, Davis EL, Christersson LA. Effect of a social cognitive intervention on oral health status, behavior reports, and cognitions. Journal of Periodontology 1992;63(7):567-75. [DOI: 10.1902/jop.1992.63.7.567]

\section{Van Leeuwen 2017 \{published data only\}}

Van Leeuwen M, Rosema N, Versteeg PA, Slot DE, HennequinHoenderdos NL, Van der Weijden GA. Effectiveness of various interventions on maintenance of gingival health during 1 year - a randomized clinical trial. International Journal of Dental Hygiene 2017;15(4):e16-e27.

\section{Weinstein 1996 \{published data only\}}

Weinstein R, Tosolin F, Ghilardi L, Zanardelli E. Psychological intervention in patients with poor compliance. Journal of Clinical Periodontology 1996;23(3 Pt 2):283-8. [DOI: 10.1111/ j.1600-051X.1996.tb02090.x]

\section{References to studies excluded from this review}

\section{Albandar 1994 \{published data only\}}

Albandar JM, Buischi YA, Mayer MP, Axelsson P. Long-term effect of two preventive programs on the incidence of plaque and gingivitis in adolescents. Journal of Periodontology 1994;65(6):605-10.

\section{Aleksejūnienè 2018 \{published data only\}}

Aleksejūnienè J, Brukienè V. A cluster randomized theoryguided oral hygiene trial in adolescents - a latent growth model. International Journal of Dental Hygiene 2018;16(2):e23-e30. [DOI: 10.1111/idh.12286]

\section{Almomani 2006 \{published data only\}}

Almomani F, Brown C, Williams KB. The effect of an oral health promotion program for people with psychiatric disabilities. Psychiatric Rehabilitation Journal 2006;29(4):274-81.

\section{Almomani 2009 \{published data only\}}

Almomani F, Williams K, Catley D, Brown C. Effects of an oral health promotion program in people with mental illness. Journal of Dental Research 2009;88(7):648-52.

\section{Arrow 2013 \{published data only\}}

Arrow P, Raheb J, Miller M. Brief oral health promotion intervention among parents of young children to reduce early childhood dental decay. BMC Public Health 2013;13:245.

\section{Arunakul 2012 \{published data only\}}

Arunakul M, Kuphasuk Y, Boonyathanasit R. Effectiveness of oral hygiene instruction media on periodontal health among hearing impaired children. Southeast Asian Journal of Tropical Medicine and Public Health 2012;43(5):1297-303.

\section{Arunakul 2015 \{published data only\}}

Arunakul M, Asvanund Y, Tantakul A, Mitrakul K, Srisatjaluk R, Vongsavan K. Effectiveness of an oral hygiene education program combined with fluoride mouthrinse among visually impaired students in Bangkok, Thailand. Southeast Asian Journal of Tropical Medicine and Public Health 2015;46(2):354-9.

\section{Axelsson 1981 \{published data only\}}

Axelsson P, Lindhe J. Effect of oral hygiene instruction and professional toothcleaning on caries and gingivitis in schoolchildren. Community Dentistry and Oral Epidemiology 1981;9(6):251-5.

\section{Bahri 2015 \{published data only\}}

Bahri N, Tohidinik HR, Bahri N, Iliati HR, Moshki M, Darabi F. Educational intervention to improve oral health beliefs and behaviors during pregnancy: a randomized-controlled trial. Journal of the Egyptian Public Health Association 2015;90(2):41-5.

\section{Blinkhorn 1981 \{published data only\}}

Blinkhorn AS, Downer MC, Mackie IC, Bleasdale RS. Evaluation of a practice based preventive programme for adolescents. Community Dentistry and Oral Epidemiology 1981;9(6):275-9.

\section{Blinkhorn 2003 \{published data only\}}

Blinkhorn AS, Gratrix D, Holloway PJ, Wainwright-Stringer YM, Ward SJ, Worthington HV. A cluster randomised, controlled trial of the value of dental health educators in general dental practice. British Dental Journal 2003;195(7):395-400. [DOI: 10.1038/sj.bdj.4810566]

\section{Brand 2013 \{published data only\}}

Brand VS, Bray KK, MacNeill S, Catley D, Williams K. Impact of single-session motivational interviewing on clinical outcomes following periodontal maintenance therapy. International Journal of Dental Hygiene 2013;11(2):134-41.

\section{Brukienè 2012 \{published data only\}}

Brukienè V, Aleksejūnienè J. Is the authoritative parenting model effective in changing oral hygiene behavior in adolescents?. Health Education Research 2012;27(6):1081-90.

\section{Choi 2012 \{published data only\}}

Choi HS, Ahn HY. Effects of mothers involved in dental health program for their children. Journal of Korean Academy of Nursing 2012;42(7):1050-61.

\section{Clarkson 2009 \{published data only\}}

Clarkson JE, Young L, Ramsay CR, Bonner BC, Bonetti D. How to influence patient oral hygiene behavior effectively. Journal of Dental Research 2009;88(10):933-7. [DOI: 10.1177/0022034509345627] 


\section{Crawford 1975 \{published data only\}}

Crawford AN, McAllan LH, Murray JJ, Brook AH. Oral hygiene instruction and motivation in children using manual and electric toothbrushes. Community Dentistry and Oral Epidemiology 1975;3(6):257-61. [PUBMED: 1059513]

Daly 2009 \{published data only\}

Daly CG. Prescribing good oral hygiene for adults. Australian Prescriber 2009;32(3):72-5.

\section{Davies 2007 \{published data only\}}

Davies GM, Duxbury JT, Boothman NJ, Davies RM. Challenges associated with the evaluation of a dental health promotion programme in a deprived urban area. Community Dental Health 2007;24(2):117-21.

\section{de Andrade Meyer 2010 \{published data only\}}

de Andrade Meyer AC, de Mello Tera T, da Rocha JC, Jardini MA. Clinical and microbiological evaluation of the use of toothpaste containing $1 \%$ chlorhexidine and the influence of motivation on oral hygiene in patients with motor deficiency. Special Care in Dentistry 2010;30(4):140-5.

\section{Dermen 2014 \{published data only\}}

Dermen KH, Ciancio SG, Fabiano JA. A pilot test of motivational oral health promotion with alcohol-dependent inpatients. Health Psychology 2014;33(4):392-5.

\section{Džiaugytè 2017 \{published data only\}}

Džiaugytè L, Aleksejūnienė J, Brukienè V, Pečiulienè V. Selfefficacy theory-based intervention in adolescents: a cluster randomized trial-focus on oral self-care practice and oral self-care skills. International Journal of Paediatric Dentistry 2017;27(1):37-46.

\section{Esfahanizadeh 2011 \{published data only\}}

Esfahanizadeh N. Dental health education programme for 6year-olds: a cluster randomised controlled trial. European Journal of Paediatric Dentistry 2011;12(3):167-70.

\section{Ferrazzano 2008 \{published data only\}}

Ferrazzano GF, Cantile T, Sangianantoni G, Ingenito A. Effectiveness of a motivation method on the oral hygiene of children. European Journal of Paediatric Dentistry 2008;9(4):183-7.

\section{Franz-Ritscherle 1983 \{published data only\}}

Franz-Ritscherle A, Lange DE. Effectiveness of various audiovisual technics to improve oral hygiene behavior. Deutsche Zahnarztliche Zeitschrift 1983;38(9):811-5.

\section{Freitas-Fernandes 2002 \{published data only\}}

Freitas-Fernandes LB, Novaes AB Jr, Feitosa AC, Novaes AB. Effectiveness of an oral hygiene program for Brazilian orphans. Brazilian Dental Journal 2002;13(1):44-8.

\section{Gathece 2011 \{published data only\}}

Gathece LW, Wang'ombe JK, Ng'ang'a PM, Wanzala PN. Effect of health education on oral hygiene and gingival status of persons living with HIV attending comprehensive care centres in Nairobi, Kenya. African Journal of AIDS Research 2011;10(4):495-500.

\section{Glavind 1981 \{published data only\}}

Glavind L, Zeuner E, Attström R. Oral hygiene instruction of adults by means of a self-instructional manual. Journal of Clinical Periodontology 1981;8(3):165-76.

Glavind 1983 \{published data only\}

Glavind L, Zeuner E, Attstrom R. Evaluation of various feedback mechanisms in relation to compliance by adult patients with oral home care instructions. Journal of Clinical Periodontology 1983;10(1):57-68. [PUBMED: 6572635]

\section{Godard 2011 \{published data only\}}

Godard A, Dufour T, Jeanne S. Application of self-regulation theory and motivational interview for improving oral hygiene: a randomized controlled trial. Journal of Clinical Periodontology 2011;38(12):1099-105.

\section{Graehn 1984 \{published data only\}}

Graehn G. A health education program for pre-school children. 1. Results on health knowledge, health behavior, and oral hygiene. Stomatologie der DDR 1984;34(4):226-35.

\section{Harnacke 2012 \{published data only\}}

Harnacke D, Mitter S, Lehner M, Munzert J, Deinzer R. Improving oral hygiene skills by computer-based training: a randomized controlled comparison of the modified Bass and the Fones techniques. PLoS One 2012;7(5):e37072.

\section{Harrison 2007 \{published data only\}}

Harrison R, Benton T, Everson-Stewart S, Weinstein P. Effect of motivational interviewing on rates of early childhood caries: a randomized trial. Pediatric Dentistry 2007;29(1):16-22.

\section{Hietasalo 2009 \{published data only\}}

Hietasalo P, Seppa L, Lahti S, Niinimaa A, Kallio J, Aronen P, et al. Cost-effectiveness of an experimental caries-control regimen in a 3.4-yr randomized clinical trial among 11-12-yrold Finnish schoolchildren. European Journal of Oral Sciences 2009;117(6):728-33.

\section{Ismail 2011 \{published data only\}}

Ismail Al, Ondersma S, Jedele JM, Little RJ, Lepkowski JM. Evaluation of a brief tailored motivational intervention to prevent early childhood caries. Community Dentistry and Oral Epidemiology 2011;39(5):433-48.

\section{Iwata 1981 \{published data only\}}

Iwata BA, Becksfort CM. Behavioral research in preventive dentistry: educational and contingency management approaches to the problem of patient compliance. Journal of Applied Behavior Analysis 1981;14(2):111-20.

\section{Jiang 2014 \{published data only\}}

Jiang EM, Lo EC, Chu CH, Wong MC. Prevention of early childhood caries (ECC) through parental toothbrushing training and fluoride varnish application: a 24-month randomized controlled trial. Journal of Dentistry 2014;42(12):1543-50.

\section{Jönsson 2012 \{published data only\}}

Jönsson B, Baker SR, Lindberg P, Oscarson N, Ohrn K. Factors influencing oral hygiene behaviour and gingival outcomes 3 and 
12 months after initial periodontal treatment: an exploratory test of an extended Theory of Reasoned Action. Journal of Clinical Periodontology 2012;39(2):138-44.

\section{Ju 2017 \{published data only\}}

Ju X, Brennan D, Parker E, Mills H, Kapellas K, Jamieson L. Efficacy of an oral health literacy intervention among Indigenous Australian adults. Community Dentistry and Oral Epidemiology 2017;45(5):413-26.

\section{Kakudate 2009 \{published data only\}}

Kakudate N, Morita M, Sugai M, Kawanami M. Systematic cognitive behavioral approach for oral hygiene instruction: a short-term study. Patient Education and Counseling 2009;74(2):191-6.

\section{Kasaj 2004 \{published data only\}}

Kasaj A, Sculean A, Willershausen B. Study of the usefulness of the DetecTar System in improving patient compliance and oral hygiene. Parodontologie 2004;15(4):343-53.

\section{Langan 1976 \{published data only\}}

Langan MJ, Yearick ES. The effects of improved oral hygiene on taste perception and nutrition of the elderly. Journal of Gerontology 1976;31(4):413-8.

\section{Lee 2009 \{published data only\}}

Lee HK, Choi SH, Won KC, Merchant AT, Song KB, Jeong SH, et al. The effect of intensive oral hygiene care on gingivitis and periodontal destruction in type 2 diabetic patients. Yonsei Medical Journal 2009;50(4):529-36.

\section{Legler 1971 \{published data only\}}

Legler DW, Gilmore RW, Stuart GC. Dental education of disadvantaged adult patients: effects on dental knowledge and oral health. Journal of Periodontology 1971;42(9):565-70.

\section{Lim 1996 \{published data only\}}

Lim LP, Davies WI. Comparison of various modalities of "simple" periodontal therapy on oral cleanliness and bleeding. Journal of Clinical Periodontololgy 1996;23(6):595-600.

\section{Lim 1996b \{published data only\}}

Lim LP, Davies WI, Yuen KW, Ma MH. Comparison of modes of oral hygiene instruction in improving gingival health. Journal of Clinical Periodontology 1996;23(7):693-7.

\section{Little 1997 \{published data only\}}

Little SJ, Hollis JF, Stevens VJ, Mount K, Mullooly JP, Johnson BD. Effective group behavioral intervention for older periodontal patients. Journal of Periodontal Research 1997;32(3):315-25.

\section{Mahantesha 2015 \{published data only\}}

Mahantesha T, Nara A, Kumari PR, Halemani PK, Buddiga V, Mythri S. A comparative evaluation of oral hygiene using Braille and audio instructions among institutionalized visually impaired children aged between 6 years and 20 years: a 3month follow-up study. Journal of International Society of Preventive and Community Dentistry 2015;5(Suppl 2):S129-32.
Makuch 2011 \{published data only\}

Makuch A, Reschke K, Rupf S. Effective teaching of toothbrushing to preschool children. Journal of Dentistry for Children 2011;78(1):9-12.

\section{Mayer 2003 \{published data only\}}

Mayer MP, de Paiva Buischi Y, de Oliveira LB, Gjermo O. Longterm effect of an oral hygiene training program on knowledge and reported behavior. Oral Health and Preventive Dentistry 2003;1(1):37-43.

\section{Meurman 2009 \{published data only\}}

Meurman P, Pienihäkkinen K, Eriksson AL, Alanen P. Oral health programme for preschool children: a prospective, controlled study. International Journal of Paediatric Dentistry 2009;19(4):263-73

\section{Moltzer 1986 \{published data only\}}

Moltzer G, Hoogstraten J. The effect of three methods of dental health care instruction and dental knowledge, attitude, behaviour, and fear. Community Dental Health 1986;3(1):83-9.

\section{Moskovitz 2009 \{published data only\}}

Moskovitz M, Abud W, Ram D. The influence of an oral health education program provided in a community dental clinic on the prevalence of caries among 12-14 year-old children. Journal of Clinical Pediatric Dentistry 2009;33(3):259-64.

\section{Ohrn 2009 \{published data only\}}

Ohrn K, Sanz M. Prevention and therapeutic approaches to gingival inflammation. Journal of Clinical Periodontology 2009;36(Suppl 10):20-6.

\section{Park 2011 \{published data only\}}

Park MS, Choi-Kwon S. The effects of oral care education on caregivers' knowledge, attitude, \& behavior toward oral hygiene for elderly residents in a nursing home. Journal of Korean Academy of Nursing 2011;41(5):684-93.

\section{Park 2015 \{published data only\}}

Park DY, Lee BJ, Kim BO, Yu SJ. Effect of the education interval and method on improving patients' plaque control ability. Journal of Korean Academy of Oral Health 2015;39(2):145-51.

\section{Patthoff 1981 \{published data only\}}

Patthoff DE, Horton AM Jr, Di Vecchio MB. Behavioral dentistry: a multiple-baseline study incorporating contracting with patients. Perceptual and Motor Skills 1981;53(2):383-6.

\section{Picard 2014 \{published data only\}}

Picard AJ, Estrella MR, Boynton J, Maxwell A, Inglehart MR. Educating parents of children receiving comprehensive dental care under general anesthesia with visual AIDS. Pediatric Dentistry 2014;36(4):329-35.

\section{Pickrell 2007 \{published data only\}}

Pickrell JE, Heima M, Weinstein P, Coolidge T, Coldwell SE, Skaret $E$, et al. Using memory restructuring strategy to enhance dental behaviour. International Journal of Paediatric Dentistry 2007;17(6):439-48. 
Pine 2007 \{published data only\}

Pine CM, Curnow MM, Burnside G, Nicholson JA, Roberts AJ. Caries prevalence four years after the end of a randomised controlled trial. Caries Research 2007;41(6):431-6.

\section{Plutzer 2008 \{published data only\}}

Plutzer K, Spencer AJ. Efficacy of an oral health promotion intervention in the prevention of early childhood caries. Community Dentistry and Oral Epidemiology 2008;36(4):335-46.

\section{Plutzer 2012 \{published data only\}}

Plutzer K, Spencer AJ, Keirse MJ. Reassessment at 6-7 years of age of a randomized controlled trial initiated before birth to prevent early childhood caries. Community Dentistry and Oral Epidemiology 2012;40(2):116-24.

\section{Reinhardt 2010 \{published data only\}}

Reinhardt CH, Noack MJ, Wassmer G, Hurrelmann K, Klein K. A strategy for encouraging young adults' adoption of a preferred oral hygiene technique. Oral Health and Preventive Dentistry 2010;8(1):3-8.

\section{Roscher 2004 \{published data only\}}

Roscher T, Rösing CK, Gjermo P, Aass AM. Effect of instruction and motivation in the use of electric and manual toothbrushes in periodontal patients. A comparative study. Brazilian Oral Research 2004;18(4):296-300.

\section{Saengtipbovorn 2017 \{published data only\}}

Saengtipbovorn S. Efficacy of Motivational Interviewing in Conjunction with Caries Risk Assessment (MICRA) programmes in improving the dental health status of preschool children: a randomised controlled trial. Oral Health \& Preventive Dentistry 2017;15(2):123-9.

\section{Sandeep 2014 \{published data only\}}

Sandeep V, Vinay C, Madhuri V, Rao VV, Uloopi KS, Sekhar RC. Impact of visual instruction on oral hygiene status of children with hearing impairment. Journal of the Indian Society of Pedodontics and Preventive Dentistry 2014;32(1):39-43.

\section{Sato 2008 \{published data only\}}

Sato T, Abe T, Ichikawa M, Fukushima Y, Nakamoto N, Koshikiya $\mathrm{N}$, et al. A randomized controlled trial assessing the effectiveness of professional oral care by dental hygienists. International Journal of Dental Hygiene 2008;6(1):63-7.

\section{Schiffner 2007 \{published data only\}}

Schiffner U, Bahr M, Effenberger S. Plaque and gingivitis in the elderly: a randomized, single-blind clinical trial on the outcome of intensified mechanical or antibacterial oral hygiene measures. Journal of Clinical Periodontology 2007;34(12):1068-73. [DOI: 10.1111/j.1600-051X.2007.01150.x]

\section{Schneider 1981 \{published data only\}}

Schneider HG, Friedländer B, Richter C, Unger E, Ziesenitz S, Bendrien S. Experience with plaque-disclosing agents. Stomatologie der DDR 1981;31(12):904-9.

\section{Schneider 1982 \{published data only\}}

Schneider HG, Rasch K. The motivation of preschool children toward oral and dental hygiene. Stomatologie der DDR 1982;32(4):261-5

\section{Schüz 2009 \{published data only\}}

Schüz B, Wiedemann AU, Mallach N, Scholz U. Effects of a short behavioural intervention for dental flossing: randomizedcontrolled trial on planning when, where and how. Journal of Clinical Periodontology 2009;36(6):498-505.

\section{Seow 2003 \{published data only\}}

Seow WK, Cheng E, Wan V. Effects of oral health education and tooth-brushing on mutans streptococci infection in young children. Pediatric Dentistry 2003;25(3):223-8.

\section{Sniehotta 2007 \{published data only\}}

Sniehotta FF, Araújo Soares V, Dombrowski SU. Randomized controlled trial of a one-minute intervention changing oral selfcare behavior. Journal of Dental Research 2007;86(7):641-5.

\section{Söderholm 1982b \{published data only\}}

Söderholm G, Egelberg J. Teaching plaque control. II. 30-minute versus 15-minute appointments in a three-visit program. Journal of Clinical Periodontology 1982;9(3):214-22. [6954163]

\section{Stenman 2012 \{published data only\}}

Stenman J, Lundgren J, Wennström JL, Ericsson JS, Abrahamsson $\mathrm{KH}$. A single session of motivational interviewing as an additive means to improve adherence in periodontal infection control: a randomized controlled trial. Journal of Clinical Periodontology 2012;39(10):947-54.

\section{Stenman 2017 \{published data only\}}

Stenman J, Wennström JL, Abrahamsson KH. A brief motivational interviewing as an adjunct to periodontal therapy - a potential tool to reduce relapse in oral hygiene behaviours. A three-year study. International Journal of Dental Hygiene 2017 Aug 24 [Epub ahead of print]. [DOI: 10.1111/idh.12308]

\section{Strippel 2010 \{published data only\}}

Strippel H. Effectiveness of structured comprehensive paediatric oral health education for parents of children less than two years of age in Germany. Community Dental Health 2010;27(2):74-80

\section{Tan 1978 \{published data only\}}

Tan HH, Saxton CA. Effect of a single dental health care instruction and prophylaxis on gingivitis. Community Dentistry and Oral Epidemiology 1978;6(4):172-5.

Tan 1979 \{published data only\}

Tan HH. Effect of dental health care instruction and prophylaxis on knowledge, attitude and behavior in Dutch military personnel. Community Dentistry and Oral Epidemiology 1979; $7(5): 252-8$.

Telford 1974 \{published data only\}

Telford AB, Murray JJ. The effect of systematic chairside oral hygiene instruction on gingivitis and oral cleanliness 
in children. Community Dentistry and Oral Epidemiology 1974;2(2):50-7. [PUBMED: 4528776]

Triana 1985 \{published data only (unpublished sought but not used)\}

Triana Cue M, Nazco Ríos C. Gingival bleeding and motivation [Sangramiento gingival y motivación]. Revista Cubana de Estomatología 1985;22(2):118-24.

Valle 2004 \{published data only\}

Valle DD, de Carvalho Vianna RB, Quintanilha LE, de Abreu FV. Evaluation of an oral health promotion program using different indicators. Journal of Clinical Pediatric Dentistry 2004;29(1):87-92.

\section{Zanin 2007 \{published data only\}}

Zanin L, Meneghim MC, Assaf AV, Cortellazzi KL, Pereira AC. Evaluation of an educational program for children with high risk of caries. Journal of Clinical Pediatric Dentistry 2007;31(4):246-50.

\section{Zee 2006 \{published data only\}}

Zee KY, Lee DH, Corbet EF. Repeated oral hygiene instructions alone, or in combination with metronidazole dental gel with or without subgingival scaling in adult periodontitis patients: a one-year clinical study. Journal of the International Academy of Periodontology 2006;8(4):125-35.

\section{Ziebolz 2009 \{published and unpublished data\}}

Ziebolz D, Herz A, Brunner E, Hornecker E, Mausberg RF. Individual versus group oral hygiene instruction for adults. Oral Health \& Preventive Dentistry 2009;7(1):93-9. [PUBMED: 19408821]

\section{References to studies awaiting assessment}

Gao 2013 \{published data only\}

Gao X, Lo EC, McGrath C, Ho SM. Innovative interventions to promote positive dental health behaviors and prevent dental caries in preschool children: study protocol for a randomized controlled trial. Trials 2013;14:118. [DOI: 10.1186/1745-6215-14-118]

IRCT2014062618248N1 \{unpublished data only\}

IRCT2014062618248N1. The effect of educational intervention based on Pender's Health Promotion Model on oral and dental health behaviors among high school students. apps.who.int/ trialsearch/Trial3.aspx?trialid=IRCT2014062618248N1 (first received 25 October 2014).

\section{References to ongoing studies}

ACTRN12605000607673 \{unpublished data only\}

ACTRN12605000607673. Oral Health Education Logan Programme (OHELP) [The effect of a personalised oral health education programme on clinical and molecular risk factors for oral and general health in an at risk population]. www.anzctr.org.au/ACTRN12605000607673.aspx (first received 12 September 2005).
ISRCTN24958829 \{unpublished data only\}

ISRCTN24958829. Dental RECUR Trial [Comparison of a new with standard child and family primary care service to reduce the re-occurrence of childhood dental caries (Dental RECUR Trial)]. www.isrctn.com/ISRCTN24958829 (first received 27 September 2013).

ISRCTN38542397 \{unpublished data only\}

ISRCTN38542397. Is photographic evidence a valuable aide to oral hygiene advice in 9-16 year olds?. www.isrctn.com/ ISRCTN38542397 (first received 28 September 2007).

NCT01118143 \{unpublished data only\} NCT01118143. Oral health literacy tailored communication [Effects of communication tailored to oral health literacy level of adult dental patients: a randomized controlled trial]. clinicaltrials.gov/ct2/show/NCT01118143 (first received 6 May 2010).

\section{Additional references}

\section{Adair 1984}

Adair JG. The Hawthorne effect: a reconsideration of the methodological artifact. Journal of Applied Psychology 1984;69(2):334-45.

\section{Axelsson 2004}

Axelsson P, Nyström B, Lindhe J. The long-term effect of a plaque control program on tooth mortality, caries and periodontal disease in adults. Results after 30 years of maintenance. Journal of Clinical Periodontology 2004;31(9):749-57.

\section{Baab 1983}

Baab DA, Weinstein P. Oral hygiene instruction using a self inspection plaque index. Community Dentistry and Oral Epidemiology 1983;11(3):174-9.

\section{Bandura 1998}

Bandura A. Health promotion from the perspective of social cognitive theory. Psychology and Health 1998;13:623-49.

\section{Bass 1954a}

Bass CC. An effective method of personal oral hygiene. Journal of the Louisiana State Medical Society 1954;106(2):57-73.

\section{Bass 1954b}

Bass CC. An effective method of personal oral hygiene; part II. Journal of the Louisiana State Medical Society 1954;106(3):100-12.

\section{Björby 1967}

Björby Å, Löe H. The relative significance of different local factors in the initiation and development of periodontal inflammation. Scandinavian Symposium in Periodontology 1966. Journal of Periodontal Research 1967;2(1):76-7 (Abs No 20). 


\section{Chadwick 2011}

Chadwick B, White D, Lader D, Pitts N. 5: Preventive behaviour and risks to oral health - a report from the Adult Dental Health Survey 2009. Leeds: The Health and Social Care Information Centre; 2011 March.

\section{Chapple 2008}

Chapple ILC, Hill K. Getting the message across to periodontitis patients: the role of personalised biofeedback. International Dental Journal 2008;65(5 Supplement 1):294-306.

\section{DBOH 2009}

Department of Health, British Association for the Study of Community Dentistry. Delivering Better Oral Health: an evidence-based toolkit for prevention. London: Department of Health; 2009 April.

\section{Deci 1985}

Deci EL, Ryan RM. The general causality orientation scale: selfdetermination in personality. Journal of Research in Personality 1985;19:109-34.

\section{Deinzer 2014}

Deinzer R, Jahns S, Harnacke D. Establishment of a new marginal plaque index with high sensitivity for changes in oral hygiene. Journal of Periodontology 2014;85(12):1730-8.

\section{Dupont 1990}

Dupont WD, Plummer WD Jr. Power and sample size calculations. A review and computer program. Controlled Clinical Trials 1990;11(2):116-28.

\section{Egger 1997}

Egger M, Davey Smith G, Schneider M, Minder C. Bias in meta-analysis detected by a simple, graphical test. $B M J$ 1997;315(7109):629-34.

\section{Elbourne 2002}

Elbourne DR, Altman DG, Higgins JP, Curtin F, Worthington HV, Vail A. Meta-analyses involving cross-over trials: methodological issues. International Journal of Epidemiology 2002;31(1):140-9.

\section{Fishbein 1980}

Fishbein M, Azjen I. Understanding Attitudes and Predicting Social Behaviour. Englewood Cliffs: Prentice-Hall, Inc., 1980.

\section{Glavind 1979}

Glavind L, Attström R. Periodontal self-examination. A motivational tool in periodontics. Journal of Clinical Periodontology 1979;6(4):238-51.

\section{Gollwitzer 1999}

Gollwitzer PM. Implementation intentions: strong effects of simple plans. American Psychologist 1999;54:493-503.

\section{Gründemann 2000}

Gründemann LJ, Timmerman MF, ljzerman Y, van der Weijden GA, van der Weijden GA. Stain, plaque and gingivitis reduction by combining chlorhexidine and peroxyborate. Journal of Clinical Periodontology 2000;27(1):9-15.

\section{Halvari 2006}

Halvari A, Halvari H. Motivational predictors of change in oral health: an experimental test of self-determination theory. Motivation and Emotion 2006;30:295-305.

\section{Halvari 2010}

Halvari AEM, Halvari H, Bjørnebekk G, Deci EL. Motivation and anxiety for dental treatment: testing a self-determination theory model of oral self-care behavior and dental clinic attendance. Motivation and Emotion 2010;34:15-33.

\section{Halvari 2012}

Halvari AEM, Halvari H, Bjørnebekk G, Deci EL. Motivation for dental home care: testing a self-determination theory model. Journal of Applied Social Psychology 2012;42:1-39.

\section{Harris 2012}

Harris R, Gamboa A, Dailey Y, Ashcroft A. One-to-one dietary interventions undertaken in a dental setting to change dietary behaviour. Cochrane Database of Systematic Reviews 2012, Issue 3. [DOI: 10.1002/14651858.CD006540.pub2]

\section{Higgins 2011}

Higgins JP, Green S, editor(s). Cochrane Handbook for Systematic Reviews of Interventions Version 5.1.0 (updated March 2011). The Cochrane Collaboration, 2011. Available from handbook.cochrane.org.

\section{Holve 2008}

Holve S. An observational study of the association of fluoride varnish applied during well child visits and the prevention of early childhood caries in American Indian children. Maternal and Child Health Journal 2008;12 Suppl 1:64-7.

\section{Hugoson 2003}

Hugoson A, Lundgren D, Asklöw B, Borgklint G. The effect of different dental health programmes on young individuals: a longitudinal evaluation of knowledge and behaviour including cost aspects. Swedish Dental Journal 2003;27(3):115-30.

\section{Kagihara 2009}

Kagihara LE, Niederhauser VP, Stark M. Assessment, management, and prevention of early childhood caries. Journal of the American Academy of Nurse Practitioners 2009;21(1):1-10.

\section{Kassebaum 2014}

Kassebaum NJ, Bernabé E, Dahiya M, Bhandari B, Murray CJ, Marcenes W. Global burden of severe periodontitis in 1990-2010: a systematic review and meta-regression. Journal of Dental Research 2014;93(11):1045-53. [DOI: $10.1177 / 0022034514552491]$

\section{Kassebaum 2015}

Kassebaum NJ, Bernabé E, Dahiya M, Bhandari B, Murray CJ, Marcenes W. Global burden of untreated caries: a systematic review and metaregression. Journal of Dental Research 2015;94(5):650-8. [DOI: 10.1177/0022034515573272] 


\section{Kay 1998}

Kay EJ, Locker D. A systematic review of the effectiveness of health promotion aimed at improving oral health. Community Dental Health 1998;15:132-44.

\section{Kay 2016a}

Kay E, Vascott D, Hocking A, Nield H, Dorr C, Barrett H. A review of approaches for dental practice teams for promoting oral health. Community Dentistry and Oral Epidemiology 2016;44(4):313-30

\section{Kay 2016b}

Kay EJ, Vascott D, Hocking A, Nield H. Motivational interviewing in general dental practice: a review of the evidence. British Dental Journal 2016;221(12):785-91.

\section{Khokhar 2016}

Khokhar MA, Khokhar WA, Clifton AV, Tosh GE. Oral health education (advice and training) for people with serious mental illness. Cochrane Database of Systematic Reviews 2016, Issue 9. [DOI: 10.1002/14651858.CD008802.pub3]

\section{Kumarihamy 2011}

Kumarihamy SL, Subasinghe LD, Jayasekara P, Kularatna SM, Palipana PD. The prevalence of early childhood caries in 1-2 year olds in a semi-urban area of Sri Lanka. BMC Research Notes 2011;4:336

\section{Lang 2003}

Lang NP, Tonetti MS. Periodontal risk assessment (PRA) for patients in supportive periodontal therapy (STP). Oral Health and Preventive Dentistry 2003;1(1):7-16.

\section{Lange 1977}

Lange DE, Plagmann H, Eenboom A, Promesberger A. Clinical methods for the objective evaluation of oral hygiene. Deutsche Zahnarztliche Zeitschrift 1977;32(1):44-7.

\section{Lange 1986}

Lange DE. Odontologie in der Täglichen Praxis. Berlin: Quintessenz Verlag, 1986.

\section{Lefebvre 2011}

Lefebvre C, Manheimer E, Glanville J. Chapter 6: Searching for studies. In: Higgins JP, Green S, editor(s). Cochrane Handbook for Systematic Reviews of Interventions Version 5.1.0 (updated March 2011). The Cochrane Collaboration, 2011. Available from handbook.cochrane.org.

\section{Lie 1998}

Lie MA, Timmerman MF, van der Velden U, van der Weijden GA. Evaluation of 2 methods to assess gingival bleeding in smokers and non-smokers in natural and experimental gingivitis. Journal of Clinical Periodontology 1998;25(9):695-700.

\section{Löe 1963}

Löe H, Silness J. Periodontal disease in pregnancy. I. Prevalence and severity. Acta Odontologica Scandinavica 1963;21:533-51.

\section{Löe 1965}

Löe H, Theilade E, Jensen SB. Experimental gingivitis in man. Journal of Periodontology 1965;36:177-87.

\section{Löe 1967}

Löe H. The Gingival Index, the Plaque Index and the Retention Index systems. Journal of Periodontology 1967;38(6):Suppl:610-6.

\section{Löe 1972}

Löe H, von der Fehr FR, Schiott CR. Inhibition of experimental caries by plaque prevention. The effect of chlorhexidine mouthrinses. Scandinavian Journal of Dental Research 1972;80(1):1-9.

\section{Magarey 2009}

Magarey A, Golley R, Spurrier N, Goodwin E, Ong F. Reliability and validity of the Children's Dietary Questionnaire; a new tool to measure children's dietary patterns. International Journal of Pediatric Obesity 2009;4(4):257-65.

\section{Mantilla Gómez 2001}

Mantilla Gómez S, Danser MM, Sipos PM, Rowshani B, van der Velden U, van der Weijden GA. Tongue coating and salivary bacterial counts in healthy/gingivitis subjects and periodontitis patients. Journal of Clinical Periodontolology 2001;28(10):970-8.

\section{Marinho 2003}

Marinho VCC, Higgins JPT, Logan S, Sheiham A. Topical fluoride (toothpastes, mouthrinses, gels or varnishes) for preventing dental caries in children and adolescents. Cochrane Database of Systematic Reviews 2003, Issue 4. [DOI: 10.1002/14651858.CD002782]

\section{Marinho 2004a}

Marinho VCC, Higgins JPT, Sheiham A, Logan S. Combinations of topical fluoride (toothpastes, mouthrinses, gels, varnishes) versus single topical fluoride for preventing dental caries in children and adolescents. Cochrane Database of Systematic Reviews 2004, Issue 1. [DOI: 10.1002/14651858.CD002781.pub2]

\section{Marinho 2004b}

Marinho VCC, Higgins JPT, Sheiham A, Logan S. One topical fluoride (toothpastes, or mouthrinses, or gels, or varnishes) versus another for preventing dental caries in children and adolescents. Cochrane Database of Systematic Reviews 2004, Issue 1. [DOI: 10.1002/14651858.CD002780.pub2]

\section{Marinho 2016}

Marinho VCC, Chong LY, Worthington HV, Walsh T. Fluoride mouthrinses for preventing dental caries in children and adolescents. Cochrane Database of Systematic Reviews 2016, Issue 7. [DOI: 10.1002/14651858.CD002284.pub2]

\section{Mohebbi 2006}

Mohebbi SZ, Virtanen JI, Vahid-Golpayegani M, Vehkalahti MM. Early childhood caries and dental plaque among 1-3-year-olds in Tehran, Iran. Journal of the Indian Society of Pedodontics and Preventive Dentistry 2006;24(4):177-81. 


\section{Mohebbi 2008}

Mohebbi SZ, Virtanen JI, Vahid-Golpayegani M, Vehkalahti MM. Feeding habits as determinants of early childhood caries in a population where prolonged breastfeeding is the norm. Community Dentistry and Oral Epidemiology 2008;36(4):363-9.

\section{Möhler 2015}

Möhler R, Köpke S, Meyer G. Criteria for Reporting the Development and Evaluation of Complex Interventions in healthcare: revised guideline (CReDECI 2). Trials 2015;16:204. [DOI: 10.1186/s13063-015-0709-y]

\section{Newton 2015}

Newton TJ, Asimakopoulou K. Managing oral hygiene as a risk factor for periodontal disease: a systematic review of psychological approaches to behaviour change for improved plaque control in periodontal management. Journal of Clinical Periodontology 2015;42 (Suppl 16):S36-S46.

\section{NICE 2015}

NICE. Oral health promotion: general dental practice. NICE guideline [NG30]. www.nice.org.uk/guidance/ng30 (accessed prior to 25 April 2018).

\section{Nyman 1984}

Nyman S, Bratthall D, Böhlin E. The Swedish dental health program for adults. International Dental Journal 1984;34(2):130-4.

\section{O'Leary 1972}

O'Leary TJ, Drake RB, Naylor JE. The plaque control record. Journal of Periodontology 1972;43(1):38.

\section{Paraskevas 2005}

Paraskevas S, Versteeg PA, Timmerman MF, Van der Velden U, Van der Weijden GA. The effect of a dentifrice and mouth rinse combination containing amine fluoride/stannous fluoride on plaque and gingivitis: a 6-month field study. Journal of Clinical Periodontology 2005;32(7):757-64.

\section{Pastagia 2006}

Pastagia J, Nicoara P, Robertson PB. The effect of patientcentered plaque control and periodontal maintenance therapy on adverse outcomes of periodontitis. Journal of Evidencebased Dental Practice 2006;6(1):25-32.

\section{Poklepovic 2013}

Poklepovic T, Worthington HV, Johnson TM, Sambunjak D, Imai P, Clarkson JE, et al. Interdental brushing for the prevention and control of periodontal diseases and dental caries in adults. Cochrane Database of Systematic Reviews 2013, Issue 12. [DOI: 10.1002/14651858.CD009857.pub2]

\section{Quigley 1962}

Quigley GA, Hein JW. Comparative cleansing efficiency of manual and power brushing. Journal of the American Dental Assocication 1962;65:26-9.

\section{Review Manager 2014 [Computer program]}

Nordic Cochrane Centre, The Cochrane Collaboration. Review Manager 5 (RevMan 5). Version 5.3. Copenhagen: Nordic Cochrane Centre, The Cochrane Collaboration, 2014.

\section{Rice 2008}

Rice C, Hosey MT. Interactive oral health education - a randomised controlled trial. European Archives of Paediatric Dentistry 2008;9(Suppl 2):20-1 (Abs No 044).

\section{Rose 2001}

Rose EA, Markland D, Parfitt G. The development and initial validation of the Exercise Causality Orientations Scale. Journal of Sports Sciences 2001;19(6):445-62.

\section{Rugg-Gunn 1979}

Rugg-Gunn AJ, Macgregor ID, Edgar WM, Ferguson MW. Toothbrushing behaviour in relation to plaque and gingivitis in adolescent schoolchildren. Journal of Periodontal Research 1979;14(3):231-8

\section{Rylander 1997}

Rylander H, Lindhe J. Chapter 15: Cause-related periodontal therapy. Periodontology and Oral Implants. 3rd Edition. Copenhagen: Munksgaard, 1997:438-60.

\section{Rücker 2008}

Rücker G, Schwarzer G, Carpenter J. Arcsine test for publication bias in meta-analyses with binary outcomes. Statistics in Medicine 2008;27(5):746-63.

\section{Schmalz 2017b}

Schmalz G, Müller M, Schmickler J, Rinke S, Haak R, Mausberg RF, et al. Influence of manual and power toothbrushes on clinical and microbiological findings in initial treatment of periodontitis - a randomized clinical study. American Journal of Dentistry 2017;30(1):40-6.

\section{Schmickler 2014}

Schmickler J, Wurbs S, Wurbs S, Lange K, Rinke S, Hornecker E, et al. Influence of the utilization time of different manual toothbrushes on oral hygiene assessed during a 6-month observation period: a randomized clinical trial. Journal of Periodontology 2014;85(8):1050-8.

\section{Schmickler 2016}

Schmickler J, Wurbs S, Wurbs S, Kramer K, Rinke S, Hornecker E, et al. The influence of the utilization time of brush heads from different types of power toothbrushes on oral hygiene assessed over a 6-month observation period: a randomized clinical trial. American Journal of Dentistry 2016;29(6):307-14.

\section{Schulz 2002}

Schulz KF, Grimes DA. Generation of allocation sequences in randomised trials: chance, not choice. Lancet 2002;359:515-9.

\section{Sheiham 2015}

Sheiham A, James WPT. Diet and dental caries: the pivotal role of free sugars reemphasized. Journal of Dental Research 2015;94(10):1341-7. 


\section{Silness 1964}

Silness J, Löe H. Periodontal disease in pregnancy. II. Correlation between oral hygiene and periodontal condition. Acta Odontologica Scandinavica 1964;22:121-35.

\section{Slade 1997}

Slade GD. Derivation and validation of a short-form oral health impact profile. Community Dentistry and Oral Epidiemiology 1997;25(4):284-90.

\section{Tickle 2003}

Tickle M, Milsom KM, King D, Blinkhorn AS. The influences on preventive care provided to children who frequently attend the UK General Dental Service. British Dental Journal 2003;194(6):329-32.

\section{Tonetti 2017}

Tonetti MS, Jepsen S, Jin L, Otomo-Corgel J. Impact of the global burden of periodontal diseases on health, nutrition and wellbeing of mankind: a call for global action. Journal of Clinical Periodontology 2017;44(5):456-62. [DOI: 10.1111/jcpe.12732]

\section{Towner 1993}

Towner $\mathrm{E}$. The history of dental health education: a case study of Britain. In: Schou L, Blinkhorn A editor(s). Oral Health Promotion. Oxford: Oxford University Press, 1993.

\section{Tsakos 2015}

Tsakos G, Hill K, Chadwick B, Anderson T. Children's Dental Health Survey 2013. Report 1: Attitudes, behaviours and children's dental health England, Wales and Northern Ireland, 2013. Leeds: The Health and Social Care Information Centre; 2015 March.

\section{Turesky 1970}

Turesky S, Gilmore ND, Glickman I. Reduced plaque formation by the chloromethyl analog of vitamin C. Journal of Periodontology 1970;41:41-3.

\section{Van der Velden 1979}

Van der Velden U. Probing force and the relationship of the probe tip to the periodontal tissues. Journal of Clinical Periodontolology 1979;6(2):106-14.

\section{Van der Velden 2009}

Van der Velden U. The Dutch periodontal screening index validation and its application in The Netherlands. Journal of Clinical Periodontology 2009;36(12):1018-24.

\section{Van der Weijden 1994}

Van der Weijden GA, Timmerman MF, Saxton CA, Russell JI, Huntington E, Van der Velden U. Intra-/inter-examiner reproducibility study of gingival bleeding. Journal of Periodontal Research 1994;29:236-41.

\section{Watt 2005}

Watt RG, Marinho VC. Does oral health promotion improve oral hygiene and gingival health?. Periodontology 2000 2005;37:35-47.

\section{Weyant 2013}

Weyant RJ, Tracy SL, Anselmo TT, Beltrán-Aguilar ED, Donly KJ, Frese WA, et al. Topical fluoride for caries prevention: executive summary of the updated clinical recommendations and supporting systematic review. Journal of the American Dental Association 2013;144(11):1279-91.

\section{WHO 1986}

World Health Organization. The Ottawa Charter for Health Promotion. www.who.int/healthpromotion/conferences/ previous/ottawa/en/ (accessed prior to 25 April 2018).

\section{WHO 1997}

World Health Organization. Oral health surveys - basic methods, 4th edition. www.who.int/iris/handle/10665/41905 (accessed prior to 25 April 2018).

\section{WHO 2003}

World Health Organization. World Oral Health Report 2003. www.who.int/oral-health/publications/world-oral-healthreport-2003/en/ (accessed prior to 25 April 2018).

\section{Williams 1996}

Williams GC, Deci ED. Internalization of biopsychosocial values by medical students: a test of self-determination theory. Journal of Personality and Social Psychology 1996;70:767-79.

\section{Wilson 1992}

Wilson PH. Principles and Practice of Relapse Prevention. New York: Guildford Press, 1992.

\section{Wolfe 1996}

Wolfe GR, Stewart JM, Meader LA, Hartz GW. Use of dental coping beliefs scale to measure cognitive changes following oral hygiene interventions. Community Dentistry and Oral Epidemiology 1996;24(1):37-41.

\section{Yaacob 2014}

Yaacob M, Worthington HV, Deacon SA, Deery C, Walmsley AD, Robinson PG, et al. Powered versus manual toothbrushing for oral health. Cochrane Database of Systematic Reviews 2014, Issue 6. [DOI: 10.1002/14651858.CD002281.pub3]

\section{Yevlahova 2009}

Yevlahova D, Satur J. Models for individual oral health promotion and their effectiveness: a systematic review. Australian Dental Journal 2009;54:190-7.

\section{References to other published versions of this review \\ Soldani 2008}

Soldani FA, Young L, Jones K, Walsh T, Clarkson JE. One-to-one oral hygiene advice provided in a dental setting for oral health. Cochrane Database of Systematic Reviews 2008, Issue 4. [DOI: 10.1002/14651858.CD007447]

* Indicates the major publication for the study 


\section{CHARACTERISTICS OF STUDIES}

Characteristics of included studies [ordered by study ID]

Aljafari 2017

Trial design: parallel (2 arms)
Location: King's College Hospital, London, UK
Number of centres: 1
Study Duration: "Recruitment took place between October 2013 and October 2014" with 3-month fol-
low-up

Participants

Participants: children referred for extraction of decayed teeth under general anaesthesia

Inclusion criteria: "included all healthy children scheduled for GA due to dental caries, given that they were $4-10$ years of age and were accompanied by a parent/guardian with sufficient English proficiency to enable consent"

Exclusion criteria: lacking English proficiency to enable consent, child having learning disability, already recruited to other research projects, legal guardian not present

Age at baseline (years): intervention group: 6.76 years ( $S D=1.49)$; control group: 6.15 (SD = 1.57)

Gender: intervention group: 25 (45\%) female and 30 (55\%) male; control group: 23 (43\%) female and 31 (57\%) male

Number randomised: 109; intervention group: 55; control group: 54

Number evaluated: 59 (intervention group: 28; control group: 31) ond edition of Delivering Better Oral Health ( $\mathrm{DBOH} 2009$ )

Intervention: computer game group: the child and parent played the computer game on a touch tablet and received a copy of it on a DVD to play at home

Control: one-to-one health educator group: the child and parent received verbal oral health education from a dental nurse with a health education qualification

Prophylaxis provided: none reported

Member of dental team delivering intervention: self-administration at home for intervention group, dental nurse for control group

Frequency of intervention: intervention group: 1-off in clinic and thereafter delivered at home; control group: 1-off intervention

Intensity of intervention (length of time): not reported

Setting: secondary care

Disease level: high caries rate logue scale (VAS), where the highest satisfaction $=100 \mathrm{~mm}$, collected immediately following delivery

(2) Child's dietary knowledge, scored using a Pictorial Dietary Quiz (PDQ) (Rice 2008), taken at baseline, immediately following the educational intervention and at a 3-month follow-up dental visit

(3) Child's dietary habits, scored by the parent using the Children's Dietary Questionnaire (CDQ) (Magarey 2009), at baseline and at a 3-month telephone call. The CDQ has 4 parameters: fruits and vegeta- 
bles; full-fat dairy; sweetened drinks; and non-core foods (those containing high amounts of saturated fat, added salt, or added sugars)

(4) The child's self-reported snacking and toothbrushing practices recorded in a diary that is given out on the day of the intervention and returned to the researcher at the GA visit

In addition to those measures, children in the computer game group verbally reported their views on the content of the game directly to the dental nurse-educator, who recorded it verbatim, and completed a 'Secret Password Questionnaire' that verified whether or not they had played the game at home

Notes

Funding: "The study is funded by King's College London and did not receive any external funding"

Sample size calculation: "The primary outcome measure used to calculate the sample size was the participant's satisfaction with the educational intervention. This was assessed on a 100-mm VAS. Assuming a standard deviation of $25 \mathrm{~mm}$, and aiming to detect a difference of at least $15 \mathrm{~mm}$ between the groups, a sample of 45 participants in each group was needed to provide $80 \%$ power at the $5 \%$ significance level and to detect effects of size 0.6 and above"

Adverse effects: not reported

Declarations/conflicts of interest: "The authors declare that they have no competing interests"

\section{Risk of bias}

\begin{tabular}{lll}
\hline Bias & Authors' judgement & Support for judgement \\
\hline $\begin{array}{l}\text { Random sequence genera- } \\
\text { tion (selection bias) }\end{array}$ & Low risk & Quote: "randomised using a computer-generated grid" \\
\hline
\end{tabular}

Allocation concealment Low risk

(selection bias)

\begin{abstract}
Quotes: "dental nurse-educator allocated the participants according to the randomisation grid and administered the immediate post-intervention measures. She also delivered the oral health education to the control group."

"After the baseline measures are completed, AA will introduce the participants to the dental nurse and leave, to ensure that he remains blinded to group allocation. The nurse will then allocate the participants to either the video-game group or the control group according to the randomization grid and will apply the intervention accordingly"
\end{abstract}

Comment: allocation method unlikely to have affected outcome
Blinding of participants Unclear risk and personnel (performance bias)

All outcomes
Quote: "The lead author (AA) collected the baseline measures. A dental nurseeducator allocated the participants according to the randomisation grid and administered the immediate post-intervention measures. She also delivered the oral health education to the control group. All data were coded and anonymised. AA administered the telephone and dental follow-up measures. He remained blinded to group allocation until after the statistical analysis was completed"

Comments: dental nurse-educators were aware of intervention allocation and provided oral health education to the control group which may have introduced bias as confirmed with author. Blinding of participants was not possible; it is unclear the influence this would have on the risk of bias for this domain
Blinding of outcome as- Low risk sessment (detection bias)

All outcomes
Quote: "The researcher (AA) will remain blinded all through data collection and input. The statistician will also be blinded during the analysis. Only after data collection is complete will one researcher (MTH) break the randomization code to input the group allocation within the pre-existing data set and enable between-group analyses. The statistician and lead researcher (AA) will remain blinded" 
Further information from author: "allocation was completely concealed from AA until after AA had completed the analysis. MTH had code break in safe, in an envelope until after the stats had been completed, checked and discussed with a statistician"

\section{Incomplete outcome data High risk} (attrition bias)

All outcomes
Quotes: "Only 55\% of the recruited sample completed the telephone follow-up 3 months after the child's GA. Hence, the reported dietary improvements need to be interpreted with caution." "A sample of 45 participants in each group will be needed to provide $80 \%$ statistical power"

Comment: although this is a high disease risk and hard to reach population, the attrition rate is very high

Selective reporting (re- Low risk $\quad$ All outcomes listed in the pre-published protocol were reported
porting bias)

Other bias Low risk Comments: no apparent other bias

Baab 1986

Methods Trial design: parallel (2 arms)

Location: University of Washington's Graduate Periodontics Clinic, USA

Number of centres: 1

Study Duration: February, March and April, 1982. Participants followed-up at 6 months

Participants: the subjects had completed active periodontal treatment, including surgery, at least 1
year previously at the University of Washington's Graduate Periodontics Clinic, and were being seen by
dental hygienists every 3 months for oral hygiene instruction, scaling and root planing

Inclusion criteria: those selected had at least 20 teeth present, including 2 contralateral molars

Exclusion criteria: no physical handicaps affecting vision or manual dexterity

Age at baseline (years): range 30 to 76

Gender: 18 (55\%) women and $15(45 \%)$ men

Number randomised: 33 (no group breakdown)

Number evaluated: 31 (intervention group 15; control group 16)

Interventions 
Baab 1986 (Continued)

inspection plaque index (SIPI) consisted of the total surfaces out of 18 ( 3 surfaces per tooth) with disclosed plaque. Patients were guided by the manual to interpret their scores and to correct deficiencies in plaque removal. No particular brushing stroke was advocated because evidence is lacking that any one technique is superior to another (Rugg-Gunn 1979). After the instructional session, the patients were given 24 erythrosin disclosing wafers (Xpose"*), the lighted dental mirror, the manual and the oral hygiene tools they had selected. Patients were asked to examine the 6 teeth for disclosed plaque once each week following personal oral hygiene. During follow- up visits at 2 weeks, 1.5 months and 3 months, the hygienist provided immediate feedback on the patients' SIPI accuracy, and reviewed the patients accuracy and reviewed the patients' self-scoring charts

Control: traditional instruction using professional monitoring of disclosed plaque. Basic treatment including:

- baseline questionnaire, plaque and bleeding indices, $\mathrm{OH}$ skill assessment, plaque index (after $\mathrm{OH})$, $\mathrm{OH}$ instruction and scaling;

- $\mathrm{OH}$ instruction at 2 weeks;

- plaque and bleeding indices, $\mathrm{OH}$ skill assessment, plaque index (after $\mathrm{OH}$ ) and $\mathrm{OH}$ instruction at 1.5 months;

- plaque and bleeding indices, $\mathrm{OH}$ skill assessment, plaque index (after $\mathrm{OH}), \mathrm{OH}$ instruction and scaling at 3 months;

- plaque and bleeding indices, $\mathrm{OH}$ skill assessment and plaque index (after $\mathrm{OH}$ ) at 6 months.

The 16 patients in the traditional group were shown where disclosed plaque remained after the oral hygiene skills assessment. The hygienist observed the patients' cleaning and afterward gave feedback regarding how long they spent brushing the facial and lingual surfaces and how effectively they used oral hygiene aids. The dental hygienist was given a relatively free hand regarding the instructional methods; emphasis was placed on plaque removal skills using the various oral hygiene aids, rather than on self-assessment of disclosed plaque. Information concerning the SIPI was not provided, and disclosing wafers and lighted dental mirrors were not dispensed

30 minutes were spent on oral hygiene instructions at follow-up visits for both groups

Prophylaxis provided: scaling at baseline and 3 months

Member of dental team delivering intervention: hygienist

Frequency of intervention: intervention: 5 visits with repeated $\mathrm{OH}$ instruction; control: 5 visits with repeated $\mathrm{OH}$ instruction

Intensity of intervention (length of time): intervention: 30 minutes; control: 30 minutes

Setting: secondary care

Disease level: high caries rate

Outcomes

Oral hygiene and gingival health were assessed by recording the presence or absence of disclosed plaque at the gingival margin (O'Leary 1972) and bleeding upon measurement probing (Van der Velden 1979). Mean observed time (seconds) spent brushing the facial and lingual surfaces during the oral hygiene skill assessment. Total time (minutes) spent by patients in oral hygiene procedures during the oral hygiene skill assessment at the initial and subsequent examinations (mean + standard deviation). Mean number of oral hygiene aids selected by subjects for the oral hygiene skill assessment at the initial and subsequent examinations

Notes Funding: this study was supported by a Biomedical Research Support Grant \#RR- 05346 from the National Institutes of Health

Sample size calculation: not reported

Adverse effects: not reported

Declarations/conflicts of interest: not reported 
Baab 1986 (Continued)

\begin{tabular}{lll} 
Bias & Authors' judgement & Support for judgement \\
\hline $\begin{array}{l}\text { Random sequence genera- } \\
\text { tion (selection bias) }\end{array}$ & Low risk & $\begin{array}{l}\text { Quote: "Subjects were randomly assigned by rolling of dice to } 2 \text { groups, self-in- } \\
\text { spection and traditional, before the initial examination" }\end{array}$ \\
\hline $\begin{array}{l}\text { Allocation concealment } \\
\text { selection bias) }\end{array}$ & Unclear risk & Not reported \\
\hline $\begin{array}{l}\text { Blinding of participants } \\
\text { and personnel (perfor- } \\
\text { mance bias) }\end{array}$ & Unclear risk & $\begin{array}{l}\text { Comment: insufficient information on allocation concealment } \\
\text { structional methods" }\end{array}$ \\
& $\begin{array}{l}\text { Comments: personnel were aware of intervention allocation. Blinding of par- } \\
\text { ticipants was not possible; it is unclear the influence this would have on the } \\
\text { risk of bias for this domain }\end{array}$
\end{tabular}

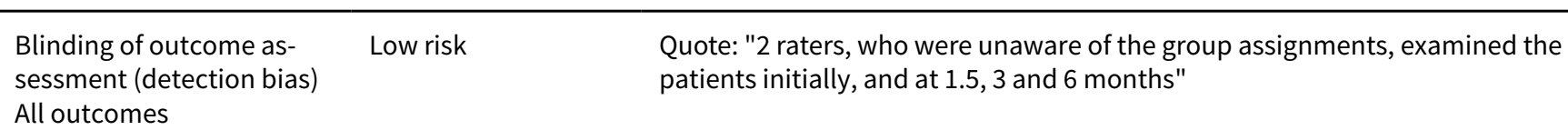

All outcomes

Incomplete outcome data Unclear risk
(attrition bias)

(atlition bias)

\begin{tabular}{lll}
\hline $\begin{array}{l}\text { Selective reporting (re- } \\
\text { porting bias) }\end{array}$ & Low risk & All outcomes in methods section were reported \\
\hline Other bias & $\begin{array}{l}\text { Comment: SIPI group and traditional group were significantly different at } \\
\text { baseline regarding plaque scores and time spent brushing facial aspects of } \\
\text { teeth }\end{array}$ \\
\hline
\end{tabular}

\section{Bali 1999}

Methods

Trial design: parallel ( 2 arms)

Location: Wien-Lainz Hospital, Austria

Number of centres: 1

Duration: enrolment took place between beginning of April 1995 until end of March 1996. Follow-up completed at 6 months and 12 months

Participants

Participants: eligible diabetic patients attending the Wien-Lainz Hospital

Inclusion criteria: type I diabetes for at least 3 years, aged between 14 years and 50 years. Minimum of 10 own teeth

Exclusion criteria: motor disability, severe visual impairment, acute diabetic foot, myocardial infarction or cerebral insult within the last 6 months

Age at baseline (years): control group: mean age 34.4 years, SD 9.5; intervention group: mean age 33.9 years, SD 9.5

Gender: not reported

Number randomised: 121 (intervention group: 61; control group: 60)

Number evaluated: 70 (intervention group: 36; control group: 34) 
Bali 1999 (Continued)

Interventions
Intervention: professional OHA after enrolment into the study + intensive patient education in oral hygiene (dental cleaning techniques, use of dental floss or interdental brushes or both) with 3 control examinations within 3 weeks to examine (by staining the plaque) the improvement in dental cleaning with training of the dental cleaning technique repeated in cases where plaque, according to a TureskyIndex, of 2.0 or more was found

Control: professional OHA after enrolment into the study

Prophylaxis provided: not reported

Member of dental team delivering intervention: not explicitly specified, however after reviewing the text the review authors were confident the intervention was undertaken by a member of the dental team

Frequency of intervention: intervention: 4 visits with repeated $\mathrm{OH}$ instruction; control: 1 visit Intensity of intervention (length of time): not reported

Setting: secondary care

Disease level: not reported

Outcomes

Main outcome measure was bleeding on probing. Secondary outcome measures were plaque index (Turesky hygiene index); probing pocket depth at 6 measurement points per tooth; DMFT
Funding: not reported

Sample size calculation: not reported

Adverse effects: not reported

Declarations/conflicts of interest: not reported

\section{Risk of bias}

Bias Authors' judgement Support for judgement

\section{Random sequence genera- Unclear risk} tion (selection bias)
Quote: "patients were allocated randomly to the intervention or control group"

Comment: insufficient information on randomisation sequence generation

\begin{tabular}{ll}
\hline $\begin{array}{l}\text { Allocation concealment } \\
\text { (selection bias) }\end{array}$ & Unclear risk \\
& Comment: insufficient information available on allocation concealment
\end{tabular}

\begin{tabular}{|c|c|c|}
\hline $\begin{array}{l}\text { Blinding of participants } \\
\text { and personnel (perfor- } \\
\text { mance bias) }\end{array}$ & Unclear risk & $\begin{array}{l}\text { Not reported } \\
\text { Comment: insufficient information to determine any bias }\end{array}$ \\
\hline
\end{tabular}

All outcomes

\begin{tabular}{lll}
\hline $\begin{array}{l}\text { Blinding of outcome as- } \\
\text { sessment (detection bias) } \\
\text { All outcomes }\end{array}$ & Unclear risk & Not reported \\
\hline $\begin{array}{l}\text { Incomplete outcome data } \\
\text { (attrition bias) }\end{array}$ & High risk & Dropouts $(42 \%)$ were not included in analysis \\
All outcomes & &
\end{tabular}

\begin{tabular}{|c|c|c|}
\hline $\begin{array}{l}\text { Selective reporting (re- } \\
\text { porting bias) }\end{array}$ & Unclear risk & $\begin{array}{l}\text { The predefined measures "panoramic X-ray" and "HbA1c" are reported initial- } \\
\text { ly but not in the result section. Panoramic X-ray was completed to document }\end{array}$ \\
\hline
\end{tabular}


the dental chart and to quantify the caries. $\mathrm{HbA} 1 \mathrm{C}$ was measured to determine the quality of the metabolic adjustment

Comment: DMFT is reported in the results section with further panoramic $X$ ray findings/completion not specifically reported. Repeat $\mathrm{HbA1C}$ not reported as planned to be repeated though changes may have had an impact on oral health outcomes

Other bias Low risk No other bias apparent

Glavind 1985

$\begin{array}{ll}\text { Methods } & \text { Trial design: parallel ( } 2 \text { arms) } \\ \text { Location: general dental practice, Denmark }\end{array}$

Number of centres: 3

Study Duration: recruitment and follow-up dates not reported. Participants followed-up at 6 months

Participants

Participants: 55 adults who sought treatment in 3 different general dental practices in Denmark

Inclusion criteria: plaque on more than $30 \%$ of their tooth surfaces

Exclusion criteria: not reported

Age at baseline (years): range 20 years to 62 years, mean 34 years; no group breakdown provided

Gender: "The distribution of patients in the 2 groups was similar with regard to sex and age"

Number randomised: 55 (intervention group: 29; control group: 26)

Number evaluated: 55 (intervention group: 29; control group: 26 al (Glavind 1979) at their initial appointment and a self-instruction manual in oral hygiene measures for use at home at their 2-week appointment

Control: a conventional personal instruction group (C) comprising 26 patients who received information about the presence of disease in the mouth and the need for improved oral cleanliness. They were given instructions in proper oral hygiene techniques at the chair-side by a dentist for approximately 25 minutes to 30 minutes at their 2-week appointment

Prophylaxis provided: scaling of teeth was completed in 2 sessions (weeks 1 and 2) and all patients were provided with oral hygiene aids such as a toothbrush, toothpicks, disclosing tablets and a lighted mouth mirror

Treatment provided: treatment of carious lesions was undertaken according to need during the experimental period

\section{Member of dental team delivering intervention: dentist}

Frequency of intervention: intervention: 2 visits, 1 with OHA; control: 2 visits, 1 with OHA

Intensity of intervention (length of time): intervention: self-instruction manual for use at home; control: 25 minutes to 30 minutes

Setting: primary care

Disease level: plaque levels 
Glavind 1985 (Continued)

Outcomes
In order to evaluate the effect of the 2 different modes of instruction, the presence or absence of disclosed dento-gingival plaque (Plak-lite) and gingival bleeding by gentle probing was scored on all tooth surfaces initially and after 3 months and 6 months. Plaque was also scored 1 week after instruction. The presence or absence of gingival bleeding was assessed for each surface while plaque was recorded for each quadrant as the number of mesial-, facial-, lingual- and distal tooth surfaces with disclosed plaque. The percentage of tooth surfaces with plaque and gingival bleeding was calculated and presented to the patient in graphical form in order to obtain feedback from the result of the treatment. A questionnaire about the treatment was answered by the patients of the self-instruction group at the 2week appointment

Notes $\quad$ Funding: quote: "This study has been supported by a grant from the Research Foundation of the Danish Dental Association"

Sample size calculation: not reported

Adverse effects: not reported

Declarations/conflicts of interest: not reported

\section{Risk of bias}

\begin{tabular}{lll}
\hline Bias & Authors' judgement & Support for judgement \\
\hline $\begin{array}{ll}\text { Random sequence genera- } \\
\text { tion (selection bias) }\end{array}$ & Unclear risk & Quote: "These patients were divided randomly into 2 treatment groups" \\
& & Comment: no further detail on randomisation method provided
\end{tabular}

Allocation concealment Unclear risk Not reported

(selection bias)

Comment: insufficient information on allocation concealment

\begin{tabular}{|c|c|c|}
\hline $\begin{array}{l}\text { Blinding of participants } \\
\text { and personnel (perfor- } \\
\text { mance bias) } \\
\text { All outcomes }\end{array}$ & Unclear risk & $\begin{array}{l}\text { Quotes: "Conventional group..... were given instructions in proper oral hygiene } \\
\text { techniques at the chair side by a dentist...", "The scoring was performed by } \\
\text { the } 3 \text { general dental practitioners (EP, HC, HR) who treated the patients in their } \\
\text { private offices. At the time of scoring, the dentist did not know to which group } \\
\text { the patient belonged" }\end{array}$ \\
\hline
\end{tabular}

Comments: blinding of participants was not possible; it is unclear the influence this would have on the risk of bias for this domain

Blinding of outcome as- Unclear risk sessment (detection bias)

All outcomes
Quote: "The scoring was performed by the 3 general dental practitioners (EP, $\mathrm{HC}, \mathrm{HR}$ ) who treated the patients in their private offices. At the time of scoring, the dentist did not know to which group the patient belonged"

Comment: insufficient information provided to determine if same dentists provided intervention and follow-up outcome measure assessment

Incomplete outcome data Low risk
(attrition bias)

Quotes: "2 patients in each group did not show up for the 3-month examination", "The questionnaire on self-examination and self-instruction in oral hygiene was answered by 26 out of the 29 patients in the self-instruction group $(\mathrm{S}) "$

All outcomes
Selective reporting (re- Low risk $\quad$ All outcomes in methods section were reported porting bias)
Low risk
No apparent other bias 
Hetland 1982

Methods
Trial design: parallel (3 arms)

Location: dental office at factory, Sandnes, Southwestern Norway

Number of centres: 1

Duration: recruitment and follow-up dates not reported. Participants followed-up at 24 weeks
Participants: 77 industrial and commercial firm employees

Inclusion criteria: participants selected at random by the personnel division of the firm among a total of 1500 employees. The test persons were to be between 25 years and 45 years of age and to have at least 20 remaining teeth. The sample was to include industrial workers as well as office and retail store employees

Exclusion criteria: not reported

Age at baseline (years): range 25 years to 44 years

Gender: follow-up: control Group A: 21 (84\%) males, 4 (16\%) females; intervention Group C: 19 (83\%) males, $4(17 \%)$ females

Number randomised: 77 participants

Number evaluated: 71 (control Group A: 25; intervention Group B: 23; intervention Group C: 25)
Interventions

\section{Interventions:}

- Group C: the participants in Group C were subjected to depuration, removal of overhangs or polishing. They were given instructions in oral hygiene procedures utilizing a 3-visit program with 1 week between each visit. Instructions in oral hygiene were carried out by 4 dental chair-side assistants who had received an intensive course of 40 hours' duration

- Group B: received OHA alone - not included further in review

\section{Control:}

- Group A: the participants in Group A received depuration of the teeth utilizing an ultrasonic apparatus (Cavitron ${ }^{\circledast}$, Cavitron Ultra- sonics Inc, Long Island City, NY, USA, or Odontoson ${ }^{\circledast}$ (Goof, Herlev, Denmark) and an Ivory number $2 / 3$ sealer. Gross overhangs were removed using a diamond point and the teeth were polished with rubber-cup and pumice (as per Group C). A maximum of 45 minutes were allocated per person for these procedures. In Group A no oral hygiene instructions were given

Prophylaxis provided: removal of retentive factors and polishing at initial appointment

Member of dental team delivering intervention: dental nurse

Frequency of intervention: intervention: 3 intervention visits with $\mathrm{OHA}$; control: no oral hygiene but appointment for prophylaxis lasted 45 minutes

Intensity of intervention (length of time): intervention Group C: 45 minutes OHA at first visit, 30 minutes for the second visit and 15 minutes for third visit. Control: no OHA provided

Setting: dental surgery attached to factory

Disease level: not reported

Outcomes

At the initial examination which took approximately 30 minutes the following registrations were performed in this sequence: DMF teeth, gingival index (Löe 1967), retention index (Björby 1967), dental surfaces harbouring visible plaque alter staining (Diaplac* tablets, Astra, Sweden) registered both from the vestibular and lingual aspect, registration of pockets of $4 \mathrm{~mm}$ depth or more using calibrated 'Hilming' periodontal probes (Brincker, Copenhagen, Denmark). For gingival index scoring, all dental surfaces were examined and attempts to provoke bleeding were performed with a pocket probe by carrying this 
Hetland 1982 (Continued)

back and forth within the sulcus. A score of 2 was given even if bleeding was observed only after some time

The following parameters were calculated on the basis of clinical examinations: (a) DMF teeth in percentage (DMFT), (b) gingival index as mean for all surfaces (GI), (c) retention index as mean for all surfaces $(R I),(d)$ number of pockets per remaining tooth $(P / T),(e)$ proportion of remaining teeth with at least 1 pocket (TP), and (f) proportion of surfaces harbouring visible plaque (PS)

The participants were interviewed with respect to smoking habits (0, 0 to 10, > 10 cigarettes per day)

Notes

Funding: not reported

Sample size calculation: not reported

Adverse effects: not reported

Declarations/conflicts of interest: not reported

\section{Risk of bias}

Bias Authors' judgement Support for judgement

Random sequence genera- Unclear risk tion (selection bias)

Quote: "On the basis of the findings at the initial examination the participants were divided into three experimental groups. Group A, Group B and Group C. The three groups were matched by stratified randomization with respect to number of participants, sex, age, smoking habits, occupation and dental findings at the start of the experiment. Several alternative assignment algorithms were examined"

Comment: unclear regarding randomisation method employed

\begin{tabular}{|c|c|c|}
\hline $\begin{array}{l}\text { Allocation concealment } \\
\text { (selection bias) }\end{array}$ & Unclear risk & $\begin{array}{l}\text { Not provided } \\
\text { Comment: insufficient information on allocation concealment }\end{array}$ \\
\hline
\end{tabular}

\begin{tabular}{|c|c|c|}
\hline $\begin{array}{l}\text { Blinding of participants } \\
\text { and personnel (perfor- }\end{array}$ & Unclear risk & $\begin{array}{l}\text { Quote: "Instructions in oral hygiene were carried out by four dental chair-side } \\
\text { assistants who had received an intensive course of } 40 \text { hours' duration" }\end{array}$ \\
\hline
\end{tabular}
and personnel (perfor"

mance bias)

Comment: blinding of participants was not possible; it is unclear the influence

All outcomes this would have on the risk of bias for this domain

Blinding of outcome as- Low risk sessment (detection bias)

All outcomes

\begin{abstract}
Quote: "The three groups were re-examined 4, 12 and 24 weeks later utilizing the same indices and following the same procedures as at the initial examination. The participants were examined by the same examiner during the entire experiment. The examiners were unaware of whether or not oral hygiene instructions had been given to the particular participant. The examiners had been calibrated during a 1-week period prior to the start of the experiments"

Comment: examiners reported to be blind to experimental group
\end{abstract}

\begin{tabular}{lll}
\hline $\begin{array}{l}\text { Incomplete outcome data } \\
\text { (attrition bias) } \\
\text { All outcomes }\end{array}$ & Unclear risk & $\begin{array}{l}\text { Comment: small dropout rate across the trial (8\%). Insufficient information } \\
\text { provided to assess whether dropouts were balanced }\end{array}$ \\
\hline $\begin{array}{l}\text { Selective reporting (re- } \\
\text { porting bias) }\end{array}$ & Low risk & All outcomes in methods section were reported \\
\hline Other bias & Low risk & No apparent other bias \\
\hline
\end{tabular}




\begin{tabular}{ll} 
Methods & Trial design: parallel ( 3 arms) \\
& Location: group practice, Abcoude, the Netherlands \\
& Number of centres: 1 \\
& Duration: recruitment and follow-up dates not reported. Participants followed-up at 12 months \\
\hline Participants & Participants: 108 male and female inhabitants of Abcoude \\
& $\begin{array}{l}\text { Inclusion criteria: recently registered patients of the group practice, between the age of } 15 \text { years and } \\
60 \text { years old }\end{array}$
\end{tabular}

Exclusion criteria: no full dentures and no more than 1 person per family admitted to the sample

Age at baseline (years): range 15 to 60

Gender: not reported

Number randomised: 150 (intervention Group A: 50; intervention Group B: 50; control Group C: 50)

Number evaluated: 108 (intervention Group A: 36; intervention Group B: 36; intervention Group C: 36)

- Group A: subjects received standard information and instruction on dental hygiene. The instruction, given by 1 of 4 female hygienists during about 30 minutes, consisted of information concerning the relations between dental health and sugar consumption, oral hygiene, different methods of oral hygiene, the use of fluoride, information about regular control visits to the dentist, etc.

- Group B: subjects received the identical standard information as Group A subjects. Before that, however, they were shown a 10-minute film (a Dutch version of "4 Tons of Teeth") presenting more or less the same issues as the hygienist's standard presentation

\title{
Control:
}

- Group C: received no instruction at all (control condition); special care was taken to insure that these subjects were excluded from information on dental hygiene

Prophylaxis provided: scaling and polishing at initial appointment

Member of dental team delivering intervention: hygienist

Frequency of intervention: intervention Group A: not clearly reported; appears to be 1 intervention visit with OHA. Intervention Group B: not clearly reported; appears to be 1 visit with $\mathrm{OHA}$ and 10-minute film. Control: no OHA provided

Intensity of intervention (length of time): intervention Group A: 30 minutes OHA. Intervention Group $\mathrm{B}: 30$ minutes $\mathrm{OHA}$ and 10-minute video. Control: no OHA provided

\section{Setting: primary care}

Disease level: not reported

\section{Outcomes}

\begin{abstract}
"The questionnaire contained items on dental knowledge, attitude, behaviour, and fear of dental treatment. The subject's knowledge was tapped with 14 multiple choice items. Each item had 5 alternatives, 1 of which was correct. The knowledge scores thus ranged from 0 to 14 . The attitude towards dental hygiene was measured with 10 items of the summated-rating format with scale points ranging from 1 (agree) to 5 (disagree). The higher the score, the more positive the subject's attitude. Fear of dental treatment was assessed with 1 item, with scale points ranging from 1 (very fearful) to 5 (not fearful). 6 aspects of self-reported dental behaviour were measured: sugar consumption (range 1-5), brushing frequency (range 1-5), brushing moment (range 1-6), use of toothbrush (range 1-6), use of interdental
\end{abstract}


stimulators (range 1-5) and oral hygiene (range 1-5). Again, the higher the score, the more positive the subjects behaviour"

"Half of the subjects of each condition received a pre-test (filling in a questionnaire). The other half did not complete this pre-test. Through this $2 \times 3$ design, not only the effect of the educational programs can be assessed, but also the possible effect of the pre-test on subsequent post-test scores"

Adverse effects: not reported

Declarations/conflicts of interest: not reported

\section{Risk of bias}

\begin{tabular}{lll}
\hline Bias & Authors' judgement & Support for judgement \\
\hline $\begin{array}{ll}\text { Random sequence genera- } \\
\text { tion (selection bias) }\end{array}$ & Unclear risk & $\begin{array}{l}\text { Quotes: "They were randomly selected", "Subjects were assigned at random to } \\
1 \text { of } 3 \text { conditions" }\end{array}$ \\
& $\begin{array}{l}\text { Comment: insufficient information provided on the random sequence genera- } \\
\text { tion }\end{array}$
\end{tabular}

Allocation concealment $\quad$ Unclear risk $\quad$ Comment: insufficient information on allocation concealment
(selection bias)

\begin{tabular}{|c|c|c|}
\hline $\begin{array}{l}\text { Blinding of participants } \\
\text { and personnel (perfor- }\end{array}$ & Unclear risk & $\begin{array}{l}\text { Comments: blinding of participants was not possible; it is unclear the influ- } \\
\text { ence this would have on the risk of bias for this domain }\end{array}$ \\
\hline
\end{tabular}
mance bias)

All outcomes

\begin{tabular}{|c|c|c|}
\hline $\begin{array}{l}\text { Blinding of outcome as- } \\
\text { sessment (detection bias) } \\
\text { All outcomes }\end{array}$ & Low risk & $\begin{array}{l}\text { Comment: patients completed a questionnaire and would have been aware o } \\
\text { the intervention provided or otherwise. The outcome is not likely to be influ- } \\
\text { enced by lack of blinding }\end{array}$ \\
\hline
\end{tabular}

\begin{tabular}{lll}
\hline $\begin{array}{l}\text { Incomplete outcome data } \\
\text { (attrition bias) } \\
\text { All outcomes }\end{array}$ & Unclear risk & $\begin{array}{l}\text { Quote: "As usual in longitudinal studies, however, there was a certain dropout } \\
\text { of subjects due to reasons such as moving house and leaving no change of ad- } \\
\text { dress, emigration or an occasional refusal to cooperate" } \\
\text { Comment: insufficient information to assess bias }\end{array}$ \\
\hline $\begin{array}{l}\text { Selective reporting (re- } \\
\text { porting bias) }\end{array}$ & Low risk & All outcomes in methods section were reported \\
\hline $\begin{array}{l}\text { Other bias } \\
\text { Unclear risk }\end{array}$ & $\begin{array}{l}\text { Quote: Group A "Whilst presenting the information to the patient, the hygienist } \\
\text { performed regular preventive measures, such as scaling and polishing" }\end{array}$ \\
& $\begin{array}{l}\text { Comment: unclear if Group B and Group C received the same regular preven- } \\
\text { tive measures. No response from contact author regarding further information }\end{array}$ \\
\hline
\end{tabular}

Location: 2 clinics: a large Public Dental Service (PDS) clinic and a private 2-dentist practice in Jönköping, Sweden 


\section{Number of centres: 2}

Study Duration: recruitment and follow-up dates not reported. Participants followed-up at 3 years

\section{Participants}

Participants: 400 subjects aged 20 years to 27 years, 211 males and 189 females, participated in the study

Inclusion criteria: young adults regularly seeking dental care where the individual was not planning to move from Jönköping within the next few years

Exclusion criteria: not reported

Age at baseline (years): 20 to 27

Gender: $189(47 \%)$ females and $211(53 \%)$ males

Number randomised: 400 participants

Number evaluated: 348 participants. The dropout rates during the study were $2.3 \%$ (9 individuals), $4.3 \%$ (17 individuals), and 6.5\% (26 individuals) after 1 year, 2 years, and 3 years, respectively, or a total of $13 \%$ (52 individuals) after 3 years $\mathrm{Pe}$ ) or dental floss (Johnson \& Johnson dentotape, Sollentuna, Sweden) were used at the oral hygiene instruction sessions. Instructions on the Bass method (Bass 1954a) were given if the subject's own brushing technique proved unsatisfactory, and all subjects were advised to start their brushing lingually in the lower jaw molar region. The patients were informed, according to routine procedures at the clinic, that the best way of establishing the habit of interdental cleaning is to clean the teeth proximally before brushing. In groups 2 and 3, the oral hygiene instruction or re-instruction was carried out after the participants used a disclosing Diaplack tablet. The proximal aids, dental floss or toothpicks, were chosen depending on anatomical conditions (e.g. crowded teeth), and the degree of gingivitis when toothpicks were recommended in cases with severe proximal inflammation or 'open' proximal spaces. The subjects were asked to demonstrate and practice the cleaning technique in their own mouths

Group 1: the control group: no organized prophylactic measures for caries and gingivitis/periodontitis within the framework of the study but had to answer a questionnaire about knowledge of dental diseases and oral hygiene behaviour. The subjects were recalled at 12-month intervals for follow-up examinations, identical to the baseline examination, over the next 3 years

Group 2: the Karlstad model. All individuals received prophylactic care every second month ( 6 times/ year) according to the Karlstad model for adult individuals. At the first visit, approximately 30 minutes, information on caries and gingivitis/periodontitis was presented and oral hygiene instruction was given based on plaque disclosure. At the next 5 visits, approximately 20 minutes each at 2-month intervals, the individual's oral status was reviewed and, when necessary, information or oral hygiene instruction was repeated. Half the number of the individuals were also randomly chosen to have no other preventive measures $\left(2_{0}\right)$. The other individuals were randomly chosen to undergo professional tooth cleaning at each visit. The cleaning was performed crosswise in 2 quadrants, which meant that the teeth in the right maxilla and the left mandible were professionally cleaned in 25 individuals $\left(2_{1}\right)$ and in the left maxilla and the right mandible in 25 individuals $\left(2_{2}\right)$. The 1-year follow-up comprised the same measures undertaken at the baseline examination. The remedial measures undertaken during the first year were repeated for the next 2 years with yearly follow-ups, the last 1 being the 3-year follow-up

NOTE: group $\left(2_{1}\right)$ and group $\left(2_{2}\right)$ received prophylactic care every 2 months and are not included further

Group 3: individual educational. All individuals underwent an individual basic preventive programme according to the National Swedish Board of Health and Welfare. The programme comprised 3 visits at 2-week intervals during the first year. At the first visit, approximately 30 minutes, information on caries and gingivitis/periodontitis was presented and oral hygiene instruction was given based on plaque disclosure. The individual's oral status was reviewed at the next 2 visits of approximately 20 minutes and 15 minutes, respectively, and when necessary, information and hygiene instruction were repeated. The 1-year follow-up comprised the measures undertaken at the baseline examination. Directly after the follow-up, the individuals were scheduled for a 30-minute repetition of indicated information and oral 
hygiene instruction. The same was done at the 2-year follow-up, after which the individuals were called for a 3-year follow-up

Group 4: group education. All individuals underwent the remedial measures recommended by the National Swedish Board of Health and Welfare for dental health preventive programmes for adults but modified for group-based information with 3 visits that had essentially the same content as the programme followed by Group 3. The time required was approximately 60 minutes for the first visit, 30 minutes for the second and 15 minutes for the third.The programme was conducted as group activities with 10 individuals in each group

NOTE: given the group nature of the intervention this group is not included further

Prophylaxis provided: "Caries restorative measures and scaling were undertaken when needed to bring the oral hygiene of all participants up to the same baseline standard"

"Each year, all the test subjects were given enough fluoride toothpaste (Acta $0.22 \%$ sodium fluoride corresponding to $0.1 \%$ fluoride, Astra-Wallco AB) to last for 1 year (8 tubes)"

Member of dental team delivering intervention: hygienist

Frequency of intervention: Group 1: 4 visits total, no OHA. Group $2_{0}: 6$ visits, each with repeated OHA. Group 3: 4 visits, OHA provided 3 times

Intensity of intervention (length of time): Group 1: no OHA. Grp 20: approximately 130 minutes. Group 3: approximately 125 minutes

Setting: mixed setting: public dental setting and primary care

Disease level: young adults regularly seeking dental care depth, and supra and subgingival calculus

Plaque and gingivitis were recorded on the buccal, lingual, mesial, and distal tooth surfaces of all teeth except the third molars. The presence of plaque was recorded after the tooth surfaces were dried with air according to the criteria for the plaque index (PLI). A PLI score of 1, 2, or 3 was considered to be a positive indicator of plaque, and the surface was registered as positive. The presence of gingivitis was recorded according to the criteria for the gingival index (GI). A GI score of 2 or 3 was used as a measure of gingivitis. Thus, bleeding was registered after the pocket probe had been applied to the opening of the gingival pocket and passed along the tooth surface in question (Löe 1967)

Notes

Funding: "Financial support to this study has been given by the Jönköping County Council and The Institute for postgraduate dental Education, Jönköping, Sweden"

"The cost analysis took into account both the direct and indirect costs where direct costs were the time the personnel sat aside the individual for each program and indirect costs the patients sat aside and the relation between these costs"

Sample size calculation: not reported

Adverse effects: not reported

Declarations/conflicts of interest: "The authors declare that they have no conflict of interests"

\section{Risk of bias}

\begin{tabular}{lll}
\hline Bias & Authors' judgement & Support for judgement \\
\hline $\begin{array}{l}\text { Random sequence genera- } \\
\text { tion (selection bias) }\end{array}$ & Low risk & $\begin{array}{l}\text { Quote: "The subjects were randomly assigned, by help of a randomising table, } \\
\text { into } 4 \text { groups of } 100 \text { individuals each. Responsible for the randomisation was } \\
\text { one of the authors" }\end{array}$ \\
\hline
\end{tabular}


Hugoson 2007 (Continued)

Allocation concealment Unclear risk Comment: insufficient information on allocation concealment (selection bias)

Blinding of participants Unclear risk and personnel (performance bias)

All outcomes

Quotes: "The study was performed as a randomized controlled study with the outcome of the result blind"; "The remedial measures were carried out by another dental hygienist. The programmes followed a detailed, written working plan to ensure that all patients received the same information and instructions"

Comment: blinding of participants was not possible; it is unclear the influence this would have on the risk of bias for this domain

\begin{tabular}{|c|c|c|}
\hline $\begin{array}{l}\text { Blinding of outcome as- } \\
\text { sessment (detection bias) } \\
\text { All outcomes }\end{array}$ & Low risk & $\begin{array}{l}\text { Quote: "The dental hygienist who carried out the baseline examination of the } \\
\text { patient also examined the patient annually and was unaware of which group } \\
\text { the patient belonged to and which programme of preventive measures the } \\
\text { participant was following" }\end{array}$ \\
\hline
\end{tabular}

Incomplete outcome data Unclear risk (attrition bias)

Quote: (Hugoson 2007) "The dropout rates during the study were $2.3 \%$ (9 indiAll outcomes viduals), $4.3 \%$ (17 individuals), and 6.5\% (26 individuals) after 1, 2, and 3 years, respectively, or a total of $13 \%$ (52 individuals) after 3 years. The main reasons for the dropouts (see Hugoson 2003 ). The dropouts were evenly distributed between the groups"

Previous paper from research group reported (Hugoson 2003): "The dropout rates during the study's first 3 years were $1 \%$ (4 individuals), $1.8 \%$ (7 individuals) and $3.8 \%$ (15 individuals) after 1, 2 and 3 years, respectively, in total $6.5 \%$ (26 individuals) after 3 years"

Comment: disparity between publications regarding dropout numbers. No response from contact author regarding further clarification

$\begin{array}{ll}\begin{array}{l}\text { Selective reporting (re- } \\ \text { porting bias) }\end{array} & \text { High risk } \\ & \begin{array}{l}\text { Comment: a number of clinical outcomes not reported upon (e.g. clinical } \\ \text { caries, restorative dental care (other than 1 extraction), pocket depths, attach- } \\ \text { ment levels and calculus). No response from contact author regarding further } \\ \text { information }\end{array}\end{array}$

Other bias Low risk No apparent other bias

Jönsson 2006

Methods $\quad$ Trial design: parallel ( 2 arms)
Location: Department of Periodontology, the County Council of Uppsala, Sweden

Number of centres: 1

Study Duration: 3-month follow-up

Participants

Participants: patients of the Department of Periodontology who demonstrated progress of disease and insufficient compliance at 1 year to 2 years review following initial periodontal therapy

Inclusion criteria: individuals 20 years to 80 years of age with insufficient compliance (i.e. individuals who reported interdental cleaning (tooth picks or interdental brushes) less than 5 times a week combined with a dental plaque score $>0.20$ according to Silness and Löe (Silness 1964)). To avoid missing the individuals who over-reported their interdental cleaning, patients who reported interdental cleaning 5 times or more a week but nevertheless showed a dental plaque score $>0.40$, were also included

Exclusion criteria: not reported 
Gender: intervention group: female/male, 9/10; control group: female/male, $8 / 8$

Number randomised: 37

Number evaluated: 35 (intervention group: 19; control group: 16)

- Visit 1. The first visit started with the initiation phase. The patient presented their own explanatory model of self-care methods and disease processes, experiences of earlier treatments, and their beliefs about the reasons for disease progress. Thereafter, the last periodontal status was demonstrated, discussed, and compared with previous status. In the assessment phase, the dental hygienist (DH) used interview strategies with the help of an interview guide to disclose patient's perceptions of selfcare behaviours, knowledge of biomedical facts, and illness experiences. As an additional component of the commitment process, the DH provided the patient with the explanatory model of periodontitis. Depending on the patient responses, the DH provided further information if necessary. The negotiation phase started with the DH exploring the patients present oral hygiene status by using an Erytrosin-based colouring disclosure agent (Rondell Red; Nordenta, Enköping, Sweden) after which appropriate dental cleaning aids were introduced. Thereafter, the $\mathrm{DH}$ and the patient discussed and negotiated with the purpose to achieve an improvement in oral hygiene. The $\mathrm{DH}$ assisted the patient to establish self-selected goals in the commitment phase. A goal was established from the patient's individual requirements for toothbrush frequencies (i.e. how often and when during the day), interdental cleaning frequencies (i.e. how often and when during the week), and tooth surfaces of particular importance for cleaning. The patient made the decisions with the assisting of the $\mathrm{DH}$. The result of the decision was documented in a written commitment containing: type of cleaning aid, frequencies and special areas. If there was enough time available at the first visit, scaling was performed

- Visit 2. At the next visit (after 1 week to 2 weeks) the client reported their compliance with the established self-care commitment (evaluation phase). The oral hygiene status was checked by using an Erytrosin-based colouring disclosure agent (Rondell Red; Nordenta, Enköping, Sweden) and new instructions and adjustments of technique were discussed if necessary. If the clients had new requirements for the commitment, adjustments were made. Necessary scaling and polishing were provided

- Visit 3. Approximately 4 weeks after baseline and the written commitment. The aim with the visit was to check if the patients had found the self-selected goals realistic and if any changes were necessary. No other treatment was performed

- Visit 4. The final evaluation was performed 12 weeks to 14 weeks after the first visit. The patients were given the second questionnaire. The same dentist performed the same clinical assessments as at baseline. The data from the clinical assessments were analysed and discussed with the patient. The commitment was also evaluated and adjusted if necessary. Finally, the recall intervals were discussed and established

\section{Control:}

- Visit 1. The latest periodontal status was demonstrated, discussed and compared with previous status. New information about the periodontal disease was given if necessary. The oral hygiene instructions was performed, controlled and adjusted if necessary, by using a colouring disclosure agent (diaplaque Oral Pharma). Necessary scaling and polishing were provided

- Visit 2. At the next visit (after 1 week to 2 weeks), the oral hygiene status was checked by using a colouring disclosure agent (diaplaque Oral Pharma) and new instructions and adjustments of technique were discussed if necessary. Necessary scaling and polishing were provided

- Visit 3. The final evaluation was performed 12 weeks to 14 weeks after the first visit. The patients were given the second questionnaire. The same dentist performed the same clinical assessments as at baseline. The data from the clinical assessments were analysed and discussed with the patient. Finally, the recall intervals were discussed and established

Prophylaxis provided: necessary scaling and polishing were provided at the first visit for the control group and where time allowed for the intervention group, and for both groups at the second visit 


\section{Member of dental team delivering intervention: hygienist}

Frequency of intervention: intervention group: 4 visits total, 3 visits with OHA; control group: 3 visits, with 2 visits with $\mathrm{OHA}$

Intensity of intervention (length of time): intervention group: not reported; control group: not reported

Setting: secondary care

Disease level: patients of the Department of Periodontology who demonstrated progress of disease and insufficient compliance at 1 year to 2 years review following initial periodontal therapy

\section{Outcomes}

The clinical examination: consisted of plaque index (PI) according to Löe 1967, gingival index (GI) according to Löe 1967, probing pocket depth (PD) measuring 6 sites (mesio-, mid-, disto-buccal, and mesio-, mid-, disto-lingual) per tooth, and bleeding on probing recorded on 4 sites as absent or present and summarized as a percentage index for all teeth

Participant reported: all participants were given a questionnaire at baseline and at the end of the study. The questionnaire covered oral self-care habits such as frequency of toothbrushing and interdental cleaning, type of interdental cleaning aid, time spent and reasons for cleaning the teeth and finally demographic data. At the end of the study, there were additional questions regarding possible change in their oral self-care

\section{Notes}

Funding: not reported

Sample size calculation: not reported

Adverse effects: not reported

Declarations/conflicts of interest: not reported

\section{Risk of bias}

\begin{tabular}{lll}
\hline Bias & Authors' judgement & Support for judgement \\
\hline $\begin{array}{ll}\text { Random sequence genera- } \\
\text { tion (selection bias) }\end{array}$ & Low risk & $\begin{array}{l}\text { Quote: "The randomization was organized by giving the } 10 \text { individuals a num- } \\
\text { ber. By using a lottery, the first } 5 \text { numbers were included to the intervention } \\
\text { group and the rest to the control group" }\end{array}$ \\
& & $\begin{array}{l}\text { ground } \\
\end{array}$
\end{tabular}

\begin{tabular}{ll}
\hline $\begin{array}{l}\text { Allocation concealment } \\
\text { (selection bias) }\end{array}$ & $\begin{array}{l}\text { Quote: "The randomization was organized by giving the } 10 \text { individuals a num- } \\
\text { ber. By using a lottery, the first } 5 \text { numbers were included to the intervention } \\
\text { group and the rest to the control group" }\end{array}$ \\
& Comment: insufficient information on allocation concealment
\end{tabular}

$\begin{array}{ll}\begin{array}{l}\text { Blinding of participants } \\ \text { and personnel (perfor- } \\ \text { mance bias) }\end{array} & \begin{array}{l}\text { Unclear risk } \\ \text { All outcomes }\end{array} \\ & \begin{array}{l}\text { Quote: "37 individuals, were included in a randomized single-blind control trial } \\ \text { to test an intervention based on the CSCCM" }\end{array} \\ & \begin{array}{l}\text { Comment: study reported as single-blind trial and that the outcome assessor } \\ \text { was blinded to allocation. Blinding of participants was not possible; it is un- } \\ \text { clear the influence this would have on the risk of bias for this domain }\end{array}\end{array}$

$\begin{aligned} & \text { Blinding of outcome as- } \\ & \begin{array}{l}\text { sessment (detection bias) } \\ \text { All outcomes }\end{array}\end{aligned} \quad \begin{aligned} & \text { Quote: "The clinical assessments were performed at baseline and at the final } \\ & \text { evaluation by the same examiner, an experienced periodontist (NO) who was } \\ & \text { blind to the group allocation" }\end{aligned}$
$\begin{aligned} & \text { Comment: study reported as single-blind trial and that the outcome assessor } \\ & \text { was blinded to allocation }\end{aligned}$

$\begin{aligned} & \text { Incomplete outcome data } \\ & \text { (attrition bias) }\end{aligned}$
$\begin{aligned} & \text { Quote: "2 of the patients dropped out; } 1 \text { became ill, and } 1 \text { declined treatment } \\ & \text { at the clinic for Periodontology" }\end{aligned}$


Jönsson 2006 (Continued)

All outcomes
Comment: unclear which group these dropped out from. Given low numbers unlikely to introduce bias

\section{Selective reporting (re- Unclear risk} porting bias)

\begin{abstract}
Quote: "All participants were given a questionnaire at baseline and at the end of the study. The questionnaire covered oral self-care habits such as frequency of toothbrushing and interdental cleaning, type of interdental cleaning aid, time spent and reasons for cleaning the teeth and finally demographic data. At the end of the study, there were additional questions regarding possible change in their oral self-care. For the intervention group, the questionnaire also included questions if the written commitment had any influence on their oral self-care habits"
\end{abstract}

Comment: not all questionnaire data presented

\begin{tabular}{ll}
\hline Other bias $\quad$ Low risk $\quad$ No apparent other bias \\
\hline
\end{tabular}

\section{Jönsson 2009}

Methods Trial design: parallel (2 arms)

Location: Department of Periodontology, Sweden

Number of centres: 1

Study Duration: recruitment March 2006 to March 2007. Participants followed-up at 12 months

\section{Participants}

Participants: participants were recruited among subjects with moderate to advanced periodontitis referred to the clinic and examined during the period from March 2006 to March 2007

Inclusion criteria: participants clinically diagnosed with chronic periodontitis and scheduled to undergo a dental hygiene treatment (i.e. non-surgical periodontal debridement and intervention influencing oral hygiene), aged between 20 and 65, literate in Swedish, and had a plaque index (PII) according to Silness 1964 of $\geq 0.3$. The criteria for Pll were set for 2 reasons. Firstly, a high standard of oral hygiene and a plaque level between $20 \%$ and $40 \%$ is suggested as a level compatible with maintenance of periodontal health (Axelsson 2004; Lang 2003). Secondly, as both interventions aimed to improve oral hygiene habits, subjects with low plaque scores would have clinical efforts focused on other aspects besides oral hygiene

Exclusion criteria: "...if they knew that they could not be available during any part of the study period, suffered from a serious disease that precluded regular sessions, and if explorative periodontal surgery was necessary before the dental hygiene treatment"

Age at baseline (years): intervention group: $52.4 \pm 8.4$; control group: $50.1 \pm 10.3$

Gender: intervention group: male: 25 (43.9\%), female: 32 (56.1\%); control group: male: 28 (50\%), female: $28(50 \%)$

Number randomised: 113 (intervention group: 57; control group: 56)

Number evaluated: 107 (intervention group: 52; control group: 55)

Interventions

Intervention: the individually tailored oral health educational programme was based on the perspective of behavioural medicine (i.e. an integration of cognitive behavioural principles and non-surgical periodontal treatment). The programme comprised 7 separate components with different tactics for tailoring each individual's personal goals regarding oral health and dental hygiene habits

1. Initiation and analysis of knowledge, expectations, and motivation: initially, an interview with openended questions ascertained the patients knowledge of periodontal disease, self-care habits, and attitude towards oral hygiene, as well as outcome expectations and experiences from earlier treatment. The extent to which information about dental diseases was provided depended on each patients prior 
knowledge. The patient formulated (in writing) 3 to 5 personal general long-term goals related to oral health that were the most important to them

2. Analysis of oral hygiene behaviour: based on the above data, the dental hygienist made recommendations related to self-care interventions that were discussed with the patient. Disclosing solution was used to illustrate any current oral biofilm and to initiate a discussion related to oral hygiene aids that might support the patients oral health goal. The patients motivation to use various oral hygiene aids was explored. A guiding principle was to introduce only 1 oral hygiene aid at each session, which allowed the patient to use the chosen aid properly and at the desired frequencies, before any new aids were introduced

3. Practice of manual dexterity for oral hygiene aids: the practice of manual dexterity was introduced when the patients oral hygiene aid was chosen. Instruction sessions on what to do and how to do it were performed by the wash basin in front of a mirror to make the circumstances as near to a home routine as possible

4. Individual goals for oral hygiene behaviour: at the end of each session, the patients self-efficacy and readiness to change an oral hygiene habit was explored through a direct question. Subsequently, the oral hygiene procedures, how, when, and where to use the desired oral hygiene aid or aids, and which area should be given particular attention to until the next session were discussed and agreed upon. The action plan for oral self-care to the next session was formulated in writing. Patients were encouraged to start using the oral hygiene aid they deemed to have the best chance of being successful in reaching the intermediate goal

5. Continuous self-monitoring: a short structured diary was provided to the patients for keeping records on their self-care between sessions. Recordings included the aids used, frequency and when they were used, as well as associated factors that facilitated use or created barriers to use. The diary was discussed and analysed at the next appointment. Positive experiences were encouraged, problems were identified, and possible solutions to the problems were discussed

6. Generalization of behaviour: when all self-care aids had been introduced and practiced, they had to be co-ordinated to function together. The individuals preference, knowledge, and capacity to adapt to necessary oral hygiene aids differed between aids. The dental hygienist allowed the self-care process to develop in a way that supported individuals to proceed at their own pace

7. Maintenance of oral hygiene behaviour and prevention of relapse: the patient was informed that relapses are common during behavioural change (Wilson 1992). Strategies for maintaining already achieved goals for oral hygiene were discussed. Specific risk situations for interdental cleaning relapse were identified (e.g. summer holiday, periods of work overload), and problem-solving strategies were discussed. The discussions focused on situations in which oral hygiene was facilitated and how to find solutions to the problems the patient encountered. If difficult/demanding situations were identified, a plan was constructed to prepare the patient on how to handle these situations. If there were signs of a relapse to previous oral hygiene habits, the disadvantages and advantages were discussed

Control: the control conditions were chosen to be equivalent to the best possible routine oral health preventive programme for patients with periodontal problems. The programme used corresponded to the description by Nyman 1984 and by Rylander 1997. The programme (labelled individual educational programme) has been tested on young adults with satisfactory results (Hugoson 2007)

- First session

- $\quad$ Periodontal status is demonstrated and discussed

- Structured information is given about the periodontal disease, its consequences, the role of careful and correct brushing twice a day, and interdental cleaning once a day

- Oral hygiene instructions after use of disclosing solution

- The dental hygienist decides and gives prescriptions on which oral hygiene aids the subjects should use and encourages the patient to do interdental cleaning before toothbrushing, preferably in the evening

- The subjects are asked to demonstrate and practice the cleaning technique in their own mouth

- The subjects are informed their own engagement is crucial for successful treatment outcome

- Second and following sessions

- The oral hygiene status is checked with a disclosure solution

- New instructions and adjustments of aids and technique are discussed and demonstrated if necessary 
- New information is given if the dental hygienist considers it necessary or if the subjects ask questions about periodontal disease or oral hygiene

Prophylaxis provided: in both groups, the participants visited the dental hygienist once a week until the scaling treatment was finished and there was an oral hygiene control performed after 1 month

Quote: "Non-surgical treatment and supportive periodontal care programme: non-surgical root surface debridement was integrated into both programmes and undertaken during the initial dental hygiene treatment (visits 1 to 5), mainly performed with hand instruments (LMs Gracys curette of 5 various designs and LMs Svärdström 1/3 and 2/4). There was some supplementary scaling after the 3-month follow- up and during the supportive maintenance care. At each session for both groups, the teeth were cleaned with polishing paste AV 170 , and with flossing on proximal surfaces. For both groups, supportive maintenance care was scheduled every third month after the initial dental hygiene treatment, i.e. 3 and 6 months after the 3-month follow-up. The supportive maintenance care sessions included checking oral hygiene status with disclosure solutions, and if necessary, re-instruction. For the experimental group these sessions included relapse prevention procedures and, when needed new goals for oral hygiene practise were discussed"

\section{Member of dental team delivering intervention: hygienist}

Frequency of intervention: intervention group: median number of intervention visits: 9; control group: median number of intervention visits: 8

Intensity of intervention (length of time): appointment time was approximately 60 minutes for each session up to the 3-month follow-up, and approximately 45 minutes for the maintenance period. In the intervention group, an extra 10 minutes was needed for the first 2 sessions

Setting: secondary care

Disease level: moderate to advanced periodontitis

"Probing pocket depth (PPD) measured at 6 surfaces of each tooth, and bleeding on probing (BoP) in connection with the measurement of periodontal pockets. The presence of plaque was recorded according to Silness \& Löe (Silness 1964) PlI. In the present study, criteria 2 and 3 were combined, i.e. all visible plaque was judged as the same amount. The presence of gingival inflammation was recorded according to the criteria for the gingival index (GI) of Löe \& Silness (Löe 1963). Experience from patients treated for periodontal disease at the clinic indicates that few patients have spontaneous bleeding and ulcerations; therefore, criteria 2 and 3 were considered to be equally severe. Thus, the highest score for both Pll and GI was 2. Both PII and GI were recorded on the buccal, lingual, mesial, and distal tooth surfaces of all teeth. The mesial and distal surfaces were recorded from the lingual perspective. To minimize the risk of underestimating Pll and GI scores, the assessment was performed from the lingual aspect, as proximal surfaces are more accessible from the lingual aspect for the observer, but are probably more difficult for the individual patient when performing their oral hygiene. The assessments for PII, GI, PPD, and BoP were performed with a mirror and a periodontal probe (CC Williams Probe 1-2-3-5-7-8-9-10, Hu-Friedys, Chicago, IL, USA)"

"Oral hygiene behaviour was assessed through questionnaires covering oral self-care habits such as frequency of toothbrushing and interdental cleaning, type of toothbrush and interdental cleaning aid, and time and place for oral cleaning. The toothbrushing and interdental cleaning were classified into 2 categories: brushing at least twice a day/less often and, cleaning proximal surfaces once a day/less often"

"To evaluate participants' opinion about the interventions and satisfaction with the treatment, 6 questions were posed at the 12-month follow-up: (1) performance of oral self-care (much better, better, no difference, and worse) compared with before treatment; (2) satisfaction with oral health (much more satisfied, more satisfied, and no difference, worse) compared with before treatment; (3) compliance with skills obtained during the treatment (daily, several times a week, some times per week, a couple of times during a month, seldom/never); (4) likelihood to maintain new habits (very likely, likely, fairly likely, and not likely); (5) satisfaction with care given by the dental hygienist (very satisfied, satisfied, fairly unsatisfied, and very unsatisfied); and (6) whether the treatment had been worthwhile (time and cost)(yes, absolutely, yes to some extent, neither yes nor no, and no)" 
Jönsson 2009 (Continued)

Notes

Funding: "This study was supported by the Swedish Research Council, Uppsala County Council, Swedish Patent Revenue Fund for Research in Preventive Odontology, Pfizer Oral Care Award, and the support of the authors institutions"

Sample size calculation: "A power calculation, with data from a previous study (Jönsson 2006), based on the detection of a difference in the mean Gl interproximally of $20 \%$ between treatment groups indicated that 75 participants were required in each group $(\alpha=0.05, \beta=0.2) "$

"The power analyses revealed that about 150 participants were required for the study. Although the desired number of participants was not reached further inclusion was discontinued for 2 reasons. First, the examiner was unable to participate in the whole process of the requirement and there were difficulties in introducing a new examiner to the study with short notice, and second, the original power analysis was based on an intervention judged as being less effective than the present one. Therefore, the effect size was probably underestimated"

Adverse effects: not reported

Declarations/conflicts of interest: "The authors declare that there are no conflicts of interest in this study"

\section{Risk of bias}

\section{Bias}

Authors' judgement Support for judgement

Random sequence genera- Low risk tion (selection bias)

Quote: "Participants were randomly allocated to an individually tailored oral health educational programme (experimental group) or to a standard treatment programme (control group). The randomization was made in blocks of various sizes by a random computer table"

Allocation concealment Low risk

(selection bias)

Quote: "Allocation concealment was secured by (i) having a person not involved with the clinic perform the randomization i.e. neither the examiner nor the therapist could influence the allocation of group belongings and (ii) providing the dental hygienists with sealed consecutively numbered envelopes containing only the assignment for an individual subject. The dental hygienist had not met the patient before the assignment. The sample was stratified for smoking and allocated to the 2 dental hygienists who performed the treatment"

\begin{tabular}{|c|c|c|}
\hline $\begin{array}{l}\text { Blinding of participants } \\
\text { and personnel (perfor- }\end{array}$ & Unclear risk & $\begin{array}{l}\text { Quote: "A randomized, evaluator-blinded, controlled trial with } 2 \text { different ac- } \\
\text { tive treatments was performed" }\end{array}$ \\
\hline All outcomes & & $\begin{array}{l}\text { Comment: study reported as evaluator-blinded. Blinding of participants was } \\
\text { not possible; it is unclear the influence this would have on the risk of bias for } \\
\text { this domain }\end{array}$ \\
\hline
\end{tabular}

Blinding of outcome as- Low risk sessment (detection bias)

All outcomes
Quote: "The same examiner, who was blind to group membership, performed all clinical measurements throughout the course of the study"

Comment: the examiner did not know which group the participants they were assessing had been assigned to
Incomplete outcome data Low risk (attrition bias)

All outcomes
Quote: "6 participants (4 women and 2 men) dropped out during the study period. In the experimental group, 1 participant discontinued treatment before the intervention started due to economic reasons and a further 2 were lost at the 3-month follow-up; 1 became seriously ill and 1 moved temporarily from the county, but came back into the study at the 12-month follow-up. Another 2 participants dropped out between the 3-and the 12-month follow-up. In the control group, 1 participant discontinued treatment" 
Jönsson 2009 (Continued)

Selective reporting (re- Low risk Probing pocket depths not reported in primary publication but subsequently porting bias) reported

Other bias Low risk No apparent other bias

Lepore 2011

Methods Trial design: parallel ( 2 arms)

Location: Columbia University Medical Center, USA

Number of centres: 1

Study duration: recruitment and follow-up dates not reported. Participants followed-up at 2 months

Participants

Participants: 69 paediatric-child patients between ages 1 and 6 years

Inclusion criteria: not reported

Exclusion criteria: not reported

Age (years): between ages 1 and 6 years, with the majority (90\%) being 2 years to 5 years (mean age of 3 years)

Gender: not reported

Number randomised: 69 (intervention group: 37; control group: 32)

Number evaluated: 69 (intervention group: 37; control group: 32)

Interventions

Intervention: dental prophylaxis and topical fluoride application, routine oral health instructions (as given to the control group). In addition a personalized oral health action plan which consisted of an assessment of the patient's current caries risk and a list of suggestions on how to improve that status. The parent and dentist together chose 1 particular suggestion they felt was achievable

Control: dental prophylaxis and topical fluoride application, routine, verbally dispensed oral hygiene and diet instructions targeting the specific needs of the patient

Prophylaxis provided: both groups received a dental prophylaxis and topical fluoride varnish application

Member of dental team delivering intervention: dentist

Frequency of intervention: intervention group: 1 initial visit with $\mathrm{OHA}$; control group: 1 initial visit with $\mathrm{OHA}$

Intensity of intervention (length of time): intervention group: not reported; control group: not reported

Setting: secondary care

Disease level: caries risk

Data collected included DMFS, gingival health and plaque scores. During the first visit, the parents were questioned regarding the oral hygiene and diet behaviour of the child in order to fulfil the 6 survey topics (frequency of toothbrushing with a fluoridated dentifrice, parent-assisted toothbrushing, bottle use, sippy cup use, frequency of juice consumption and frequency of between-meal snacking). Data for the reported behaviour was categorized as low, moderate or high caries risk and assigned a numerical value of 0,1 or 2 , respectively 
Lepore 2011 (Continued)

Notes Funding: not reported

Sample size calculation: not reported

Adverse effects: not reported

Declarations/conflicts of interest: not reported

\section{Risk of bias}

\begin{tabular}{|c|c|c|}
\hline Bias & Authors' judgement & Support for judgement \\
\hline $\begin{array}{l}\text { Random sequence genera- } \\
\text { tion (selection bias) }\end{array}$ & Unclear risk & $\begin{array}{l}\text { Quote: "divided randomly into control and intervention groups" } \\
\text { Comment: insufficient information on random sequence generation }\end{array}$ \\
\hline $\begin{array}{l}\text { Allocation concealment } \\
\text { (selection bias) }\end{array}$ & Unclear risk & Comment: insufficient information on allocation concealment \\
\hline $\begin{array}{l}\text { Blinding of participants } \\
\text { and personnel (perfor- } \\
\text { mance bias) } \\
\text { All outcomes }\end{array}$ & Unclear risk & $\begin{array}{l}\text { Quotes: " } 32 \text { patients in the control group received routine, verbally dispensed } \\
\text { oral hygiene and diet instructions targeting the specific needs of the patient. In } \\
\text { addition to the routine oral health instructions given to the control group, the } \\
37 \text { patients in the intervention group received a personalized oral health ac- } \\
\text { tion plan" and "The parent and dentist together chose } 1 \text { particular suggestion } \\
\text { they felt was achievable" } \\
\text { Comment: blinding of participants was not possible; it is unclear the influence } \\
\text { this would have on the risk of bias for this domain }\end{array}$ \\
\hline $\begin{array}{l}\text { Blinding of outcome as- } \\
\text { sessment (detection bias) } \\
\text { All outcomes }\end{array}$ & Unclear risk & $\begin{array}{l}\text { Quotes: "Finally, since this was a single blind study, upon follow-up examina- } \\
\text { tion, experimenter bias has to be considered and results may be skewed" and } \\
\text { "...This discrepancy could probably be accounted for considering the other } 3 \\
\text { major limitations of this study: the sample size, observation time and potential } \\
\text { examiner bias" } \\
\text { Comment: unclear on who was blinded to group allocation }\end{array}$ \\
\hline
\end{tabular}

\begin{tabular}{lll}
\hline $\begin{array}{l}\text { Incomplete outcome data } \\
\text { (attrition bias) } \\
\text { All outcomes }\end{array}$ & Unclear risk & $\begin{array}{l}\text { Comment: no dropouts reported, however difference in group allocation (37 } \\
\text { versus 32). The authors may not have reported any possible dropouts, only re- } \\
\text { porting those available at the end of the study }\end{array}$ \\
\hline $\begin{array}{l}\text { Selective reporting (re- } \\
\text { porting bias) }\end{array}$ & Low risk & $\begin{array}{l}\text { Comment: all outcomes in methods section were reported. Unclear what } \\
\text { plaque index and gingival health index were used but unlikely to influence out- } \\
\text { come }\end{array}$ \\
\hline Other bias & Unclear risk & $\begin{array}{l}\text { Unclear baseline comparability and ITT not completed } \\
\text { Method states DMFS to be scored but within abstract and results table dmft is } \\
\text { reported }\end{array}$ \\
\hline
\end{tabular}

\section{López-Jornet 2014}

$\begin{array}{ll}\text { Methods } & \text { Trial design: parallel (2 arms) } \\ \text { Location: Department of Oral Medicine, Murcia University Dental School, Murcia, Spain } \\ \text { Number of centres: } 1\end{array}$


López-Jornet 2014 (Continued)

Study duration: 8-week follow-up of patients attending during 2009 and 2010

Participants

Participants: patients with hyposalivation attending the Department of Oral Medicine

Inclusion criteria: "..patients complaining of dry mouth as assessed by a response of $30 \mathrm{~mm}$ or greater on at least 1 of 8 Dry Mouth Visual Analogue Scale (VAS) questions; subjects with an unstimulated whole salivary flow rate of less than $1.5 \mathrm{~mL} / 15$ minutes; patients who had never received periodontal treatment or been taught the brushing technique; and patients who were considered sufficiently fit in terms of physical capacity to implement hygiene measures"

Exclusion criteria: "..patients younger than 18 years; patients with insufficient manual dexterity; edentulous patients; and subjects with an uncontrolled medical condition that might require changes in medication during the course of the study"

Age (years): $56.7 \pm 15.4$ (range, 31 years to 84 years old)

Gender: overall: female: 48 (80\%), male: 12 (20\%); intervention group: 22 (73\%) females and 8 (27\%) males; control group: $26(87 \%)$ females and $4(13 \%)$ males

Number randomised: 60 (intervention group: 30; control group: 30)

Number evaluated: 60 (intervention group: 30; control group: 30) over the 8-week period"

Intervention: advice on conventional hygiene procedures using a motivational-behavioural skills protocol designed following principles of self-efficacy theory, which required a longer time. This was a systematic method, consisting of 6 steps designed to help patients make effective lifestyle changes and to identify and resolve problems. It consisted of the following steps: step 1: creating confidence and commitment; step 2: increasing self-awareness of behaviour; step 3: developing and implementing an action plan; step 4: evaluating the plan; step 5: maintaining change; and step 6: preventing relapse (Kakudate 2009)

Control: instruction in conventional hygiene procedures for 20 minutes based on the Bass method of oral health education (Quigley 1962)

Prophylaxis provided: not reported

Member of dental team delivering intervention: dental care professional

Frequency of intervention: intervention group: 4 visits with OHA; intervention group: 4 visits with OHA

Intensity of intervention (length of time): intervention group: quote "which required a longer time;" control group: 20 minutes

Setting: secondary care

Disease level: dry mouth with no history of periodontal treatment

Quotes: "On the first visit, patient data were registered (age, gender, medical history, disease process, drug history, family history and clinical signs and symptoms), and then plaque extension index, bleed ing index and CPITN were measured," "the periodontal health of all patients was assessed on the first visit and at the end of the oral hygiene instruction programme," "all patients were subjected to a periodontal clinical examination performed at 6 sites per tooth (excluding third molars) to determine the plaque extension index (PEI) following plaque disclosure using a $2 \%$ aqueous erythrosine solution. $A$ cotton swab was submerged in the solution for 10 seconds and was then applied to the tooth surfaces. After rinsing once with water, plaque deposits were assessed using the Quigley and Hein index, modified by Turesky et al, with scores from 0 to 5 . Periodontal condition was assessed by means of the World Health Organization (WHO) Community Periodontal Index of Treatment Needs (CPITN), using the specially designed WHO periodontal probe (23/CP11, Hu-Friedy, Leimen, Germany) with a sensing force of no more than $20 \mathrm{~g}$. Each patient's mouth was divided into sextants, and each sextant was examined providing that there were $\geq 2$ teeth present and that these were not indicated for extraction. The teeth 
López-Jornet 2014 (Continued)

examined were 1.7, 1.6, 1.1, 2.1, 2.6, 2.7, 4.7, 4.6, 4.1, 3.1, 3.6, and 3.7. The highest index found in each sextant was recorded according to the following scores: $0=$ good periodontal health; $1=$ gingival bleeding; 2 = calculus detected during probing; 3 = pocket $4 \mathrm{~mm}$ to $5 \mathrm{~mm}$ in depth; and 4 = pocket $\geq 6 \mathrm{~mm}$ in depth. The periodontal condition of each patient was reported as the worst sextant CPITN score"

Funding: not reported
Sample size calculation: not reported
Adverse effects: not reported
Declarations/conflicts of interest: not reported
Additional information from author correspondence: "..intervention was provided in a dental clinic
setting....The advice were (made) by dental care professional"
setting.... The advice were (made) by dental care professional"

\section{Risk of bias}

\begin{tabular}{|c|c|c|}
\hline Bias & Authors' judgement & Support for judgement \\
\hline $\begin{array}{l}\text { Random sequence genera- } \\
\text { tion (selection bias) }\end{array}$ & Low risk & $\begin{array}{l}\text { Quote: "Patients were randomly assigned to } 2 \text { groups - control group and in- } \\
\text { tervention group - by a single researcher using a random numbers table" }\end{array}$ \\
\hline $\begin{array}{l}\text { Allocation concealment } \\
\text { (selection bias) }\end{array}$ & Unclear risk & Comment: insufficient information on allocation concealment \\
\hline $\begin{array}{l}\text { Blinding of participants } \\
\text { and personnel (perfor- } \\
\text { mance bias) } \\
\text { All outcomes }\end{array}$ & Unclear risk & $\begin{array}{l}\text { Quote: "In both groups, oral hygiene instruction was given once every } 15 \text { days } \\
\text { with a total of } 4 \text { sessions over the } 8 \text {-week period" } \\
\text { Comment: blinding of participants was not possible; it is unclear the influence } \\
\text { this would have on the risk of bias for this domain }\end{array}$ \\
\hline $\begin{array}{l}\text { Blinding of outcome as- } \\
\text { sessment (detection bias) } \\
\text { All outcomes }\end{array}$ & Low risk & $\begin{array}{l}\text { Quote: "The same examiner (CRA), blinded to group assignment, performed all } \\
\text { clinical measurements throughout the study" } \\
\text { Comment: the examiner did not know which group the participants they were } \\
\text { assessing had been assigned to }\end{array}$ \\
\hline $\begin{array}{l}\text { Incomplete outcome data } \\
\text { (attrition bias) } \\
\text { All outcomes }\end{array}$ & Low risk & Comment: no missing outcome data, all participants followed-up \\
\hline $\begin{array}{l}\text { Selective reporting (re- } \\
\text { porting bias) }\end{array}$ & Low risk & All outcomes in methods section were reported \\
\hline Other bias & Low risk & No apparent other bias \\
\hline
\end{tabular}

Memarpour 2016

Trial design: parallel (3 arms)
Location: Shiraz, Iran
Number of centres: 5
Duration: recruitment began in December 2012 and was completed within 4 months. Follow-up ap-
pointments were scheduled at 4 months, 8 months, and 12 months after the initial dental appointment
for each child


Memarpour 2016 (Continued)

Participants
Participants: 300 children participants

Inclusion criteria: "The main inclusion criterion was age between 12 and 24 months at the beginning of the study. All children had resided since birth in Shiraz, where water fluoridation levels are similar (< $0.07 \mathrm{ppm}$ ) in all areas. All participants had at least 4 erupted primary teeth. None of the teeth showed signs of non-cavitated or cavitated caries $(\mathrm{dmft}=0)$. The parents did not use any oral hygiene methods such as toothbrushing or any fluoride products at home or in other clinics. All parents were interviewed to explain the aim of the study, and all parents provided their informed consent in writing. A schedule of appointments was provided and parents were asked to attend the healthcare center to receive both free health and dental care service during the study period"

Exclusion criteria: "The exclusion criteria were medical history of systemic diseases, drug allergies, congenital physical or mental disabilities, oral or dental anomalies or disabilities, and unwillingness to participate due to lack of time"

Age at baseline (months): mean age intervention Group A: $20.70 \pm 7.04$; intervention Group B: $21.04 \pm$ 8.86; control: $19.73 \pm 8.24$

Gender: intervention Group A: 48 (48\%) female and 52 (52\%) male; intervention Group B: 47 (47\%) female and $53(53 \%)$ male; control group: 42 (42\%) female and $58(58 \%)$ male

Number randomised: 300 (intervention Group A: 100; intervention Group B: 100; control Group: 100)

\section{Number evaluated:}

- month 4 follow-up: total 288 (intervention Group A: 97, intervention Group B: 95, control group: 96)

- month 8 follow-up: total 281 (intervention Group A: 94, intervention Group B: 93, control group: 94)

- month 12 follow-up: total 260 (intervention Group A: 85, intervention Group B: 87, control group: 88)

Intervention Group A: at the first appointment, parents in group 2 completed the questionnaires and received a free gift bag that contained an educational pamphlet and a toothbrush. The pamphlet explained the importance of caring for primary teeth, the factors that influence Severe Early Childhood Caries (SECC), instructions on how to prevent SECC with a non-cariogenic diet and feeding methods, and instructions for oral hygiene. Parents received face-to-face oral health instructions that were included in the pamphlet and were trained in the proper use of a toothbrush (Kagihara 2009). Children in this group received a placebo fluoride varnish as previously described. Subsequent appointments were scheduled until the end of the follow-up period, and the placebo varnish was applied at baseline and at the 6-month follow-up appointment

Intervention Group B: the parents received oral health instruction as described for group 2. The dentist cleaned the children's teeth by brushing and isolated them with cotton rolls. Fluoride varnish that contained 5\% sodium fluoride (DuraShield, Sultan Healthcare, Hackensack, NJ, USA) was applied with a disposable brush to all tooth surfaces and left for 1 minute. A small amount of varnish was applied to all primary teeth at baseline. The parents were advised not to allow the child to eat rough (abrasive) foods for the remainder of the day (Holve 2008) and not to brush until the following day (Weyant 2013). The fluoride varnish was applied again 6 months later. This group is not further included in this review

Control: mothers completed the questionnaires, and the children's teeth were examined at baseline. Control group participants did not receive any oral healthcare intervention. The placebo, a water-based coloured solution similar to fluoride varnish, was painted over the tooth surfaces. The solution was tasteless and odourless. The baseline procedure for placebo application was repeated at the follow-up appointment 6 months later

Prophylaxis provided: no baseline prophylaxis

Member of dental team delivering intervention: dentist

Frequency of intervention: each group attended for 2 'intervention' appointments and 3 review appointments. Each child received a new toothbrush every 3 months 
Intensity of intervention (length of time): all procedures including completion of the questionnaires, oral hygiene instruction and performing the intervention took about 30 minutes to 40 minutes for each child in all groups

Setting: public health care centres

Disease level: none of the teeth showed signs of non-cavitated or cavitated caries $(\mathrm{dmft}=0)$

Outcomes Clinical outcomes: "The primary outcome was the influences of the interventions on the incidence of caries. The children's teeth were examined by 2 trained dentists with the arm-cradling or knee-to-knee positions. First the dentists were given instructions by a senior author (MM) with a role-playing technique on how to perform the oral examination, interview the mothers, provide oral health instructions, and complete the questionnaire. To ensure consistency, under supervision by the senior author, both examiners assessed 15 children as part of the training for this research (pilot study) during 1 week. The examiners used disposable dental mirrors, a head light and ball-ended World Health Organization CPI probes according to their criteria for the diagnosis of dental caries (WHO 1997). Initially the teeth were cleaned with a toothbrush, then wiped with a cotton roll and allowed to air dry. We used the dmft index to record the presence of any caries. This index is defined by ' $d$ ' indicating a decayed tooth, ' $m$ ' indicating a missing tooth due to decay, and ' $f$ ' indicating a filled tooth. Both dentists were present at the follow-up appointments. The Kappa values for caries detection showed a high level of agreement between the 2 examiners at all 3 follow-up time points (range 0.940-1). In case of disagreement during the evaluations, consensus evaluations were obtained between the examiners. The data were collected and recorded at each follow-up period"

Knowledge and performance outcomes: "Parents' knowledge and performance regarding oral health was assessed as the secondary outcome. The questionnaire addressed (1) demographic information of the child, i.e. age, gender, place of birth, general health status, and dental history; (2) parents' information, including level of education, employment, family income, and mother's age; (3) parents' knowledge, evaluated as their knowledge about factors that contribute to SECC, the role of brushing and fluoride in caries prevention, bottle feeding of milk or sweet liquids, and the importance of caring for primary teeth, and (4) parents' performance on activities to ensure the child's oral health, including brushing the child's teeth, frequency of brushing, frequency of snacking, method of milk feeding, sharing utensils with the child during meals and checking the child's teeth"

Notes

Funding: "Vice-Chancellery of Research of Shiraz University of Medical Sciences, Shiraz, Iran. Grant No 92-6158"

Sample size calculation: "A sample size of 60 persons per group was estimated to be sufficient to detect a clinically significant difference of $20 \%$ between groups in caries incidence using a 2-tailed test of proportions between 2 groups with $80 \%$ power and a $5 \%$ level of significance. This difference represents a 30\% incidence of caries in the control group [Kumarihamy 2011; Mohebbi 2006; Mohebbi 2008] and a $10 \%$ incidence of caries in the fluoride varnish group 12 months after the start of the study. However, because of the long study period, a sample size of 300 children (100 in each group) was finally selected at baseline to compensate for the high rate of probable withdrawal (>50\%)"

Adverse effects: not reported

Declarations/conflicts of interest: quote: "There are no conflicts of interest"

\section{Risk of bias}

Bias Authors' judgement Support for judgement

Random sequence genera- Low risk tion (selection bias)
Quote: "A staff member randomly assigned 100 children from the list of children with $\mathrm{dmft}=0$ to each group using a block randomization method (total $\mathrm{n}$ $=300$ ), with a block length of $B=6$. Random allocation sequences were generated by a statistician with a random number table and were concealed from the 2 examiners until the start of the study"

Comment: adequate random sequence generation 
Memarpour 2016 (Continued)

Allocation concealment Unclear risk Quote: "..and were concealed from the 2 examiners until the start of the study" (selection bias)

Comment: insufficient information regarding allocation concealment

Blinding of participants Unclear risk and personnel (perfor-

mance bias)

All outcomes

Quote: "Parents were blinded to the study groups. They were not aware which group their child had been randomized to regarding the use of fluoride varnish or a placebo"

Comment: the dentists were likely to know the patients allocation. Blinding of participants was not possible; it is unclear the influence this would have on the risk of bias for this domain

Blinding of outcome as- Unclear risk
sessment (detection bias) All outcomes

Quote: "Parents were blinded to the study groups. They were not aware which group their child had been randomized to regarding the use of fluoride varnish or a placebo"

Comment: the parents and children (aged 12 months to 14 months) would be unlikely to know what group they were allocated to. The dentists may have known the patients allocation when clinically assessing participants teeth and parent's performance so unclear if this may have affected outcome assessment

Incomplete outcome data Low risk Comment: all participants accounted for, explanation of dropouts provided
(attrition bias)

All outcomes

\begin{tabular}{lll}
\hline $\begin{array}{l}\text { Selective reporting (re- } \\
\text { porting bias) }\end{array}$ & Low risk & All outcomes in methods section were reported \\
\hline Other bias & Low risk & No apparent other bias \\
\hline
\end{tabular}

Müinster Halvari 2012

\begin{tabular}{ll}
\hline Methods & Trial design: parallel ( 2 arms) \\
Location: Colosseum Dental Clinic in Sandvika, Norway \\
Number of centres: 1 \\
Duration: recruitment and follow-up dates not reported. Participants followed-up at 5.5 months \\
\hline
\end{tabular}

Participants Participants: 158 adults

Inclusion criteria: adult participants that showed up at the clinic, understood Norwegian, and gave informed consent

Exclusion criteria: periodontal pockets $\geq 4.0 \mathrm{~mm}$, as measured by a pocket probe, and/or serious bone loss visualized by digital $X$ rays during the dental examination; significant additional oral or other diseases; pregnant women

Age at baseline (years): range 18 to 32 , mean age 23.31 years, $S D=3.5$

Gender: total: $112(71 \%)$ female and $46(29 \%)$ male

Number randomised: 158 (intervention group: 79; control group: 79)

Number evaluated: 141 (intervention group: 70; control group: 71) 
Münster Halvari 2012 (Continued)

Interventions
Quotes: "When participants first arrived at Time 1a (T1a; ........), they completed a survey assessing autonomy orientation, autonomous motivation for dental home care, perceived dental competence, dental behaviours, and demographics. The standard oral examination. The exam lasted about 45 minutes for all participants, during which time T1a oral health variables were assessed. The DH was autonomy supportive when giving the information about the examination. The $\mathrm{DH}$ addressed an introduction to the exam ( 5 minutes); measures of dental plaque and gingivitis on all teeth surfaces (112 for patients with all teeth intact; 20 minutes); clinical and X-ray exam for caries (5 minutes); and pocket exam (5 minutes). The final dialogue lasted about 10 minutes and included information on how caries looks and how to detect it on patients' own X rays, and the importance of choice and self-initiation regarding treatment options in order to promote an informed basis for patient choice and decision making (Beauchamp \& Childress 2001)" and "Immediately thereafter, a 45-minute intervention took place for the experimental group, whereas control group participants went directly to a 45-minute standard teeth cleaning. The experimental group received the cleaning after the intervention. The cleaning in both groups was done in an autonomy-supportive way"

Intervention: "The DH started the intervention by asking participants about their perceived oral health and problems, and listening to and acknowledging their feelings and perspectives, before giving competence-related information about their perceived oral health and problems. Based on this conversation, the contents of the intervention were (a) education in plaque-related diseases such as gingivitis, periodontitis, and caries; (b) demonstrating effective brushing and flossing, with participants practicing these tasks and receiving positive feedback and corrections; (c) giving health promotion and disease preventive information, and offering rationales for the dental behaviours by explaining the relations of behaviours to disease prevention and health; (d) giving information about the value of fluorides and regular meals; and (e) offering choice and options concerning their dental home care"

Control: "This 45-minute cleaning was given to the control group after the exam and to the experimental group after the intervention. The $\mathrm{DH}$ focused on the importance of removing calculus in order to make participants' dental home care easier to perform. The cleaning made the baseline the same for both groups."

"The control group was viewed as having received usual care; however, because of ethical considerations, the emphasis on patient autonomy support in this clinic likely made this usual-care condition more autonomy supportive than would have been the case in other clinics. If that were so, it would make the test of the intervention more stringent than if usual care had been provided without the autonomy support, as the primary difference between the 2 groups would likely have been just the competence enhancing intervention itself and/or any possible interaction between the intervention and the autonomy support"

Prophylaxis provided: scaling at baseline

Member of dental team delivering intervention: hygienist

Frequency of intervention: intervention group: 1 visit with OHA; control group: 1 visit with $\mathrm{OHA}$

Intensity of intervention (length of time): intervention group: 90 minutes; control group: 45 minutes

Setting: primary care

Disease level: routinely attending adults with no signs of periodontal disease

Outcomes
Clinical outcomes: dental plaque (dental plaque index (Löe 1967)), gingivitis (dental gingival index (Löe 1967)). Both plaque and gingivitis were assessed on distal, buccal, mesial, and lingual tooth surfaces on all teeth except third molars. A participant's scores were the sums for plaque and gingivitis, respectively, divided by the total number of surfaces measured. For the purpose of reliability estimation for plaque and gingivitis, the average scores of each of the 4 teeth quadrants as indicators, and used observations of plaque in the 4 teeth quadrants in modelling of latent indicators for plaque in Structural Equation Modeling (SEM)

Psychological outcomes (questionnaires): autonomy orientation (Dental Care Autonomy Orientation Scale), perceived autonomy support (6-item version of the Health Care Climate Questionnaire (Williams 1996)), autonomous motivation for the dental project (Evaluation of Dental Project Scale (Halvari 2006)), autonomous motivation for dental home care (a 3-item identified subscale of the Self- 
Münster Halvari 2012 (Continued)

Regulation for Dental Home Care Questionnaire (Halvari 2012)); perceived dental competence (Dental Coping Beliefs Scale (Wolfe 1996) using the 5 items with the best factor loadings (Halvari 2006) and 2 added items from a previous study (Halvari 2010)); dental health behaviours (dental health behaviour was assessed by a 4-item formative composite scale (Halvari 2010))

Notes

Funding: "The Faculty of Odontology, University of Oslo, for funding the 4-year PhD period; the Norwegian Ministry of Health, who funded the study"

Sample size calculation: "A power analysis using data from a previous study (Halvari 2006) indicated that the necessary number of participants in each group should be 14 for dental plaque, 18 for gingivitis, and 56 for perceived competence to detect significant differences (using t tests) between averages for the experimental and control groups with a power of $.90(\alpha=.05)$. Based on the power estimates and an unknown participant dropout from Time 1 to Time 2, 79 participants were randomly assigned to each condition and were considered to be sufficient"

Adverse effects: not reported

Declarations/conflicts of interest: not reported

\section{Risk of bias}

Bias Authors' judgement Support for judgement

Random sequence genera- Unclear risk tion (selection bias)

Quote: "After the exam, 79 participants were randomly assigned to each condition"

Comment: insufficient information on the method of random sequence generation

Allocation concealment Unclear risk
(selection bias)

Quote: "Immediately thereafter, a 45-minute intervention took place for the experimental group, whereas control group participants went directly to a 45minute standard teeth cleaning. The experimental group received the cleaning after the intervention. The cleaning in both groups was done in an autonomy-supportive way"

Comment: insufficient information on allocation concealment

\begin{tabular}{|c|c|c|}
\hline $\begin{array}{l}\text { Blinding of participants } \\
\text { and personnel (perfor- }\end{array}$ & Unclear risk & $\begin{array}{l}\text { Quote: "This 45-minute cleaning was given to the control group after the exam } \\
\text { and to the experimental group after the intervention" }\end{array}$ \\
\hline All outcomes & & $\begin{array}{l}\text { Comment: the dental hygienist providing the intervention also provided the } \\
\text { baseline 'cleaning' and would therefore be aware of the allocation. Blinding of } \\
\text { participants was not possible; it is unclear the influence this would have on the } \\
\text { risk of bias for this domain }\end{array}$ \\
\hline
\end{tabular}

Blinding of outcome as- Low risk sessment (detection bias) All outcomes
Quote: "At T2 (after 5.5 months), participants responded to all the same questionnaires completed before the teeth exam at T1a, except autonomy orientation and demographics, which were not included at T2. Then, the second teeth examinations were conducted by a different $\mathrm{DH}$ than the one for T1a. The second $\mathrm{DH}$ was blind to experimental conditions"

Comment: the examiner did not know which group the participants they were assessing had been assigned to

Incomplete outcome data Low risk Comment: all participants accounted for, explanation of dropouts provided (attrition bias)

All outcomes

$\begin{aligned} & \text { Selective reporting (re- } \\ & \text { porting bias) }\end{aligned} \quad$ Low risk All outcomes in methods section were reported


Münster Halvari 2012 (Continued)

Other bias Low risk
Quote: "207 potential participants from the University of Oslo indicated interest in the study on motivation and dental behaviour after seeing a poster or being approached by the researcher... They were informed that they would get a free dental examination, a free dental cleaning, and a chance to win travel worth NOK 10000 (about USD 1700)"

Comment: unlikely to influence outcome

Ramsay 2018

Trial design: parallel (6 arms)
Location: general dental practices in Scotland and the North East of England
Number of centres: 63
Study Duration: participants recruited between Febrruary 2012 and March 2013 with a 3-year fol-
low-up
low-up

Participants

Participants: adults attending National Health Service general dental practices in Scotland and the North East of England

Inclusion criteria: adult patients ( $\geq 18$ years of age) with periodontal health, gingivitis or moderate periodontitis (Basic Periodontal Examination (BPE) score 0 to 3) who are dentate; have attended for a check-up at least twice in the previous 2 years; and receive their dental care in part or fully as a National Health Service patient

Exclusion criteria: patients with severe periodontal disease with a BPE score of 4 (probing depth $>6$ $\mathrm{mm}$ and/or furcation involvements or attachment loss of $7 \mathrm{~mm}$ or more) in any sextant on the basis more extensive periodontal care is indicated. Patients with an uncontrolled chronic medical condition (e.g. diabetes, immunocompromised)

Age at baseline (years): intervention group: mean 47.4 years (SD 16.1); control group: mean 48.3 years (SD 15.3)

Gender: intervention group: 387 males (38\%), 321 females (62\%); control group: 290 males (33\%), 576 females (67\%)

Number randomised: 1877 participants

Number evaluated: 1237 participants

Intervention: personalised OHA: "Personalised OHA intervention based upon Social Cognitive Theory (Bandura 1998) and Implementation Intention Theory (Gollwitzer 1999) was delivered. The content of the advice delivered was personalised according to the dentist's/hygienist's assessment of the needs of the patient. At a minimum the content included advice and instruction in self-diagnosis (e.g. bleeding gums on brushing indicates the presence of reversible gingival inflammation) and advice and instruction on toothbrushing and flossing (frequency and technique). Upon completion of the advice, the dentist agreed an action plan with the patient. The feasibility and utility of including personalised biofeedback (Chapple 2008) in the personalised OHA intervention was considered by the research team and the Periodontal Advisory Group." "In addition, the Control and Intervention groups were further randomised at patient-individual randomisation level to no periodontal instrumentation (PI), 6 monthly PI or 12 monthly PI"

Control: routine OHA: "Routine OHA indicates current practice. There is no published information describing 'routine' OHA, but anecdotal evidence suggests that this is often the provision of minimal advice (e.g. 'you need to brush your teeth more frequently' or no advice)"

Prophylaxis provided: at baseline all patients received OHA according to cluster level randomisation. A full mouth supra- and subgingival PI was carried out by the dentist/hygienist on all participants pri- 
or to randomisation. No time limit was set on this treatment and dentists/hygienists were instructed to scale the teeth and root surfaces until they were free of all deposits and smooth to probing

Member of dental team delivering intervention: dentist or hygienist

Frequency of intervention: reinforcement of OHA was provided at the discretion of the dentist/hygienist during the trial and recorded

Intensity of intervention (length of time): no information available

Setting: primary care setting

Disease level: periodontal health, gingivitis or moderate periodontitis (Basic Periodontal Examination (BPE) score 0 to 3)

Outcomes

The primary clinical outcome was inflammation at the gingival margin measured by running a University of North Carolina probe circumferentially around each tooth just within the gingival sulcus or pocket (gingival index of Löe (Löe 1967)). After 30 seconds, bleeding was recorded as being present or absent on the buccal and lingual surface and reported as the percentage of sites (twice the number of teeth) with bleeding. Oral hygiene self-efficacy was measured on a 1 to 7 scale with 7 being extremely confident

Economic net benefits were calculated as mean willingness to pay for services and outcomes (obtained from a general population discrete choice experiment) minus mean health service perspective costs

Secondary outcomes were calculus and clinical probing depth, patient-reported dental quality of life (OHIP-14) (Slade 1997), oral health behaviour and intention, additional private scale and polish treatments, referral and having a plan for better self-care. Providers' beliefs relating to providing OHA and maintenance of periodontal health were collected at 3 years

Notes

Funding: "Funded by the Health Technology Assessment Programme of the National Institute for Health Research, Current Controlled Trials number ISRCTN56465715"

Sample size calculation: "Oral health advice $(\mathrm{OHA})$ : to calculate the sample size required to estimate the main effect of $\mathrm{OHA}$, it is recognised that the data are contained within a cluster RCT. Assuming a conservative estimate of the intracluster correlation (ICC) of 0.0531 , a cluster RCT of 50 dentists collecting information from 25 patient participants each $\left(25^{\star} 25=625\right.$ patients per arm) will have $90 \%$ power to detect a difference of $7.5 \%$. Should the correlation be 0.1 , the trial will still have approximately $80 \%$ power to detect a difference of $7.5 \% "$

Adverse effects: none reported

Declarations/conflicts of interest: all authors declare: no support from any organisation for the submitted work; no financial relationships with any organisations that might have an interest in the submitted work in the previous 3 years; no other relationships or activities that could appear to have influenced the submitted work

\section{Risk of bias}

Bias Authors' judgement Support for judgement

Random sequence genera- Low risk tion (selection bias)

Quote: "A computer-generated randomization system was used and managed by the Centre for Healthcare Randomised Trials (CHaRT), University of Aberdeen, UK. Both dentist and patient participants underwent randomization with even allocation. The minimization algorithms for the practice allocation were, employs dental hygienist (yes/no) and has 3 or more dentists (yes/no), and for patient allocation absence of gingival bleeding on probing (yes/no), highest BPE score 3 (yes/no) and current smoking (yes/no)"

$\begin{array}{ll}\begin{array}{l}\text { Allocation concealment } \\ \text { (selection bias) }\end{array} & \text { Quotes: "Dentist allocation to OHA group: recruited dentists will be allocated } \\ & \text { to routine or personalised OHA by minimisation on } 2 \text { factors - (i) practice em- } \\ \text { ploys dental hygienist (yes/no) and (ii) practice size ( } 2 \text { or less dentists in prac- }\end{array}$

One-to-one oral hygiene advice provided in a dental setting for oral health (Review)

Copyright @ 2018 The Cochrane Collaboration. Published by John Wiley \& Sons, Ltd. 
tice/3 or more dentists)" and "Patient participant allocation to PI group: allocation will take place once the outcome assessor has completed the baseline outcome assessment and will be minimised on (i) absence of gingival bleeding on probing (yes/no), (ii) highest sextant BPE score (BPE less than 3/BPE 3) and (iii) current smoking (yes/no)"

Blinding of participants Unclear risk and personnel (performance bias)

All outcomes
Quotes: "Both dentist and patient participants underwent randomization with even allocation. The minimization algorithms for the practice allocation were, employs dental hygienist (yes/no) and has 3 or more dentists (yes/no), and for patient allocation absence of gingival bleeding on probing (yes/no), highest BPE score 3 (yes/no) and current smoking (yes/no);" "This is a 5-year multicentre, randomized, open trial with blinded outcome evaluation" and "Patient participant allocation to PI group...... A letter will be sent to patient participants to inform them of their trial group allocation and the practice will be contacted by the TCOD to arrange the first intervention appointment"

Comments: study reported as evaluator blinded however personnel delivering intervention would know group allocation. Blinding of participants was not possible; it is unclear the influence this would have on the risk of bias for this domain

\begin{tabular}{|c|c|c|}
\hline $\begin{array}{l}\text { Blinding of outcome as- } \\
\text { sessment (detection bias) } \\
\text { All outcomes }\end{array}$ & Low risk & $\begin{array}{l}\text { Quote: "Clinical outcomes were recorded by blinded assessors at baseline } \\
\text { and } 3 \text { years. Outcome assessor training was provided to ensure intra- and in- } \\
\text { terassessor alignment" }\end{array}$ \\
\hline
\end{tabular}

All outcomes terassessor alignment"

Incomplete outcome data Low risk

(attrition bias)

Quote: "Attendance (70\%) at the 3-year clinical examination and return of the

All outcomes

final questionnaire $(75 \%)$ was balanced across groups"

Comment: all participants accounted for and reported on

\begin{tabular}{lll}
\hline $\begin{array}{l}\text { Selective reporting (re- } \\
\text { porting bias) }\end{array}$ & Low risk & All outcomes in methods section were reported \\
\hline Other bias & Low risk & No apparent other bias \\
\hline
\end{tabular}

Schmalz 2018

$\begin{array}{ll}\text { Methods } & \text { Trial design: parallel (6 arms) } \\ & \text { Location: Department of Cariology, Endodontology and Periodontology, University of Leipzig, Ger- } \\ \text { many }\end{array}$

Number of centres: 1

Duration: between May 2015 and November 2016. Participants followed-up at 12 weeks

Participants
Participants: a total of 162 participants were screened for eligibility, of which 150 were included into the study

Inclusion criteria: healthy oral conditions (i.e. no active carious lesions, which require invasive treatment ( $D-T=0)$, and no periodontal treatment need (PSR/PSI $\leq 2)$ ); a minimum number of 20 remaining teeth; age between 18 years and 30 years; ability to give informed consent and voluntary participation

Exclusion criteria: age < 18 years or $>30$ years; inability to participate due to severe general diseases; diseases affecting motor skills; presence of metabolic diseases (diabetes mellitus); infectious diseases (hepatitis A/B/C, HIV); renal insufficiency; seizure or neurological disorders; pregnancy; addiction (alcohol, drugs); required antibiotic prophylaxis due to endocarditis risk or immunosuppression (e.g. due to organ transplantation); dental background (dentist, dental student, or related occupation); allergies against using toothpaste or other materials used within the study; presence of dental (carious lesions 
with a cavitation of the tooth surface) and/or periodontal treatment need (periodontal probing depth > $3.5 \mathrm{~mm})$

Age at baseline (years): all groups: $23.44 \pm 2.89$; Group A1 and Group A2: $22.98 \pm 2.52$; Group B1 and Group B2: $23.66 \pm 2.95$; Group C1 and Group C2: $23.70 \pm 3.13$

Gender: all: female 112 (81\%), male 27 (19\%); Group A1 and Group A2: female 38 (83\%), male 8 (17\%); Group B1 and Group B2: female 35 (78\%), male 10 (22\%); Group C1 and Group C2: female 39 (81\%), male $9(19 \%)$

Number randomised: all 150 participants. Group A1: 25; Group A2: 25; Group B1: 25; Group B2: 25; Group C1: 25; Group C2: 25

Number evaluated: all 131 participants. Group A1: 21; Group A2: 22; Group B1: 22; Group B2: 22; Group C1: 22; Group C2: 22

Interventions
Group A1: powered toothbrush (Professional Care ${ }^{\mathrm{TM}} 7000$, Procter \& Gamble GmbH, Schwalbach am Taunus, Germany) with no instruction

Group A2: powered toothbrush (Professional Care ${ }^{\mathrm{TM}} 7000$, Procter \& Gamble GmbH, Schwalbach am Taunus, Germany) received 1 standardized instruction of the toothbrush system according to the manufacturers recommendations

Group B1: powered toothbrush (SoniCare ${ }^{\mathrm{TM}}$, Philips GmbH, Hamburg, Germany) with no instruction

Group B2: powered toothbrush (SoniCare ${ }^{\mathrm{TM}}$, Philips $\mathrm{GmbH}$, Hamburg, Germany) received 1 standardized instruction of the toothbrush system according to the manufacturers recommendations

Group C1: manual toothbrush (elmex ${ }^{\circledast}$ INTERX, CP GABA GmbH, Hamburg, Germany) with no instruction

Group C2: manual toothbrush (elmex ${ }^{\oplus}$ INTERX, CP GABA GmbH, Hamburg, Germany) received instruction on 1 occasion to use the Fones technique

All participants used the same toothpaste (Sensodyne ${ }^{\circledR}$ Fluoride; GlaxoSmithKline Oral Health Care $\mathrm{GmbH}$, Brühl, Germany) during the whole study

All groups were required to brush twice daily for 2 minutes to 3 minutes and to abandon other oral hygiene aids such as dental floss and/or interdental brushes or mouthrinses

Prophylaxis provided: participants received a professional tooth cleaning including the removal of supragingival calculus, biofilm, and extrinsic discolourations as well as polishing of the tooth surfaces

Member of dental team delivering intervention: dentist

Frequency of intervention: instruction groups: 1 visit with $\mathrm{OHA}$

Intensity of intervention (length of time): not reported

Setting: secondary care

Disease level: healthy individuals with no active carious lesions and not requiring periodontal treatment

Outcomes

Clinical outcomes: "Gingival inflammation was evaluated using the Papilla Bleeding Index (PBI) (Lange 1977) and the Gingival Index (GI) by Löe and Silness (Löe 1963). To assess PBI, gingival sulcus was spread out using a periodontal probe (PCP 15, Hu-Friedy, Chicago, IL, USA); the PBI score ranges from score 0 (no bleeding) to score 4 (profuse bleeding). Furthermore, the GI was used to assess changes of the gingiva. A score from 0 (normal gingiva, inflammation-free, no discolouration, no bleeding) to score 3 (severe inflammation, reddening and swelling, tendency toward spontaneous bleeding or ulceration) was used. After assessment of gingival inflammation, plaque extension was evaluated using the Plaque Index by Quigley and Hein (QHI) modified by Turesky et al after using a plaque disclosing agent (Mira-2-Ton ${ }^{\circledR}$, Hager score $5=$ plaque extending to the coronal third). Furthermore, the Marginal Plaque Index (MPI) by Deinzer et al was used to differentiate plaque extension at the gingival mar- 
Schmalz 2018 (Continued)

gin (Deinzer 2014). The evaluation was performed on 8 measuring points at each tooth (score $0=$ no plaque; score 1 = plaque)"

Notes

Funding: "Philips GmbH (Hamburg, Germany), CP GABA (GmbH, Hamburg, Germany), and GlaxoSmithKline Oral Health Care GmbH (Brühl, Germany) for providing materials for the study"

Sample size calculation: "This RCT should detect differences based on PBI and QHI of an effect size $\delta$ $=1$ with a power of $80 \%$. Under estimation of normal distribution, for a 2 -sided $t$ test at the significance level of 5\%, 20 participants in each group were required. To compensate potential dropouts, 20 to 25 participants per group should be included"

Adverse effects: not reported

Declarations/conflicts of interest: "The authors declare that they have no conflict of interest"

\section{Risk of bias}

Bias Authors' judgement Support for judgement

Random sequence genera- Unclear risk tion (selection bias)

Quote: "Participants were randomly divided into 3 groups (OR, SA, MTB; $n=50$ each group) with 2 subgroups each: participants receiving no instructions (NI) and participants receiving instructions (I) ( $n=25$ per group). Randomization and attribution to groups were performed by an independent examiner (DZ). The plaque accumulation at screening examination of each patient was classified into 3 categories using the baseline modified Quigley-Hein Plaque Index (mod QHI) as follows: good (2). Based on these categories, as well as smoking habits, gender, and left-handedness, a matching was performed according to previous studies of this working group (Schmalz 2017b; Schmickler 2014; Schmickler 2016), to ensure comparable groups"

Comment: insufficient information available regarding randomisation method

\begin{tabular}{|c|c|c|}
\hline $\begin{array}{l}\text { Allocation concealment } \\
\text { (selection bias) }\end{array}$ & Unclear risk & $\begin{array}{l}\text { Not mentioned } \\
\text { Comment: insufficient information on allocation concealment }\end{array}$ \\
\hline $\begin{array}{l}\text { Blinding of participants } \\
\text { and personnel (perfor- } \\
\text { mance bias) } \\
\text { All outcomes }\end{array}$ & Unclear risk & $\begin{array}{l}\text { Not mentioned regarding participant blinding } \\
\text { Quote: "With respect to their subgroup (I or NI), participants got a brush-spe- } \\
\text { cific instruction (DZ)" } \\
\text { Comment: personnel delivering intervention (DZ) would have been aware of } \\
\text { intervention group. Blinding of participants was not possible; it is unclear the } \\
\text { influence this would have on the risk of bias for this domain }\end{array}$ \\
\hline $\begin{array}{l}\text { Blinding of outcome as- } \\
\text { sessment (detection bias) } \\
\text { All outcomes }\end{array}$ & Low risk & $\begin{array}{l}\text { Quote: "All study-related examinations were performed under standardized } \\
\text { conditions by a skilled, calibrated, and blinded dentist (kappa }>0.8, \mathrm{KK} \text { ) in the } \\
\text { Department of Cariology, Endodontology and Periodontology, University of } \\
\text { Leipzig, Germany" } \\
\text { Comment: outcome assessor blinded to participant group }\end{array}$ \\
\hline
\end{tabular}

Incomplete outcome data Low risk Comment: dropouts reported and similar across intervention groups
(attrition bias)

All outcomes

\begin{tabular}{lll}
\hline $\begin{array}{l}\text { Selective reporting (re- } \\
\text { porting bias) }\end{array}$ & Low risk & All outcomes reported on \\
\hline Other bias & Low risk & No apparent other bias \\
\hline
\end{tabular}


Methods Trial design: parallel ( 3 arms)

Location: Department of Periodontology, School of Dentistry, University of Lund, Malmö, Sweden Number of centres: 1

Study Duration: recruitment and follow-up dates not reported. Participants followed-up at 12 weeks

Participants

Participants: 69 white-collar employees at a shipyard in Malmö, Sweden

Inclusion criteria: not reported

Exclusion criteria: not reported

Age at baseline (years): 5-Visit Group: 35.3 years (SE 0.8); 2-Visit Group: 36.3 years (SE 0.8); Control Group: 35.6 years (SE 35.6)

Gender: 5-Visit Group: female 3 (13\%), male 20 (87\%); 2-Visit Group: female 3 (13\%), male 20 (87\%); Control Group: female 3 (13\%), male 20 (87\%)

Number randomised: 69 (5-Visit Group: 23; 2-Visit Group: 23; Control Group: 23)

Number evaluated: 41 (5-Visit Group: 19; 2-Visit Group: 22; Control Group: not available)

5-Visit Group: plaque control program given during 5 visits. The interval between each of the visits was 2 days to 3 days. Each visit was scheduled as a 30- minute appointment

2-Visit Group: plaque control program given during 2 visits. The 2 visits were spaced 7 days to 10 days apart and were scheduled as 60-minute appointments.

No other treatment except the oral hygiene instruction was provided at the plaque control visits. Oral hygiene instructions were given by 2 plaque control nurses.

The intervention program was based on the following educational aids and principles:

- a step-by-step approach was used in teaching the patients the performance of oral hygiene procedures. New devices or techniques were not recommended or used until the patients had tried and found that those previously used were insufficient

- the teaching was as far as possible based upon positive reinforcement. Negative criticism was kept at a minimum

- plaque-disclosing dyes and mouth mirrors were used and given to the patients

- repeated charting of plaque was used for instruction and feedback to the patients

Control: did not receive $\mathrm{OHA}$, however they were omitted at the 12-week examination as many of these patients had started restorative care and had been given OHA. This group is not included further in this review

Prophylaxis provided: "After the initial examination all participants received a dental prophylaxis. This was given in 1 visit and consisted of scaling and removal of large overhangs to remove interference with plaque control. The treatment was provided by a dental hygienist and completed within 1 hour. 2 months later the experiment started (baseline examination). This delay was used in order to ensure that reduction in bleeding tendency and periodontal pocket depth resulting from the initial prophylaxis would have occurred prior to the start of the experiment"

Member of dental team delivering intervention: dental nurse and hygienist

Frequency of intervention: intervention groups: 5 visits with $\mathrm{OHA}$ or 2 visits with $\mathrm{OHA}$ 
Intensity of intervention (length of time): 5-Visit Group: 150 minutes; 2-Visit Group: 120 minutes

Setting: secondary care

Disease level: not reported

Plaque score: the percentage of tooth surfaces (mesial, buccal, distal and lingual) with plaque. Plaque
was defined as the soft material on the tooth surfaces which stains dark red with an erythrosine-dis-
closing solution (Diaplac Rondell, Astra, Sweden) and which could be removed easily with the blunt
side of a probe. The mesial and distal of the teeth were evaluated from the vestibular aspect
Periodontal pocket score: percentage of tooth surfaces (mesial, buccal, distal and lingual) with peri-
odontal pockets equal to or greater than $5 \mathrm{~mm}$
Gingival bleeding score: percentage of gingival areas (mesial, buccal, distal and lingual) showing bleed-
ing after probing for pocket measurement
Number of teeth
Age

Notes

Funding: not reported

Sample size calculation: not reported

Adverse effects: not reported

Declarations/conflicts of interest: not reported

\section{Risk of bias}

\section{Bias \\ Authors' judgement Support for judgement}

Random sequence genera- Unclear risk tion (selection bias)
Quote: "In an attempt to obtain comparable groups of subjects the individuals were first matched in combinations of 3 with the help of a computer. Different weight was attached to the above 5 recordings. The plaque score was given the greatest weight followed by their periodontal pocket score, gingival bleeding score, number of teeth and age, respectively. The 3 individuals in a matched combination were randomly placed in 1 of the 3 study groups. Males and females were treated separately. Each group originally contained 23 individuals (20 males and 3 females)"

Comment: insufficient information on the method of random sequence generation

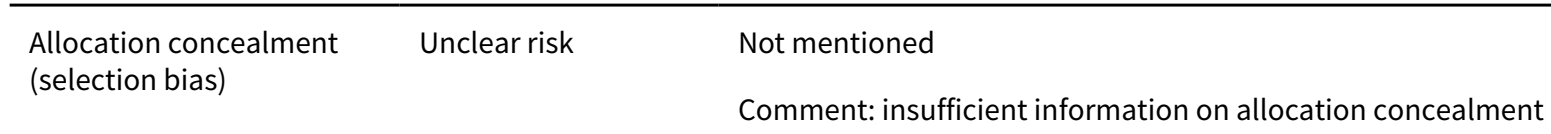

Blinding of participants Unclear risk and personnel (performance bias)

All outcomes

Quotes: "The treatment was provided by a dental hygienist and completed within 1 hour" and "Oral hygiene instructions were given by 2 plaque control nurses. At random, half of the participants in each of the 2 experimental groups was assigned to 1 of the nurses and the remaining half to the other nurse"

Comment: patient and personnel would have been aware of allocation ( 5 visits versus 2 visits). Blinding of participants was not possible; it is unclear the influence this would have on the risk of bias for this domain

\begin{tabular}{|c|c|c|}
\hline $\begin{array}{l}\text { Blinding of outcome as- } \\
\text { sessment (detection bias) } \\
\text { All outcomes }\end{array}$ & Low risk & $\begin{array}{l}\text { Quotes: "The clinical examinations were performed by } 2 \text { of the authors (GS } \\
\text { and NN). Each of these examiners scored the same subjects throughout the ex- } \\
\text { periment. The } 2 \text { examiners scored equal numbers of subjects in each of the } 3\end{array}$ \\
\hline
\end{tabular}


study groups, and were not aware to which study group the individual subjects belonged" and "Each of these (2) examiners scored the same subjects throughout the experiment....and were not aware to which study group the individual subjects belonged"

Comment: the examiner did not know which group the participants they were assessing had been assigned to

Incomplete outcome data Low risk (attrition bias)

All outcomes 12-week follow-up data reported for intervention groups as per study protocol with additional 12-, 24-, 36- and 48-month data also reported

12-month follow-up 5-Visit Group: 23 to 19; 2-Visit Group: 23 to 22

24-month follow-up 5-Visit Group: 19 to 17; 2-Visit Group: 22 to 21

36-month follow-up 5-Visit Group: 17 to 19; 2-Visit Group: 21 to 19

48-month follow-up 5-Visit Group: 19 to 18; 2-Visit Group: 19 to 20

Comment: all groups data reported as per initial study protocol

Selective reporting (re- Low risk All outcomes in methods section were reported

porting bias)

Other bias Low risk No apparent other bias

Tedesco 1992

Methods Trial design: parallel (2 arms)

Location: Oral Health Enhancement Clinic, Greater Buffalo metropolitan area, New York, USA

Number of centres: 1

Study Duration: recruitment and follow-up dates not reported. Participants followed-up at 9 months

Participants

Participants: individuals between the ages of 21 and 65 were recruited from the Greater Buffalo metropolitan area

Inclusion criteria: participants were required to have mild to moderate gingivitis, defined as at least $55 \%$ of oral sites with gingival bleeding on probing (scores of 2 or 3 on the Löe and Silness gingival index (Löe 1963; Silness 1964)) and to have at least at least 10 teeth per dental arch

Exclusion criteria: all prospective participants were required to have a screening visit prior to acceptance into the study and were disqualified if they had any area with periodontal attachment loss greater than $1.5 \mathrm{~mm}$, radiographic evidence of bone loss greater than 25\% (anterior/posterior bitewing radiographs or periapical radiographs), or previous periodontal therapy. Study participants were required to be in good health (no diabetes or heart disease), not pregnant, and not taking medications, including antibiotics, for any chronic diseases

Age at baseline (mean years): intervention group: 32.9; control group: 31.3

Gender: intervention group: female 56 (51\%), male 55 (49\%); control group: female 24 (43\%), male 32 $(57 \%)$

Number randomised: 167 (intervention group: 111; control group: 56)

Number evaluated: 91 (intervention group: 62; control group: 29) 
Tedesco 1992 (Continued)

Interventions
Participants visited the clinic 7 times over a 14-month period. Visits 1 and 2 provided baseline measures, and visits 2 through 5 were intervention (experimental) or control visits. Visits 6 and 7 were 3month and 9-month follow-up visits, respectively

Intervention: at visit 2, study participants received traditional oral hygiene instruction in the same manner as control group participants. The same standardized delivery and management of the visit were employed. Before the second prophylaxis was performed, however, study participants were shown a phase contrast slide of their own subgingival flora on a video monitor. A videotape record was made simultaneously. During video monitor viewing, the hygienist described and labelled the patient's oral pathogens and explained their association to the development of periodontal disease. The patient was encouraged to ask questions and offer his or her reactions to the video monitor display. The patient received a complete prophylaxis and then a new slide was made, viewed on the video monitor and recorded on videotape to show the subject the relative absence of bacteria. The hygienist emphasized that this was the picture of a healthy mouth. Emphasis was placed on how the patient can control the health of his/her mouth and always "possess" this picture of wellness. Visits 3 , 4, and 5, following 1 month after each other, repeated the intervention, with the subject watching the videotape from the previous visit and viewing a fresh slide on the video monitor made at the visit in progress. During these visits emphasis was placed on the patient's accomplishments; i.e. performance accomplishments. The patient's and hygienist's conversations and descriptions of the video monitor display were linked to the plaque index and gingival index scores, problem areas, etc., detected clinically by the hygienist. At visits 6 (3-months post-intervention) and 7 (9-months post-intervention) assessments were taken as follow-up procedures, and a final prophylaxis was performed before terminating study participation

Control: at visit 2 control group participants received traditional oral hygiene instruction that included brushing and flossing techniques from a hygienist. Study participants were also given feedback on their entry state of oral hygiene, with problem areas for improvement emphasized. The hygienist also explained the range and meaning of plaque index and gingival index scores. Control group participants were encouraged to present problems and ask questions. Before dismissal, a complete oral prophylaxis was performed. Psychological and social assessment instruments were also administered during these visits. At visits, 3, 4, and 5 patients were given feedback on how clean their teeth and gingival surfaces were, and what areas needed most improvement, and assessments (clinical, psychological, and social) were taken. At visits 6 and 7 follow-up assessments were taken and a final prophylaxis was performed

Prophylaxis provided: prophylaxis provided to both groups

Member of dental team delivering intervention: hygienist

Frequency of intervention: intervention group: 7 visits with 4 visits of $\mathrm{OHA}$; control group: 7 visits with 4 visits of $\mathrm{OHA}$

Intensity of intervention (length of time): intervention group: not reported; control group: not reported

Setting: not reported

Disease level: mild to moderate gingivitis

Self-efficacy assessed via Oral Health Behaviour Expectation Scale

Theory of reasoned action variables assessed via Theory of Reasoned Action Oral Health Scale

Self-reported brushing and flossing behaviours

Plaque accumulation (Löe and Silness plaque index, Löe 1963)

Gingival inflammation (Löe and Silness gingival index, Silness 1964)

Brushing and flossing skill observation

Notes

Funding: "The study was supported by NIH-NIDR grant DE-07335"

Sample size calculation: not reported 
Declarations/conflicts of interest: not reported

\section{Risk of bias}

Bias Authors' judgement Support for judgement

Random sequence genera- Unclear risk tion (selection bias)

Allocation concealment Unclear risk
(selection bias)

Unclear risk

Blinding of participants and personnel (performance bias)

All outcomes

Quote: "Subjects were randomly assigned to experimental or control groups"

Comment: insufficient information on the method of random sequence generation

Not mentioned

Comment: insufficient information on allocation concealment

Quote: "All procedures were trained to a written script and intervention protocol. In addition to periodic recalibration exercises, the hygienist was periodically monitored for appropriate intervention delivery, communication, and patient feedback"

Comment: patient and personnel would have been aware of allocation. Blinding of participants was not possible; it is unclear the influence this would have on the risk of bias for this domain

\begin{tabular}{|c|c|c|}
\hline $\begin{array}{l}\text { Blinding of outcome as- } \\
\text { sessment (detection bias) } \\
\text { All outcomes }\end{array}$ & Unclear risk & $\begin{array}{l}\text { Quote: " } 1 \text { hygienist completed all the plaque and gingival assessments follow- } \\
\text { ing the screening. She received calibration training prior to her work on this } \\
\text { project. All procedures were trained to a written script and intervention proto- } \\
\text { col. In addition to periodic recalibration exercises, the hygienist was periodi- } \\
\text { cally monitored for appropriate intervention delivery, communication, and pa- } \\
\text { tient feedback" }\end{array}$ \\
\hline
\end{tabular}

Comment: it is possible that there was only 1 hygienist involved who provided intervention and outcome assessment. No response from contact author regarding further information. Unclear if outcome would have been influenced

Incomplete outcome data Low risk (attrition bias)

Quote: "At the last intervention visit (Visit 5), 18.6\% of the sample did not return. This dropout rate increased to $28.7 \%$ and $45.5 \%$ by Visit 6 , (3-month follow-up), and Visit 7 (9-month follow-up), respectively. Dropout rates were similar for both experimental and control groups; by the end of the study, $52 \%$ of the control group and $56 \%$ of the experimental group remained. Dropouts at Visits 6 and 7 were disproportionally represented in the lower income and education groups (less than high school education and income under $\$ 20,000$ ). In addition, there was a difference for race, with proportionally more non-Caucasian minorities leaving the study by Visits 6 and 7 than Caucasian subjects (who outnumbered minority groups 4:1 at the beginning of the study). When compared with participants, dropouts at Visits 6 and 7 had higher plaque and gingival index scores at Visits 5 and 6 . The same pattern emerged for per cent "0" gingival index scores; that is, dropouts had a lower percentage of nonbleeding sites (poorer oral health status) when compared with all study participants"

\begin{tabular}{lll}
\hline $\begin{array}{l}\text { Selective reporting (re- } \\
\text { porting bias) }\end{array}$ & Low risk & All outcomes in methods section were reported \\
\hline Other bias & Low risk & $\begin{array}{l}\text { Quote: "Prospective subjects were offered } 3 \text { free cleanings and free oral health } \\
\text { education for their participation in } 7 \text { visits at the Oral Health Enhancement } \\
\text { Clinic" }\end{array}$
\end{tabular}




$\begin{array}{ll}\text { Methods } & \text { Trial design: parallel (6 groups) } \\ \text { Location: Department of Periodontology of the Academic Centre for Dentistry, Amsterdam, the Nether- } \\ \text { lands }\end{array}$

\section{Number of centres: 1}

Study Duration: recruitment November 2009 to November 2010. Participants followed-up at 12 months

Participants: "Participants were students recruited from different universities and colleges in and around Amsterdam by e-mail and flyers"

Inclusion criteria: $\geq 18$ years of age, have a minimum of 5 evaluable teeth per quadrant, and have moderate to advanced gingivitis ( $\geq 40 \%$ bleeding on marginal probing (BOMP)) (Lie 1998; Van der Weijden 1994)

Exclusion criteria: open caries, pockets of $4 \mathrm{~mm}$ to $5 \mathrm{~mm}$ in combination with gingival recession or pockets of $\geq 6 \mathrm{~mm}$, as assessed according to the Dutch Periodontal Screening Index (DPSI) scores 3+ and 4 (Mantilla Gómez 2001; Van der Velden 2009), orthodontic appliances or removable (partial) dentures, a history of allergic reactions to erythrosine and/or any of the mouthrinse components, pregnancy, systemic disease or any adverse medical history or long-term medication that might interfere with the response variables. No restriction with respect to smoking status was applied

Age at baseline (mean years): Control I: 21.1 (SD 2.66); Control II: 21.4 (SD 2.99); OHI: 21.2 (SD 2.91); PP: 21.6 (3.36); OA + CHX: 21.9 (SD 3.17); COMBI: 20.6 (SD 2.19)

Gender: male/female: Control I: 13/27; Control II: 11/33; OHI: 10/33; PP: 7/35; OA + CHX: 6/34; COMBI $6 / 32$

Number randomised: 267 (Control I: 44, Control II: 45, OHI: 44, PP: 45, OA + CHX: 44, COMBI: 45)

Number evaluated: 247 (Control I: 40, Control II: 44, OHI: 43, PP: 42, OA + CHX: 40, COMBI: 38)

Control I and Control II: the participants in control groups I and II were instructed to adhere to this basic oral hygiene regimen only. To minimize the potential Hawthorne effect (Adair 1984), the clinical parameters of Control I were assessed at day 0 , baseline ( 3 weeks later) and 12 months later. The clinical parameters of all other groups were assessed at day 0, baseline, 4, 7, 10 and 12 months

OHI Group: the oral hygiene instruction group $(\mathrm{OHI})$ received the same interventions as those in the control groups. Additionally they received professional individual oral hygiene instruction (at day 0 )

PP Group: the professional prophylaxis group (PP) received a professional oral prophylaxis from an experienced dental hygienist at day 0 . This group is not further included in this review

OA + CHX Group: "During the treatment phase from day 0 until baseline, the oxygenating-agent (OA) and chlorhexidine $(\mathrm{CHX})$ group $(\mathrm{OA}+\mathrm{CHX})$ were instructed to rinse with a combination of the OA Bocasan (Oral-B Laboratories, Boston, MA, USA) and CHX 0.20\% (Corsodyl; GlaxoSmithKline, Zeist, the Netherlands) twice daily for 3 weeks in addition to the basic oral hygiene." This group is not included further in this review 
COMBI Group: "In addition to the basic oral hygiene regimen, participants in the COMBI group received all 3 supplementary preventive interventions: $\mathrm{OHI}$, PP and OA + CHX." This group is not included further in this review

Prophylaxis provided: only for those in the PP Group. "Subjects were not allowed to use any other dental products or interdental cleaning aids during the study and/or to undergo a dental prophylaxis during routine dental check-ups"

Member of dental team delivering intervention: hygienist

Frequency of intervention: 3-week treatment phase, intervention administered once

Intensity of intervention (length of time): not reported

Setting: Department of Periodontology of the Academic Centre for Dentistry, Amsterdam

Disease level: not reported - students in Amsterdam

Outcomes Baseline, 4 months, 7 months, 10 months, 12 months:

- staining was assessed (NLHH) at 4 sites per tooth, according to the Grundemann Modification of the Stain Index (GMSI), on a scale of 0 to 3 (Gründemann 2000)

- gingival health was assessed at 6 sites (mesio-buccal, mid-buccal, disto-buccal, mesio-lingual, midlingual and disto-lingual) around the selected quadrants by scoring BOMP on a scale of 0 to 2 (Lie 1998; Van der Weijden 1994)

- dental plaque was also assessed at 6 sites after disclosing with Mira-2-Ton (Hager \& Werken GmbH \& Co KG, Duisburg, Germany), and scores were based on the modified Quigley and Hein (Quigley 1962) plaque index (QHPI) with a scale of 0 to 5

12 months only: "Upon completion of the clinical assessments, all participants were asked to complete a questionnaire designed to evaluate their attitudes towards the assigned intervention. The participants answered the questions by placing a vertical mark on a $10-\mathrm{cm}$-long uncalibrated line (the visual analogue scale, VAS); the left of this line represented the 'negative' extreme, whereas the right represented the 'positive' extreme. As such, a mean score of 5 would represent an 'average' score, being neither positive nor negative"

Notes

Funding: The Netherlands Organisation for Health Research and Development

Sample size calculation: "The sample size of 40 participants per group was calculated a priori (PS: Power and Sample Size program) (Dupont 1990)

based on a pooled standard deviation ( $r$ ) of 0.23 (as taken from the gingivitis scores in a previous 6month mouthrinse study by Paraskevas et al (Paraskevas 2005) and a detectable difference (d) of 0.18 (between groups) with an $a=0.05$ to obtain $80 \%$ power"

\section{Adverse effects: not reported}

Declarations/conflicts of interest: "ACTA Dental Research BV received financial support from The Netherlands Organization for Health Research and

Development (ZonMW). The authors designed, performed and analysed the study project without any interference from other parties. Van der Weijden, Rosema and Slot have formerly received either external advisor fees, lecturer fees or research grants from companies that produce mouthwash products. Among these were Colgate, Dentaid, GABA, Johnson \& Johnson Lactona, Oral-B, Philips, Procter \& Gamble, Sara Lee, Sunstar, and Unilever. All authors declare that they have no conflicts of interest"

Risk of bias

\begin{tabular}{lll}
\hline Bias & Authors' judgement & Support for judgement \\
\hline $\begin{array}{ll}\text { Random sequence genera- } \\
\text { tion (selection bias) }\end{array}$ & Low risk & $\begin{array}{l}\text { Quote: "Randomization for group and quadrant selection was performed (by } \\
\text { CB) using true random numbers generated by sampling } \\
\text { and processing a source of entropy outside the computer. The source was at- } \\
\text { mospheric noise, which was sampled and fed into a computer without any }\end{array}$ \\
\hline
\end{tabular}


Van Leeuwen 2017 (Continued)

buffering mechanisms in the operating system (www.random.org). The study co-ordinator assigned the participants to their randomly chosen group"

\begin{tabular}{|c|c|c|}
\hline $\begin{array}{l}\text { Allocation concealment } \\
\text { (selection bias) }\end{array}$ & Low risk & $\begin{array}{l}\text { Quote: "Allocation was concealed by using sequentially numbered, opaque, } \\
\text { sealed envelopes (SNOSE-method) (Schulz 2002)" }\end{array}$ \\
\hline $\begin{array}{l}\text { Blinding of participants } \\
\text { and personnel (perfor- } \\
\text { mance bias) } \\
\text { All outcomes }\end{array}$ & Unclear risk & $\begin{array}{l}\text { Quote: "The participants were not informed about the group allocation" } \\
\text { Comment: personnel delivering oral hygiene instruction intervention would be } \\
\text { aware of which group participant was in. Blinding of participants was not pos- } \\
\text { sible; it is unclear the influence this would have on the risk of bias for this do- } \\
\text { main }\end{array}$ \\
\hline $\begin{array}{l}\text { Blinding of outcome as- } \\
\text { sessment (detection bias) } \\
\text { All outcomes }\end{array}$ & Low risk & $\begin{array}{l}\text { Quotes: "The examiners were blinded to treatment randomization, and the } \\
\text { records of earlier examinations were not available at the time of re-examina- } \\
\text { tion" and "The examiners were blinded with respect to treatment allocation" }\end{array}$ \\
\hline $\begin{array}{l}\text { Incomplete outcome data } \\
\text { (attrition bias) } \\
\text { All outcomes }\end{array}$ & Low risk & $\begin{array}{l}\text { Comment: all participants lost to follow-up accounted for including reason } \\
\text { (e.g. "used another dentifrice," "absent without notice," etc.) }\end{array}$ \\
\hline $\begin{array}{l}\text { Selective reporting (re- } \\
\text { porting bias) }\end{array}$ & Low risk & All outcomes in methods section were reported \\
\hline Other bias & Low risk & No apparent other bias \\
\hline
\end{tabular}

\section{Weinstein 1996}

$\begin{array}{ll}\text { Methods } & \text { Trial design: parallel (4 arms) } \\ & \text { Location: Italy } \\ & \text { Number of centres: } 1 \\ & \text { Study Duration: recruitment and follow-up dates not reported. Participants followed-up at } 60 \text { days }\end{array}$

Participants Participants: "All 20 subjects presented periodontic problems for which long-term behavioural main-
tenance of oral hygiene routines were prescribed by the periodontist"

Inclusion criteria: not reported

Exclusion criteria: not reported

Age at baseline (mean years): not reported by group, age range was 32 to 50 years

Gender: group breakdown not provided: female 9 (45\%), male 11 (55\%)

Number randomised: 20 (Intervention Group A: 5; Intervention Group B: 5; Intervention Group C: 5; and Control Group D: 5)

Number evaluated: 20 (Intervention Group A: 5; Intervention Group B: 5; Intervention Group C: 5; and Control Group D: 5)

Interventions $\quad$ "Core procedures and the duration of visits were kept standard for all groups"
"Like all the other groups, these patients had also received the same instructions and suggestions con-
cerning oral hygiene, etc."

Intervention group A: "Received standard instructions on Bass' technique.... were required to call in the results of the plaque score self-evaluations twice weekly to their periodontist who provided them 
with additional verbal feedback about their maintenance status. ..The results of plaque score self-evaluation using a detecting pill were subjective and as a consequence, the patients' feedback was approximate according to the value of the self-evaluation. These patients, like any other group, had to visit their periodontist monthly for the control of their full mouth plaque score (FMPS)"

Intervention Group B: "...examined directly by their periodontists $2 \mathrm{x}$ weekly who provided them with objective feedback about their status. In addition the periodontists gave them positive social reinforcement contingent upon having maintained the plaque score within acceptable limits"

Intervention Group C: this group received the same interventions as those in Intervention Group B. Additionally they carried out a self-monitoring system by completing an 'oral hygiene task checklist'

Control (Group D): "Consisted of instructions and demonstrations of Bass' technique of dental flossing, etc.. The patients were invited to take again medical examination after 1 and 2 months. In that occasion the full mouth plaque was notified"

Prophylaxis provided: none reported

Member of dental team delivering intervention: not explicitly specified, however after reviewing the text the review authors were confident the intervention was undertaken by a member of the dental team

Frequency of intervention: Intervention Group A: 3 visits with twice week phone call to periodontist to report self-evaluated plaque score; Intervention Group B: approximately 16 visits with OHA (twice weekly examinations by periodontist); Intervention Group C: approximately 16 visits with OHA (twice weekly examinations by periodontist) and daily completion of oral hygiene task checklist; Control Group D: 3 visits

Intensity of intervention (length of time): Intervention Group A: not reported; Intervention Group B: not reported; Intervention Group C: not reported; Control Group D: not reported

Setting: not reported

Disease level: periodontal patients - disease level not reported

Outcomes

The effects on compliance of the different methods of patient's treatment were measured using the Full Mouth Plaque Score (FMPS) according to the procedure suggested by O'Leary, Drake and Naylor (O'Leary 1972)

Notes Funding: not reported

Sample size calculation: not reported

Adverse effects: not reported

Declarations/conflicts of interest: not reported

\section{Risk of bias}

Bias Authors' judgement Support for judgement

Random sequence genera- Unclear risk tion (selection bias)

Quote: "Were assigned to 1 of 4 groups and given regular evaluation appointment times at random"

Comment: insufficient information provided on sequence generation

$\begin{array}{ll}\begin{array}{l}\text { Allocation concealment } \\ \text { (selection bias) }\end{array} & \text { Unclear risk }\end{array} \quad \begin{aligned} & \text { Quote: "Were assigned to } 1 \text { of } 4 \text { groups and given regular evaluation appoint- } \\ & \text { ment times at random" }\end{aligned}$

Comment: insufficient information provided on allocation concealment 
Weinstein 1996 (Continued)

Blinding of participants Unclear risk Insufficient information provided on who provided interventions. The different and personnel (perforgroups had markedly different number of appointments

mance bias)

All outcomes

Comment: insufficient information provided to make judgement but blinding of participants was likely to be not possible; it is unclear the influence this would have on the risk of bias for this domain

$\begin{array}{lll}\begin{array}{l}\text { Blinding of outcome as- } \\ \text { sessment (detection bias) }\end{array} & \text { Unclear risk } & \text { Blinding of outcome assessment not reported } \\ \text { All outcomes } & \text { Comment: insufficient information provided to make judgement }\end{array}$

\begin{tabular}{ll}
\hline Incomplete outcome data $\quad$ Unclear risk $\quad$ Noported dropouts \\
(attrition bias)
\end{tabular}

(attrition bias)

All outcomes

\begin{tabular}{lll}
\hline $\begin{array}{l}\text { Selective reporting (re- } \\
\text { porting bias) }\end{array}$ & Low risk & All outcomes in methods section were reported \\
\hline Other bias & Low risk & No apparent other bias \\
\hline
\end{tabular}

$\mathrm{BOMP}$ = bleeding on marginal probing; $\mathrm{DH}$ = dental hygienist; DMFS = number of decayed, missing or filled permanent surfaces; dmft = number of decayed, missing or filled primary teeth; DMFT = number of decayed, missing or filled permanent teeth; GA $=$ general anaesthesia; ITT = intention to treat; $\mathrm{OH}=$ oral hygiene; $\mathrm{OHA}=$ oral hygiene advice; $\mathrm{ppm}=$ parts per million; $\mathrm{PSR} / \mathrm{PSI}=$ periodontal screening; $\mathrm{RCT}$ = randomised controlled trial; $\mathrm{SD}=$ standard deviation; $\mathrm{SE}$ = standard error.

\section{Characteristics of excluded studies [ordered by study ID]}

\begin{tabular}{ll}
\hline Study & Reason for exclusion \\
\hline Albandar 1994 & Not in a dental setting \\
& Intervention not provided on a 1-to-1 basis \\
\hline Aleksejūnienè 2018 & School-based: not in a dental setting \\
\hline Almomani 2006 & "Education room": not in a dental setting \\
\hline Almomani 2009 & Intervention not delivered by member of dental team \\
\hline Arrow 2013 & Not in a dental setting: confirmed with author \\
\hline Arunakul 2012 & \begin{tabular}{l} 
Not in a dental setting \\
\hline Arunakul 2015
\end{tabular} \\
\hline Axelsson 1981 & $\begin{array}{l}\text { Following baseline examination the test group participants received oral prophylaxis in addition } \\
\text { to instruction and practice in oral hygiene techniques at regular interval; the control group only re- } \\
\text { ceived annual review and further treatment as appropriate. No additional information from author } \\
\text { available }\end{array}$ \\
\hline
\end{tabular}

$\begin{array}{ll}\text { Bahri } 2015 & \text { Not in a dental setting } \\ \text { Intervention not delivered by member of dental team: confirmed with author }\end{array}$

\begin{tabular}{ll}
\hline Blinkhorn 1981 & Test group had addition of fluoride tablet use \\
\hline Blinkhorn 2003 & Intervention groups not treated equally: fluoride issued to intervention group throughout study \\
\hline
\end{tabular}




\begin{tabular}{|c|c|}
\hline Study & Reason for exclusion \\
\hline Brand 2013 & Intervention not provided by a member of the dental team \\
\hline Brukienè 2012 & Not in a dental setting \\
\hline Choi 2012 & Not in a dental setting \\
\hline Clarkson 2009 & Electric toothbrush provided as part of intervention \\
\hline Crawford 1975 & Fluoride provided to intervention group \\
\hline Daly 2009 & Not a randomised controlled trial \\
\hline Davies 2007 & Not in a dental setting \\
\hline \multirow[t]{2}{*}{ de Andrade Meyer 2010} & Less than 8-week follow-up \\
\hline & Compared 2 different toothpaste formulations \\
\hline Dermen 2014 & Not in a dental setting \\
\hline Džiaugytè 2017 & Not in a dental setting \\
\hline Esfahanizadeh 2011 & Not in a dental setting \\
\hline Ferrazzano 2008 & Not a randomised controlled trial \\
\hline Franz-Ritscherle 1983 & Not in a dental setting \\
\hline Freitas-Fernandes 2002 & Not in a dental setting \\
\hline Gathece 2011 & Not in a dental setting \\
\hline Glavind 1981 & Not a randomised controlled trial \\
\hline Glavind 1983 & Not a randomised controlled trial \\
\hline Godard 2011 & Less than 8-week follow-up \\
\hline Graehn 1984 & Not in a dental setting \\
\hline Harnacke 2012 & Not in a dental setting \\
\hline Harrison 2007 & Intervention not delivered by member of dental team \\
\hline Hietasalo 2009 & $\begin{array}{l}\text { Experimental group received oral health advice plus fluoride toothpaste + fluoride and xylitol } \\
\text { lozenges therefore unable to compare to control group regarding the effect of } 1 \text {-to- } 1 \text { oral health ad- } \\
\text { vice only }\end{array}$ \\
\hline \multirow[t]{2}{*}{ Ismail 2011} & Intervention not delivered by member of dental team \\
\hline & $\begin{array}{l}\text { Additional information from author: "The interviews were conducted by trained non-dental inter- } \\
\text { viewers" }\end{array}$ \\
\hline Iwata 1981 & $\begin{array}{l}\text { Not a randomised controlled trial } \\
\text { Compares educational programme versus educational programme }+ \text { fee reduction }\end{array}$ \\
\hline
\end{tabular}




\begin{tabular}{|c|c|}
\hline Study & Reason for exclusion \\
\hline \multirow[t]{2}{*}{ Jiang 2014} & Intervention not in a dental setting \\
\hline & $\begin{array}{l}\text { Additional information from author: "The fluoride varnish was mostly applied by a dentist in a } \\
\text { community setting, usually in a community or social services centre" }\end{array}$ \\
\hline Ju 2017 & Not in a dental setting \\
\hline Jönsson 2012 & Testing a model of behaviour only \\
\hline Kakudate 2009 & Less than 8-week follow-up \\
\hline Kasaj 2004 & Less than 8-week follow-up \\
\hline Langan 1976 & Less than 8-week follow-up \\
\hline Lee 2009 & $\begin{array}{l}\text { Intervention group received supragingival scaling on a monthly basis compared with control group } \\
\text { who did not }\end{array}$ \\
\hline
\end{tabular}

$\begin{array}{ll}\text { Legler } 1971 & \begin{array}{l}\text { Part of intervention not delivered on 1-to-1 basis: movies presented in the waiting room environ- } \\ \text { ment as part of intervention }\end{array}\end{array}$

\begin{tabular}{|c|c|}
\hline Lim 1996 & Not in a dental setting \\
\hline Lim 1996b & Not in a dental setting \\
\hline Little 1997 & Part of intervention not delivered on 1-to-1 basis \\
\hline Mahantesha 2015 & Setting of intervention unclear. No additional information available from authors \\
\hline Makuch 2011 & Not in a dental setting \\
\hline Mayer 2003 & Not in a dental setting \\
\hline \multirow[t]{2}{*}{ Meurman 2009} & $\begin{array}{l}\text { Advice not all provided by a dental care professional (provided by public maternity health nurses } \\
\text { as well as dental hygienists) }\end{array}$ \\
\hline & $\begin{array}{l}\text { Xylitol lozenges provided to children in the intervention group who were positive for Streptococci } \\
\text { mutans }\end{array}$ \\
\hline Moltzer 1986 & No pre-treatment measurements completed with which to compare effect of intervention \\
\hline Moskovitz 2009 & Not a randomised controlled trial \\
\hline Ohrn 2009 & Not a randomised controlled trial \\
\hline Park 2015 & Less than 8-week follow-up \\
\hline Park 2011 & Not in a dental setting \\
\hline Patthoff 1981 & Not a randomised controlled trial \\
\hline Picard 2014 & Less than 8-week follow-up \\
\hline Pickrell 2007 & Not related to oral health education \\
\hline Pine 2007 & Not in a dental setting \\
\hline
\end{tabular}




\begin{tabular}{|c|c|}
\hline Study & Reason for exclusion \\
\hline Plutzer 2008 & $\begin{array}{l}\text { Not in a dental setting: printed information leaflets provided to pregnant women at antenatal clin- } \\
\text { ics }\end{array}$ \\
\hline Plutzer 2012 & Not in a dental setting \\
\hline Reinhardt 2010 & Not in a dental setting \\
\hline Roscher 2004 & Manual versus powered toothbrush trial \\
\hline Saengtipbovorn 2017 & Not in a dental setting \\
\hline Sandeep 2014 & Not in a dental setting \\
\hline Sato 2008 & Not in a dental setting \\
\hline Schiffner 2007 & Intervention groups recieved oral aides or fluoride mouthwash or both \\
\hline Schneider 1981 & No oral hygeine advice provided \\
\hline Schneider 1982 & No oral hygiene advice provided \\
\hline Schüz 2009 & Intervention not delivered by a member of dental team \\
\hline Seow 2003 & Not in a dental setting \\
\hline Sniehotta 2007 & Not a 1-to-1 intervention \\
\hline Stenman 2012 & Intervention not delivered by a member of the dental team \\
\hline Stenman 2017 & Intervention not provided by a member of the dental team (clinical psychologist) \\
\hline Strippel 2010 & Not in a dental setting \\
\hline Söderholm 1982b & Not a randomised controlled trial \\
\hline Tan 1978 & $\begin{array}{l}\text { Intervention groups received a group lecture in addition to individualised instruction as part of the } \\
\text { dental healthcare instruction }\end{array}$ \\
\hline Tan 1979 & $\begin{array}{l}\text { Intervention groups received a group lecture in addition to individualised instruction as part of the } \\
\text { dental healthcare instruction }\end{array}$ \\
\hline Telford 1974 & Not a randomised controlled trial \\
\hline Triana 1985 & Less than 8-week follow-up \\
\hline Valle 2004 & Not in a dental setting \\
\hline Zanin 2007 & Not a 1-to-1 intervention: lectures and group discussion \\
\hline Zee 2006 & No oral hygiene advice comparator \\
\hline Ziebolz 2009 & Not a randomised controlled trial: quasi-randomised \\
\hline
\end{tabular}


Characteristics of studies awaiting assessment [ordered by study ID]

Gao 2013

\begin{tabular}{ll} 
Methods & $\begin{array}{l}\text { Randomised controlled trial stratified by parental education and child's caries experience at base- } \\
\text { line }\end{array}$ \\
\hline Participants & $\begin{array}{l}\text { 3-year old children enrolled in kindergarten grade } 1 \text { (K1), who have unfavourable oral health be- } \\
\text { haviour(s) (i.e. a child who needs intervention). Unfavourable oral health behaviours are defined } \\
\text { as "brush teeth less often than twice a day" and/or "snack } 3 \text { times or more a day." Each child will } \\
\text { be required to join this study together with his/her parent (mother or father) who spends the most } \\
\text { time with him/her, so that a parent-child dyad can be recruited. A child will be excluded if (i) he/she } \\
\text { has a serious medical condition or (ii) his/her parents are non-Chinese speaking and cannot under- } \\
\text { stand the oral health materials and counselling, which will be in Chinese }\end{array}$
\end{tabular}

Interventions

Conventional oral health education versus conventional oral health education and motivational interviewing versus conventional oral health education and motivational interviewing and interactive risk assessment

The primary outcome will be caries increment in children and the proportion of caries-free children
Other outcomes: changes in parental efficacy in protecting children's oral health and changes in
children's dental behaviours

Notes HKCTR-1455

Author contacted for further information: no response so unable to clarify further

\section{IRCT2014062618248N1}

\begin{tabular}{ll}
\hline Methods & $\begin{array}{l}\text { Randomised controlled trial; 2-stage sampling method (clinical examination and question- } \\
\text { naire-based) }\end{array}$ \\
\hline Participants & 2nd grade high school students who voluntarily participated in the study \\
\hline Interventions & $\begin{array}{l}\text { Educational intervention was designed based on the data collected from pre-test and carried out in } \\
550 \text {-minute to } 60 \text {-minute sessions within } 4 \text { weeks }\end{array}$ \\
\hline Outcomes & Main outcomes: dental plaque and oral health behaviour \\
& Other outcomes: toothbrushing \\
\hline Notes & Author contacted for further information: no response so unable to clarify further \\
\hline
\end{tabular}

Characteristics of ongoing studies [ordered by study ID]

\section{ACTRN12605000607673}

Trial name or title

Oral Health Education Logan Programme (OHELP) (The effect of a personalised oral health education programme on clinical and molecular risk factors for oral and general health in an at risk population)

\begin{tabular}{ll}
\hline Methods & Parallel randomised controlled trial \\
\hline Participants & $\begin{array}{l}\text { 18- to } 60 \text {-year old patients with a minimum of } 12 \text { teeth and not requiring antibiotic cover for dental } \\
\text { treatment }\end{array}$
\end{tabular}

One-to-one oral hygiene advice provided in a dental setting for oral health (Review)

Copyright $\odot 2018$ The Cochrane Collaboration. Published by John Wiley \& Sons, Ltd. 
ACTRN12605000607673 (Continued)

Interventions
The oral health promotion programme being tested will involve oral health therapists/hygienists providing an individualised oral health promotion

programme, in addition to standard care, over 1 to 4 visits. This will include motivation enhancement, goal setting, problem solving, assertion skills,

followed by monthly reporting on adherence until the 2-year examination

Main outcome: the level of oral disease
Other outcomes: clinical and molecular risk factors for oral and general health such as diet, oral
care, smoking, alcohol consumption, body mass index (BMI)

Starting date

3 January 2003

Contact information

Dr Mary Cullinan, Oral Care Research Programme, Oral Biology and Pathology, The University of Queensland, Brisbane QLD 4072, Australia

m.cullinan@uq.edu.au

\section{Notes}

Author contacted: data collection completed, data analysis to be completed

\section{ISRCTN24958829}

Trial name or title

Dental RECUR trial (Comparison of a new with standard child and family primary care service to reduce the re-occurrence of childhood dental caries (Dental RECUR Trial))
Outcomes
Randomised controlled trial

Children aged 5 years to 7 years old who are having 1 or more teeth removed at a secondary care centre

All participants are given help to find and register with a local family dentist if they wish. Every child is given a free dental checkup 2 years after the extraction. This is done at the child's school by a dentist trained in looking for dental decay in children. All families are invited to attend a review appointment at some point in the first 6 weeks following tooth extraction. The session will be delivered by a dental nurse. For families in the new service group, the session will look at ways to help prevent further decay in the child's remaining first teeth and permanent teeth. The new service group families are also invited for an appointment with their dentist every 3 months for a year. At the end of the year the child will go back to visiting their dentist as normal. For families in the usual follow-up care group, the session will look at future dental development for their child. At the end of the session families in this group will go back to visiting their dentist as normal

Main outcome: dental caries experience after 2 years

Other outcomes:

1. parental readiness to change and beliefs about caring for their children's teeth. Measured by the modified Contemplation Ladder

2. parental self-efficacy in relation to the implementation of dental health-related behaviours for the study children. Measured by the Child Oral Health Behaviours Questionnaire and Parenting Self-Efficacy Scale

3. oral cleanliness by plaque assessment of anterior teeth at dental examinations

4. use of dental services; child oral health behaviours including dietary behaviours. Measured by the Child Oral Health Behaviours Questionnaire 
5.1. fully cost the community-based DR-BNI and prevention in dental practice programme (as compared with costs of usual dental care)

5.2. record study participant dental service use, primary and secondary care health service use, social care and special educational service use (using a CSRI, costed using national unit costs)

5.3. conduct a primary cost-effectiveness analysis (using dental caries rates as measure of effectiveness)

5.4. conduct a secondary cost-consequences study relating costs to a range of consequences spanning measures of: dental decay in participating child, regular dental attendance, parent participation in better oral health behaviours (e.g. sugar-free bedtime routine) and school attendance, and where appropriate, potential child neglect

\begin{tabular}{ll}
\hline Starting date & 1 November 2013 \\
\hline Contact information & $\begin{array}{l}\text { Ms Louise Robinson, Research and Development Directorate, Salford Royal Hospitals NHS Trust, } \\
\text { Mayo Building, 3rd Floor, Stott Lane, Salford M6 8HD, United Kingdom } \\
\text { louise.robinson@srft.nhs.uk }\end{array}$ \\
\hline Notes & $\begin{array}{l}\text { Author contacted: data collection will be completed November 2018, no interim measures avail- } \\
\text { able }\end{array}$ \\
\hline
\end{tabular}

\section{ISRCTN38542397}

\begin{tabular}{|c|c|}
\hline Trial name or title & Is photographic evidence a valuable aide to oral hygiene advice in 9- to 16 -year olds? \\
\hline Methods & Randomised controlled trial \\
\hline Participants & $\begin{array}{l}\text { Patients with visible plaque (tartar) levels on } 3 \text { or more tooth surfaces (i.e. a minimum plaque score } \\
\text { of 3); attending Barking and Dagenham Special Needs and Community Dental Service; aged be- } \\
\text { tween } 9 \text { years to } 16 \text { years old; who have the ability to brush their own teeth unsupervised; and have } \\
\text { no conditions that would contraindicate measuring the bleeding from the gums }\end{array}$ \\
\hline \multirow[t]{2}{*}{ Interventions } & $\begin{array}{l}\text { Group 1: standard intervention (control) including manual toothbrush and standardized oral and } \\
\text { written toothbrushing instruction based on the Bass technique }\end{array}$ \\
\hline & $\begin{array}{l}\text { Group 2: as with standard intervention with the addition of standardized photographic evidence of } \\
\text { the subjects oral health status and instructions how best to use this }\end{array}$ \\
\hline \multirow[t]{2}{*}{ Outcomes } & Modified plaque and bleeding indices \\
\hline & Questionnaire (how did they use the information given, what was most helpful) \\
\hline Starting date & 1 December 2006 \\
\hline \multirow[t]{2}{*}{ Contact information } & Dr Zahra Syed, Upminster Dental Clinic, 230 St Mary's Lane, Upminster RM14 3DH, United Kingdom \\
\hline & +4401708796786 \\
\hline Notes & Author contacted for further information: no response so unable to clarify further \\
\hline
\end{tabular}


NCT01118143

Trial name or title

\section{Methods}

Participants
Oral health literacy tailored communication (Effects of communication tailored to oral health literacy level of adult dental patients: a randomised controlled trial)

Randomised parallel controlled trial

Inclusion criteria: participants > 20 years of age; who master the Norwegian language; who are registered at the university dental clinic (IKO)

Exclusion criteria: people who do not master the Norwegian language; strongly visually impaired people that have difficulty in reading; people with a history of heart attack in the past 6 months; immunocompromised people and organ-transplanted people; people with other conditions that might lead to more disadvantages than advantages by participating

Interventions Behavioural: tailored oral health literacy instruction

The intervention includes oral hygiene instruction tailored to the level of oral health literacy, and will include information about the outcome of the clinical examination. Providing relevant information to the participant will be in focus, and there will be given a personalized demonstration as well as guidance on how to conduct proper oral hygiene practices at home. The aim of the intervention is to improve oral hygiene and attitudes towards dental care by taking the literacy level of the participant into consideration. Other Name: lifestyle counselling

\section{Outcomes}

Main outcome: gingival index (time frame: 6 months after intervention)

Other outcome: plaque index (time frame: 6 months after intervention)

\begin{tabular}{ll}
\hline Starting date & June 2010 \\
\hline Contact information & Professor Jan O Bergdahl, University of Tromsoe, Norway \\
\hline Notes & Author contacted: data collection completed, data analysis to be completed/published \\
\hline
\end{tabular}




\begin{tabular}{|c|c|c|c|c|c|c|c|}
\hline \multicolumn{8}{|c|}{ 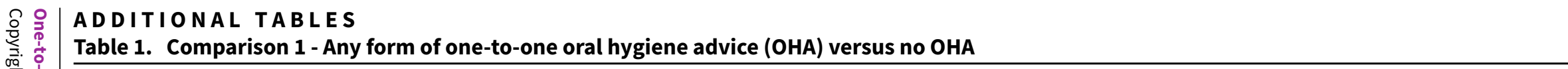 } \\
\hline \multicolumn{8}{|c|}{ Hetland 1982} \\
\hline \multicolumn{8}{|c|}{ Intervention: $\mathrm{OHA}$ provided by dental nurse } \\
\hline \multicolumn{8}{|c|}{ Frequency: 3 intervention visits with $\mathrm{OHA}$, each visit 1 week apart } \\
\hline \multicolumn{8}{|c|}{ Intensity: 45 minutes first visit, 30 minutes at second visit, 15 minutes at third visit } \\
\hline \multicolumn{8}{|c|}{ Control: no OHA } \\
\hline \multicolumn{8}{|c|}{ (Adults; primary care setting) } \\
\hline \multirow[t]{3}{*}{ Endpoint } & \multicolumn{3}{|c|}{ Gingivitis (GI) } & \multicolumn{3}{|c|}{ Plaque (visible plaque after staining) } & Caries (DMFT) \\
\hline & $\mathrm{OHA}$ & No OHA & & $\mathrm{OHA}$ & No OHA & & \multirow{2}{*}{$\begin{array}{l}\text { No summary statistics or effect estimates } \\
\text { reported. Authors report "Only small and } \\
\text { statistically insignificant changes oc- } \\
\text { curred in the } 3 \text { groups during the experi- } \\
\text { mental period" }\end{array}$} \\
\hline & $\begin{array}{l}\mathrm{n} \\
\text { Mean (SD) }\end{array}$ & $\begin{array}{l}\mathrm{n} \\
\text { Mean (SD) }\end{array}$ & $\begin{array}{l}\text { MD } \\
(95 \% \mathrm{Cl})\end{array}$ & $\begin{array}{l}\mathrm{n} \\
\text { Mean (SD) }\end{array}$ & $\begin{array}{l}\mathrm{n} \\
\text { Mean (SD) }\end{array}$ & $\begin{array}{l}\text { MD } \\
(95 \% \mathrm{Cl})\end{array}$ & \\
\hline \multirow[t]{2}{*}{3 months } & $\mathrm{n}=23$ & $n=25$ & 0.25 & $n=23$ & $n=25$ & $-0.41(-0.54$ to -0.28$)$ & \\
\hline & $1.63(0.23)$ & $1.38(0.41)$ & (0.05 to 0.45$)$ & $0.21(0.19)$ & $0.62(0.28)$ & & \\
\hline \multirow[t]{2}{*}{6 months } & 23 & 25 & -0.38 & $n=23$ & $n=25$ & $-0.44(-0.56$ to -0.32$)$ & \\
\hline & $0.98(0.39)$ & $1.36(0.46)$ & $(-0.62$ to -0.14$)$ & $0.22(0.19)$ & $0.66(0.24)$ & & \\
\hline
\end{tabular}

\section{Hoogstraten 1983}

Intervention: $\mathrm{OHA}$ provided by dental hygienist with or without film (combined groups). (For info, the 2 relevant arms of this study also appear in Comparison 4 enhanced $\mathrm{OHA}$ )

Frequency: not fully reported

Intensity: not fully reported

Control: no $\mathrm{OHA}$

(Adults; primary care setting)

\begin{tabular}{llll}
\hline Endpoint & Gingivitis & Plaque & Caries \\
\hline 12 months & Outcome not measured & Outcome not measured & Outcome not measured \\
\hline
\end{tabular}




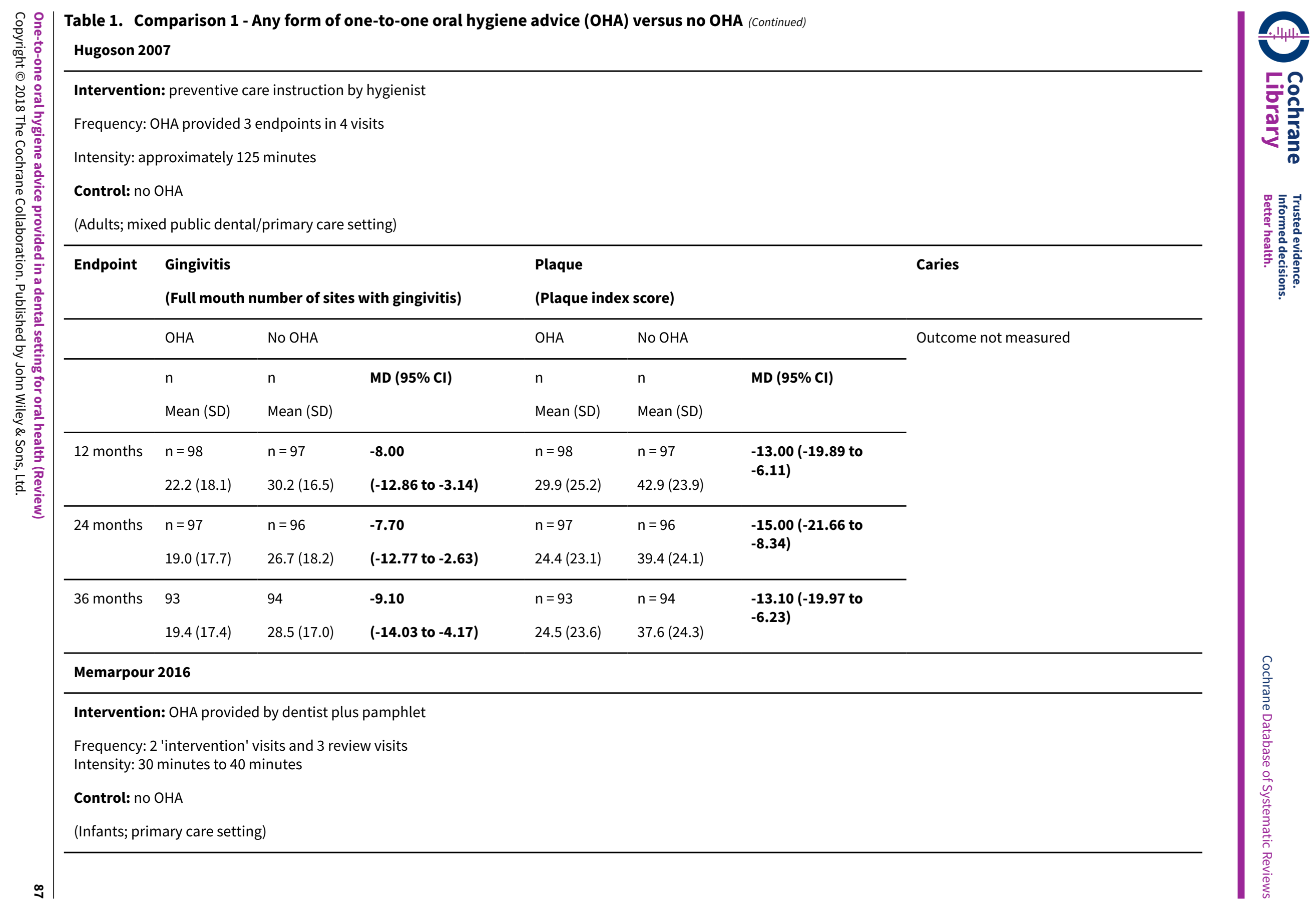




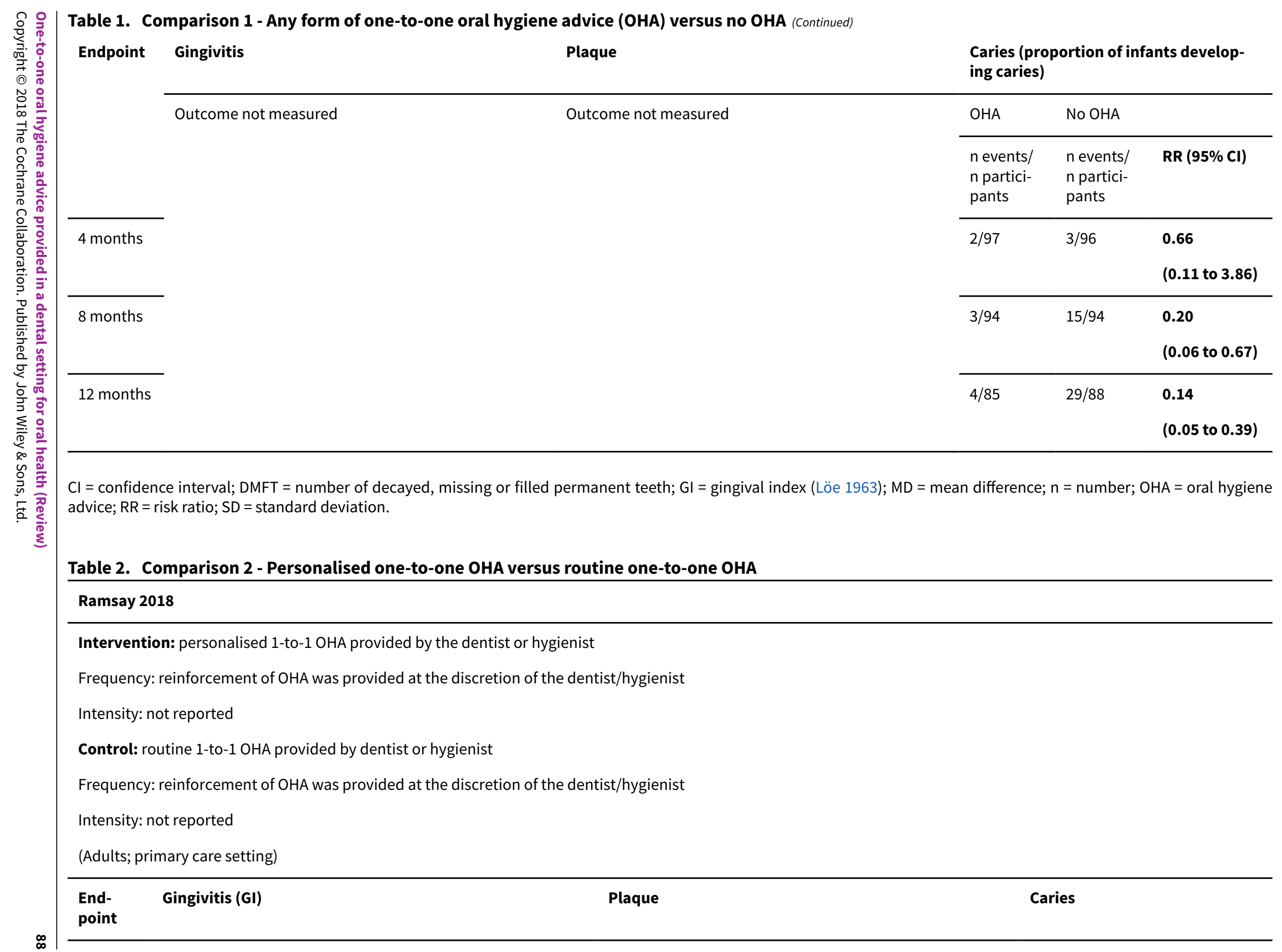




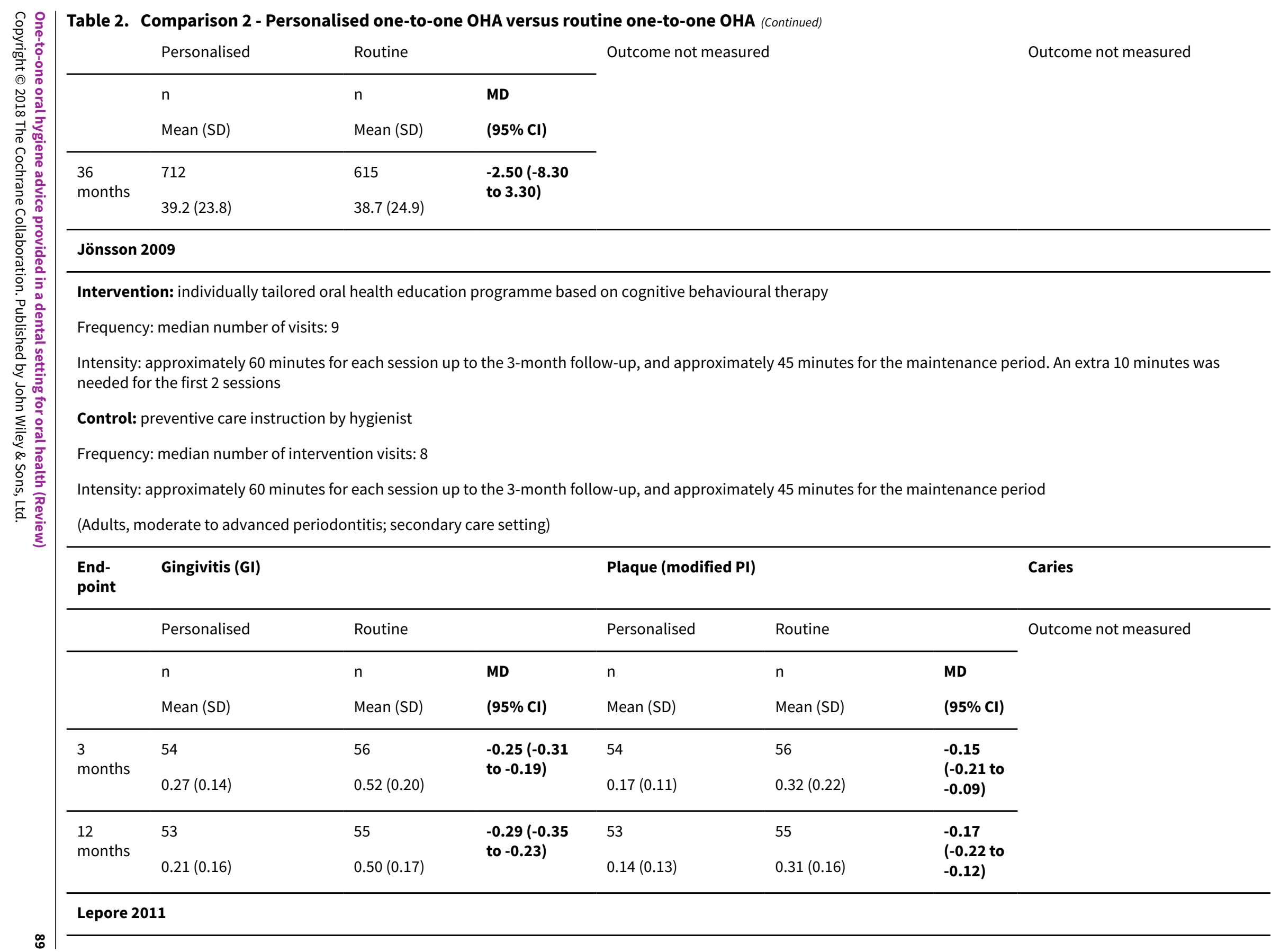




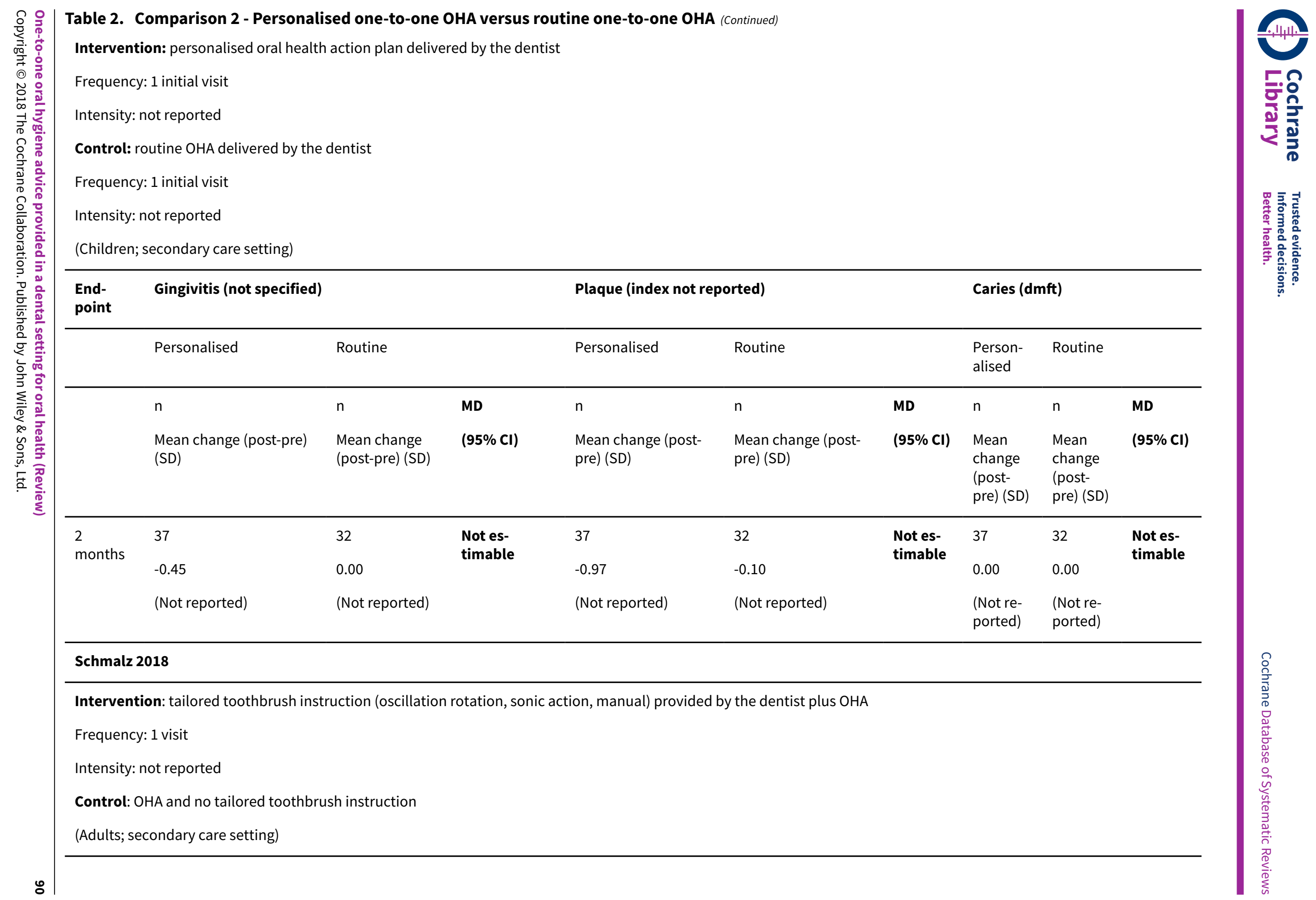




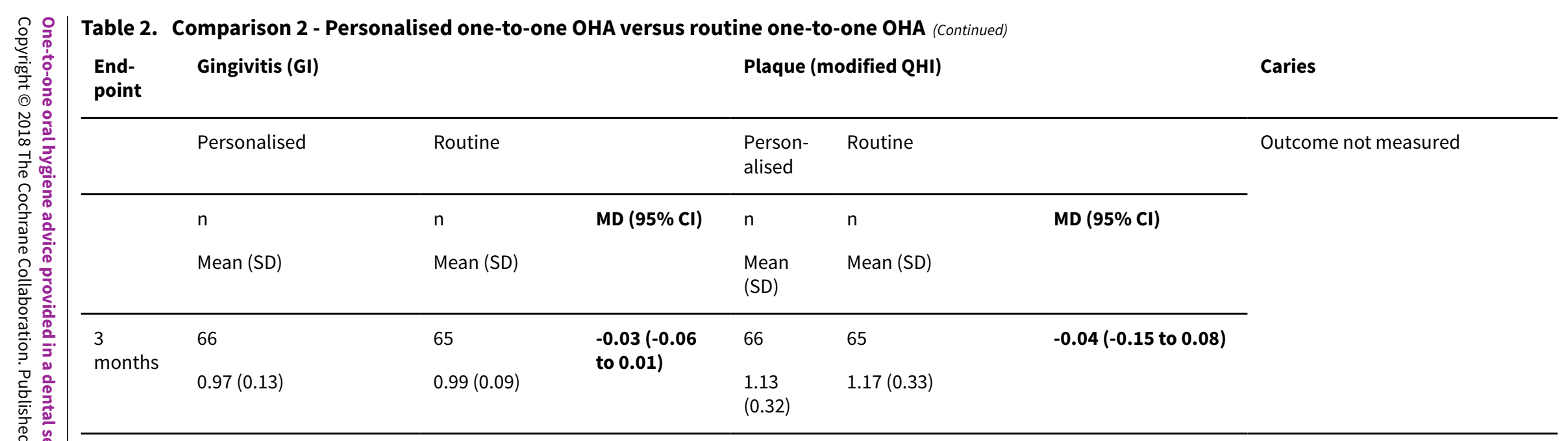

$\mathrm{Cl}=$ confidence interval; $\mathrm{dmft}=$ number of decayed, missing or filled primary teeth; $\mathrm{GI}$ = gingival index (Löe 1963); MD = mean difference; modified QHI = Turesky Modified Quigley and Hein plaque index; $\mathrm{n}=$ number; $\mathrm{OHA}$ = oral hygiene advice; $\mathrm{PI}=$ plaque index (Silness 1964); $\mathrm{SD}$ = standard deviation.

\section{Table 3. Comparison 3 - Self-management versus professional OHA}

\section{Aljafari 2017}

Intervention: computer game group: the child and parent played the computer game on a touch tablet and received a copy of it on a DVD to play at home

Frequency: 1-off in clinic and thereafter delivered at home

Intensity: not reported

Control: the child and parent received verbal oral health education from a dental nurse with a health education qualification

Frequency: 1-off intervention

Intensity: not reported

(High caries risk children; secondary care setting)

\begin{tabular}{llll}
\hline Endpoint & Gingivitis & Plaque & Caries \\
\hline Baab 1986 & Outcome not measured & Outcome not measured & Outcome not measured \\
\hline
\end{tabular}

Intervention: $\mathrm{OHA}$ using a self-inspection plaque index 


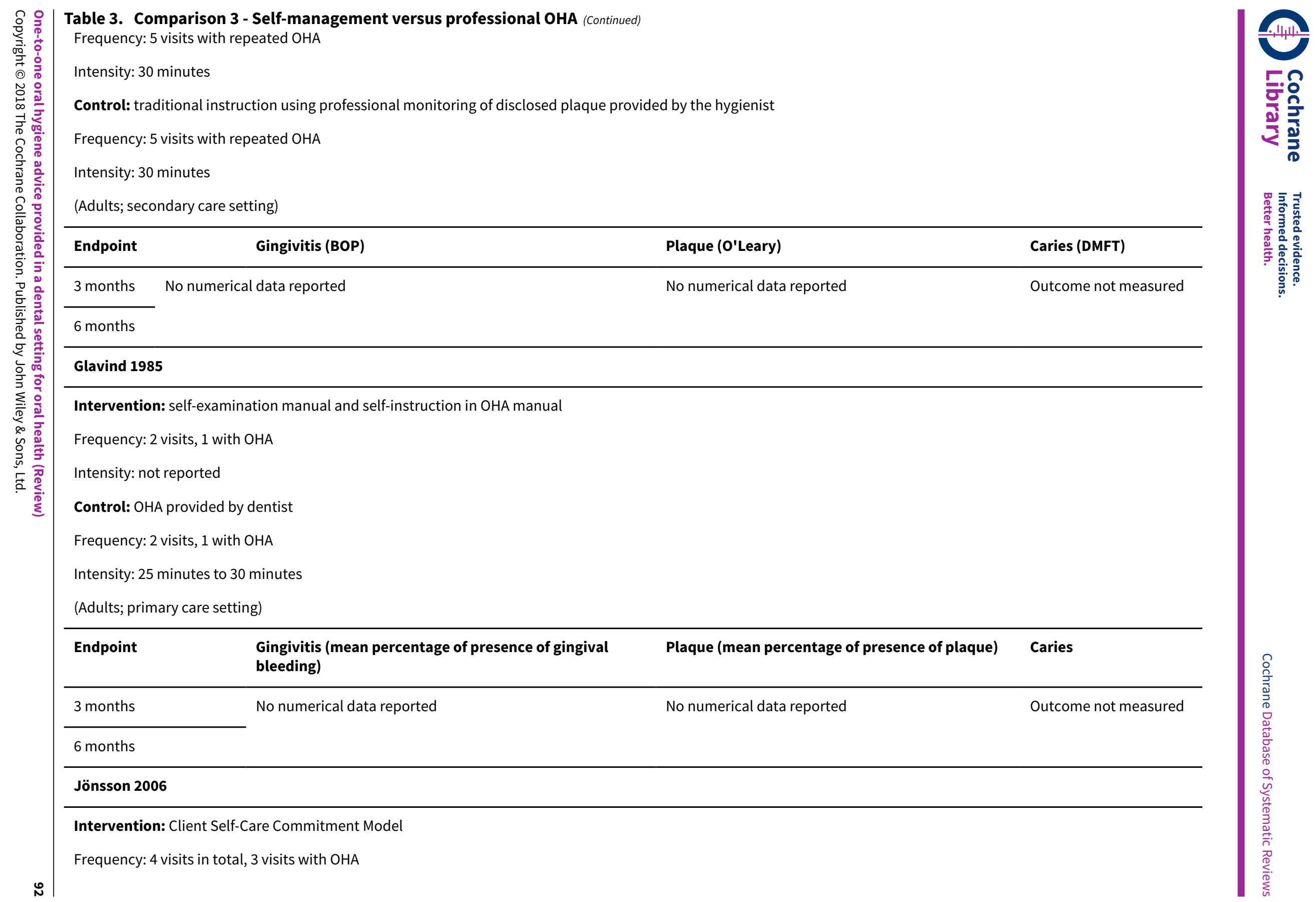




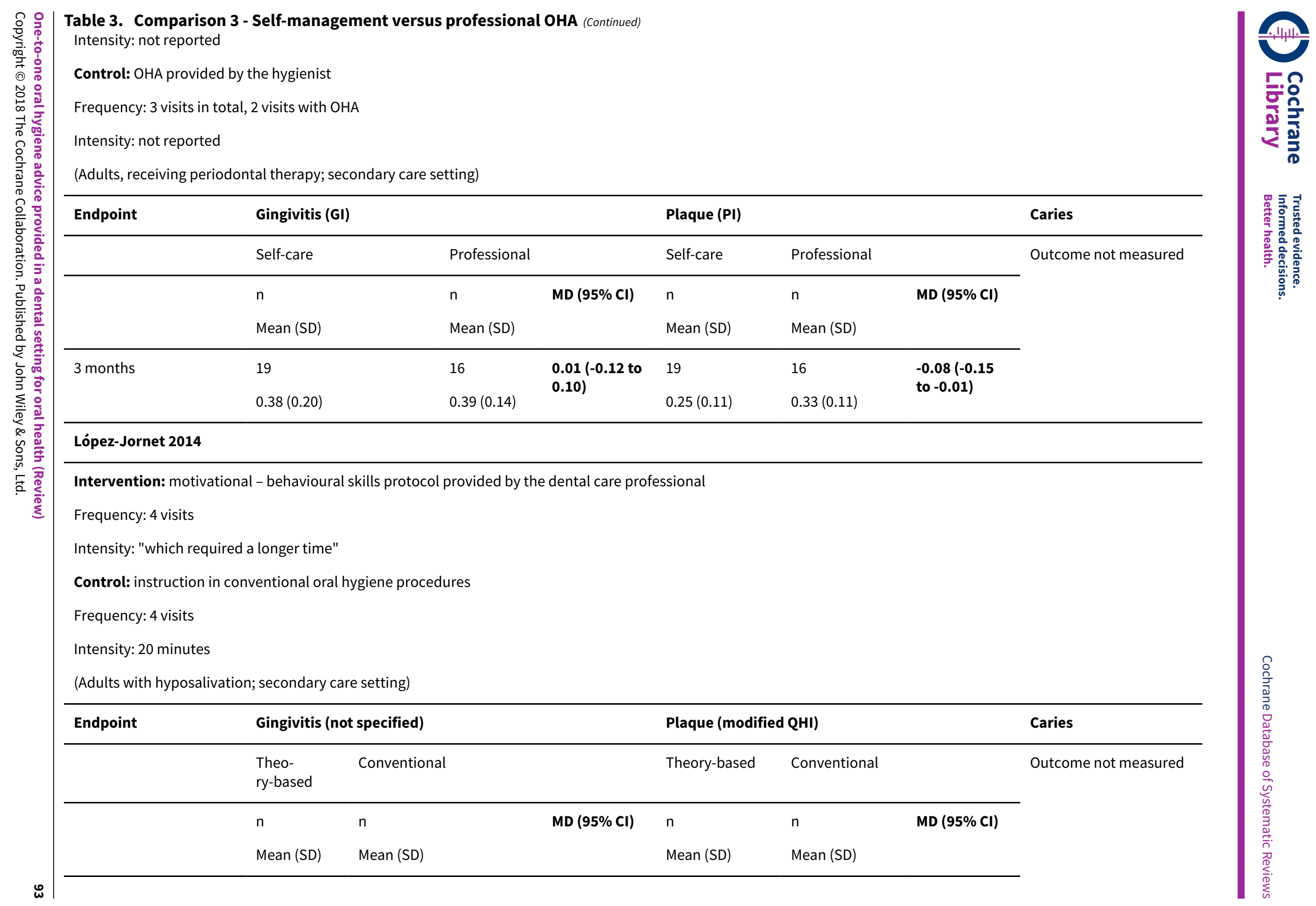


Table 3. Comparison 3 - Self-management versus professional OHA (Continued)

2 months 30

$30 \quad 30$

30

$18.4(25.8)$

$6.1(13.4)$

22.70)

30

$0.2(0.1)$

30

$-0.10(-0.18$

to -0.02 )

BOP = bleeding on probing; $\mathrm{Cl}=$ confidence interval; DMFT = number of decayed, missing or filled permanent teeth; $\mathrm{Gl}=$ gingival index (Löe 1963$) ; \mathrm{MD}=$ mean difference; modified $\mathrm{QHI}=$ Turesky Modified Quigley and Hein plaque index; $\mathrm{n}=$ number; $\mathrm{OHA}=$ oral hygiene advice; $\mathrm{O}^{\prime}$ Leary = disclosed plaque at the gingival margin (O'Leary 1972$) ; \mathrm{PI}=$ plaque index (Löe 1967); SD = standard deviation.

\section{Table 4. Comparison 4 - Enhanced one-to-one OHA versus one-to-one OHA}

Bali 1999

Intervention: professional OHA plus intensive patient education in oral hygiene

Frequency: 4 visits with repeated $\mathrm{OH}$ instruction

Intensity: not reported

Control: professional OHA

Frequency: 1 visit

Intensity: not reported

(Adults, type 1 diabetes; secondary care setting)

\begin{tabular}{|c|c|c|c|c|c|c|c|c|c|}
\hline \multirow{2}{*}{$\begin{array}{l}\text { End- } \\
\text { point }\end{array}$} & \multicolumn{3}{|l|}{ Gingivitis (BOP) } & \multicolumn{3}{|c|}{ Plaque (Turesky hygiene index) } & \multicolumn{3}{|l|}{ Caries } \\
\hline & Enhanced OHA & $\mathrm{OHA}$ & & Enhanced $\mathrm{OHA}$ & $\mathrm{OHA}$ & & $\begin{array}{l}\text { En- } \\
\text { hanced } \\
\text { OHA }\end{array}$ & $\mathrm{OHA}$ & \\
\hline & $\mathrm{n}$ & $\mathrm{n}$ & MD $(95 \% \mathrm{CI})$ & $\mathrm{n}$ & $\mathrm{n}$ & MD $(95 \% \mathrm{CI})$ & $\mathrm{n}$ & $\mathrm{n}$ & $\begin{array}{l}\text { MD } \\
(95 \% \mathrm{Cl})\end{array}$ \\
\hline & Median & Median & & Median & Median & & Median & Median & \\
\hline & Range & Range & & Range & Range & & Range & Range & \\
\hline \multirow{3}{*}{$\begin{array}{l}6 \\
\text { months }\end{array}$} & 37 & 37 & \multirow{3}{*}{$\begin{array}{l}\text { Not es- } \\
\text { timable }\end{array}$} & 37 & 37 & \multirow{3}{*}{$\begin{array}{l}\text { Not es- } \\
\text { timable }\end{array}$} & 37 & 37 & \multirow{3}{*}{$\begin{array}{l}\text { Not es- } \\
\text { timable }\end{array}$} \\
\hline & 50.0 & 57.1 & & 2 & 2.1 & & 18 & 18 & \\
\hline & 0,100 & 0,100 & & $0,3.7$ & $0,3.9$ & & 3,26 & 1,32 & \\
\hline
\end{tabular}




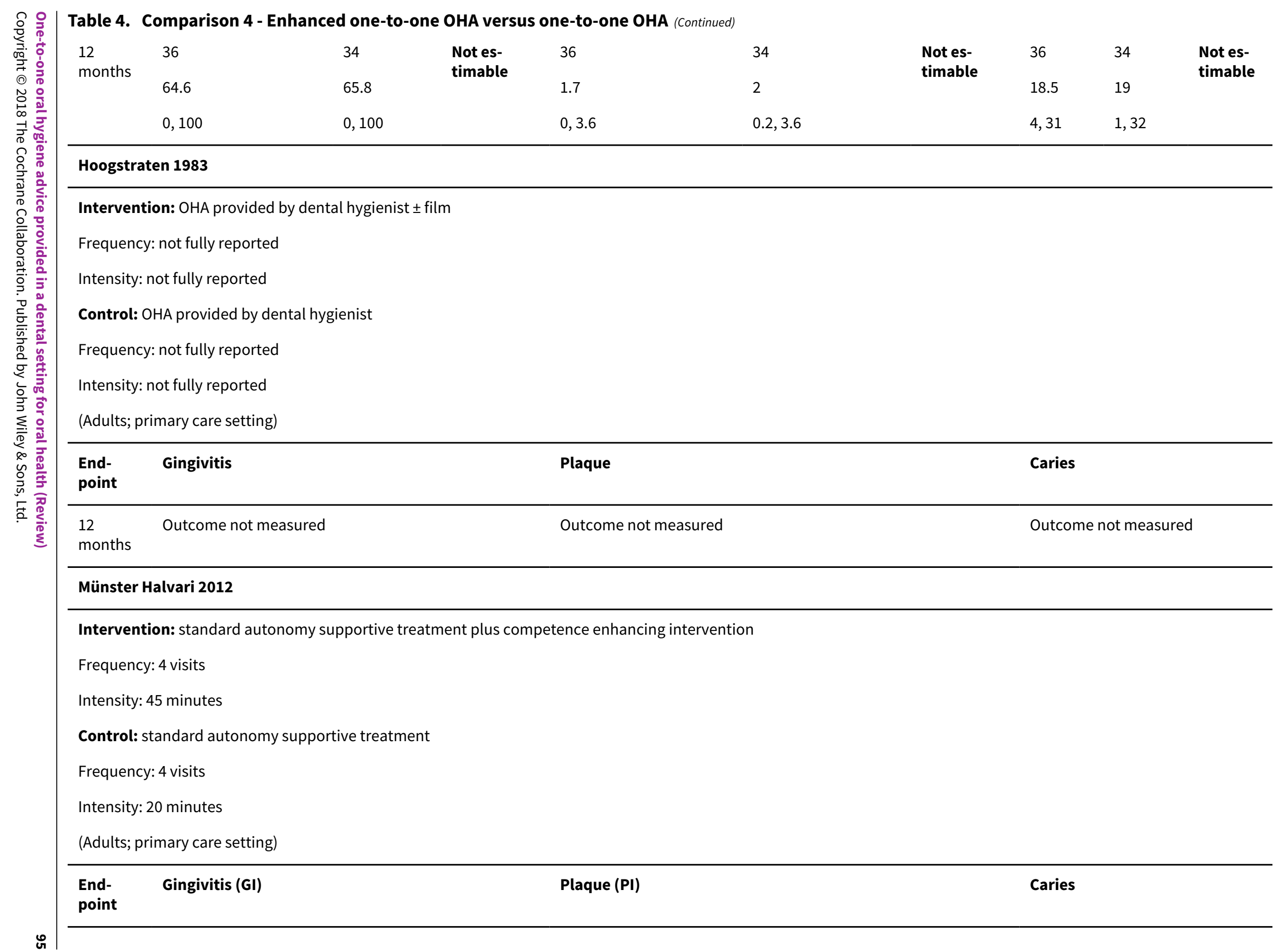




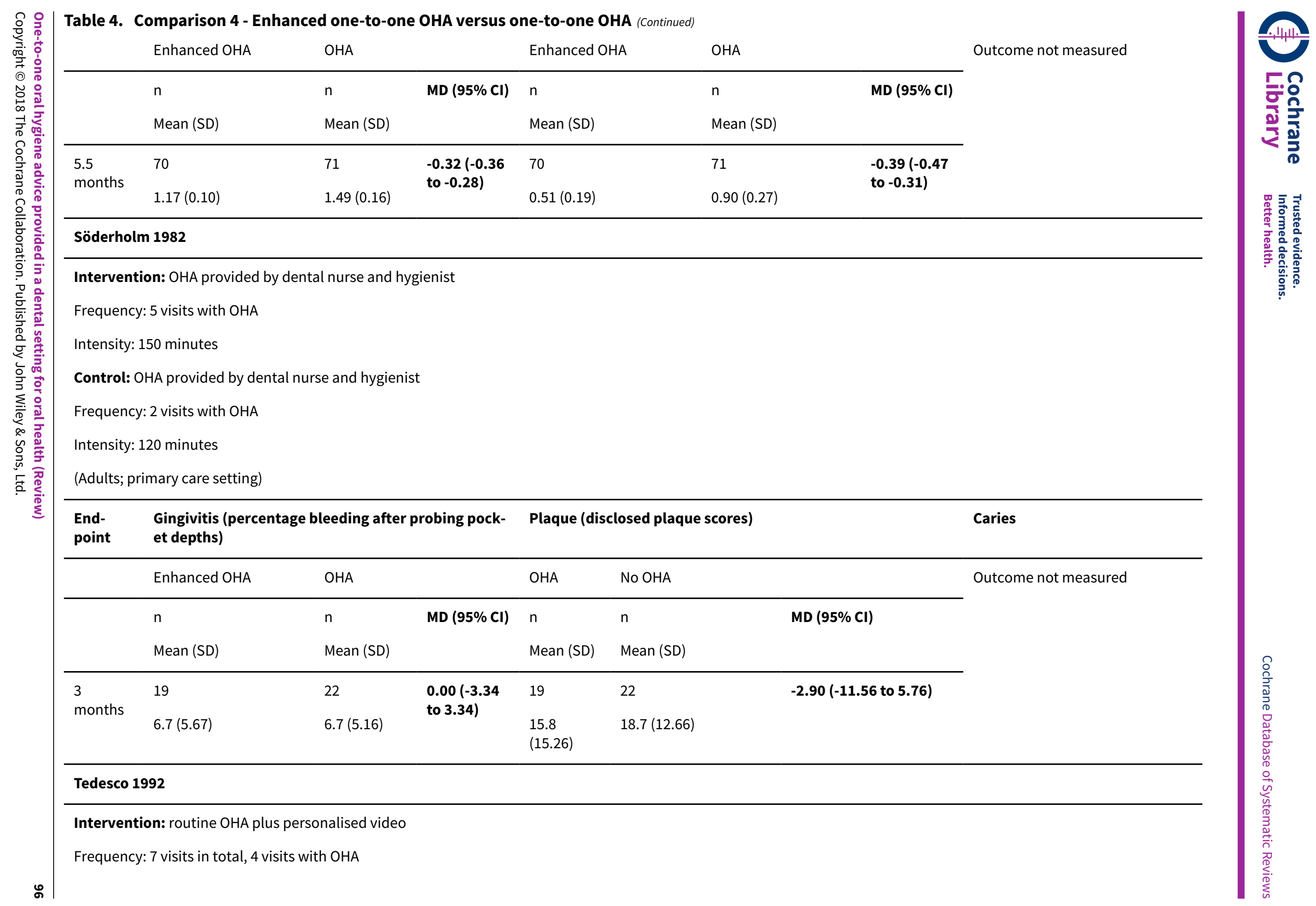




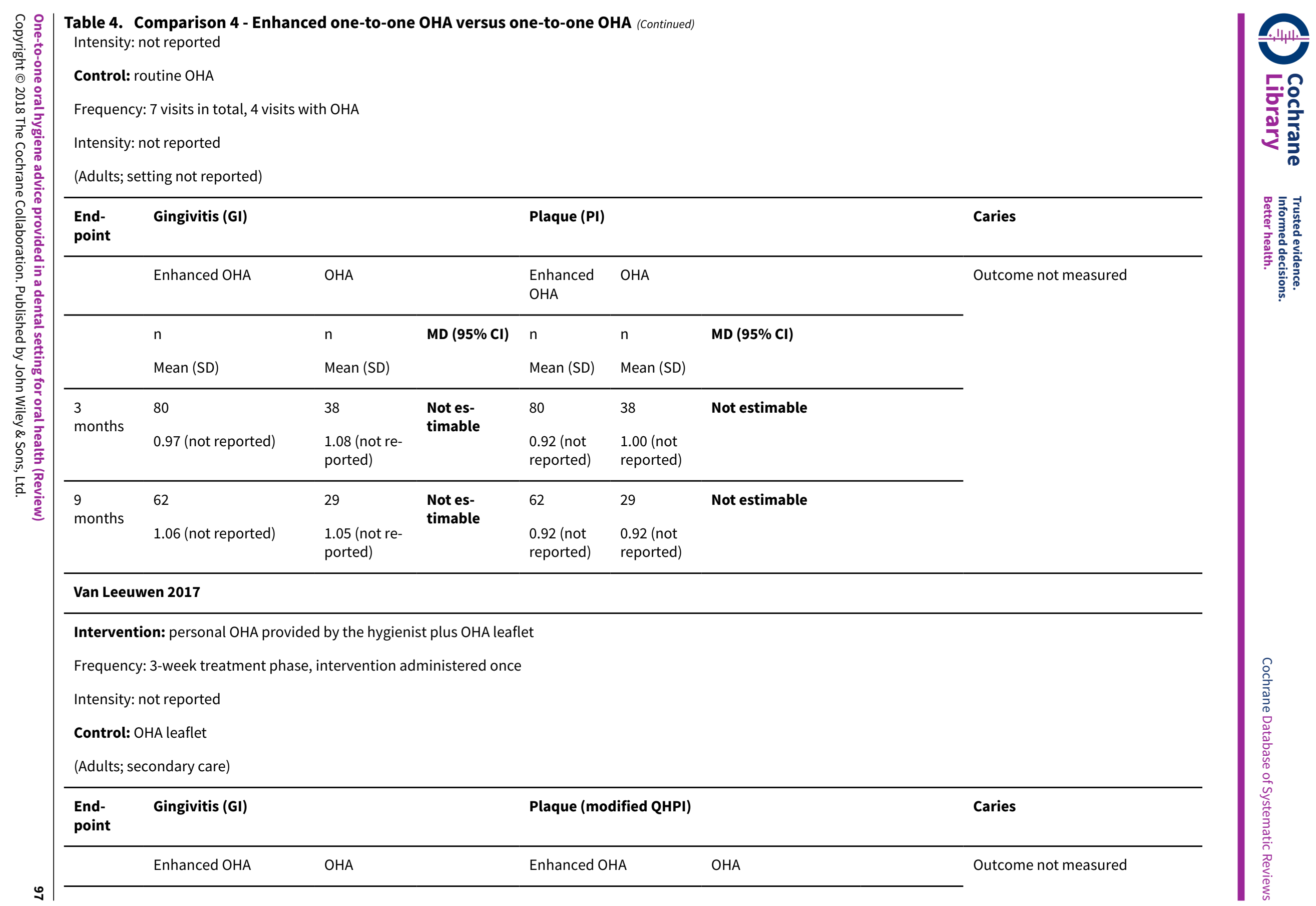




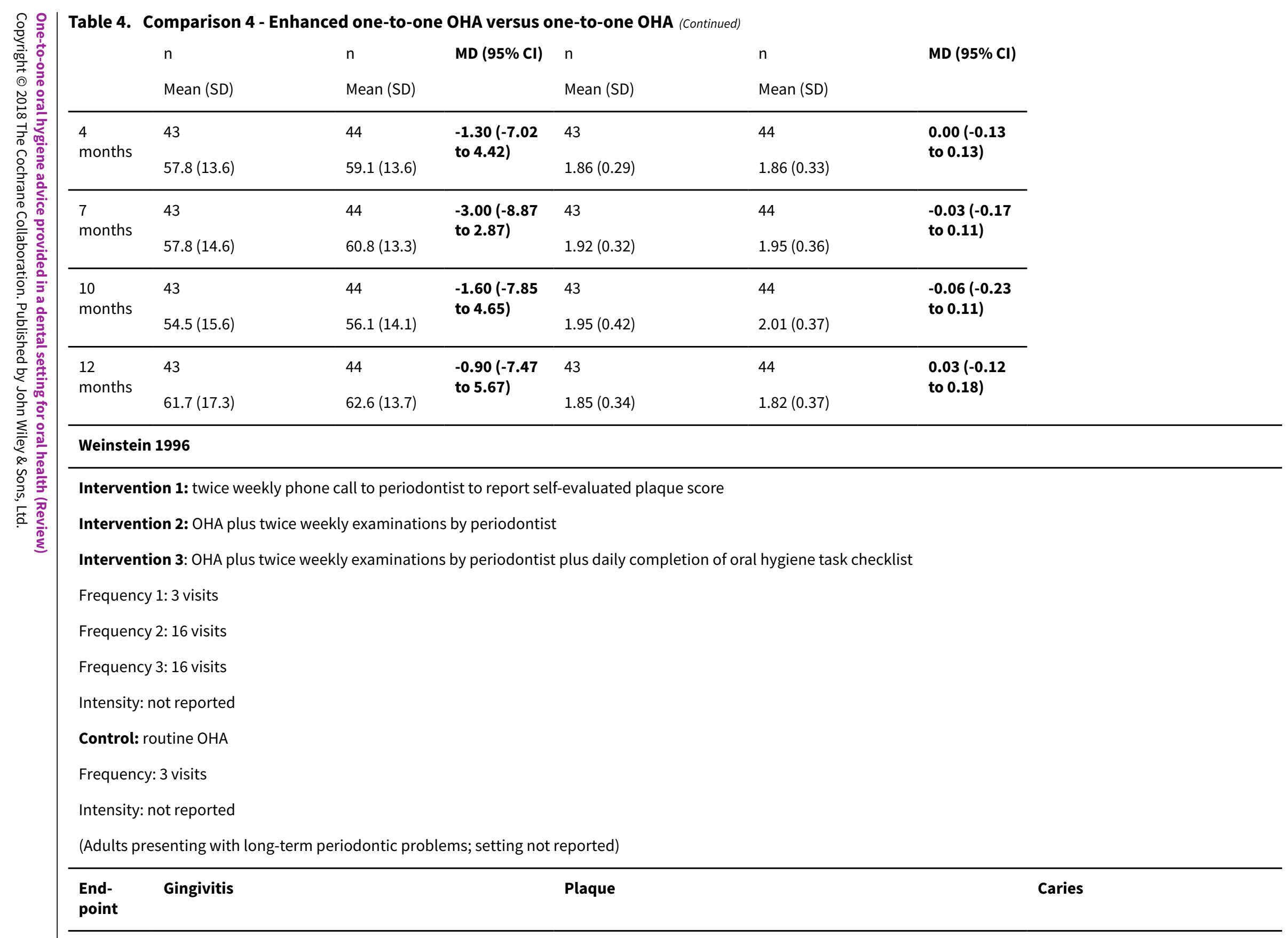




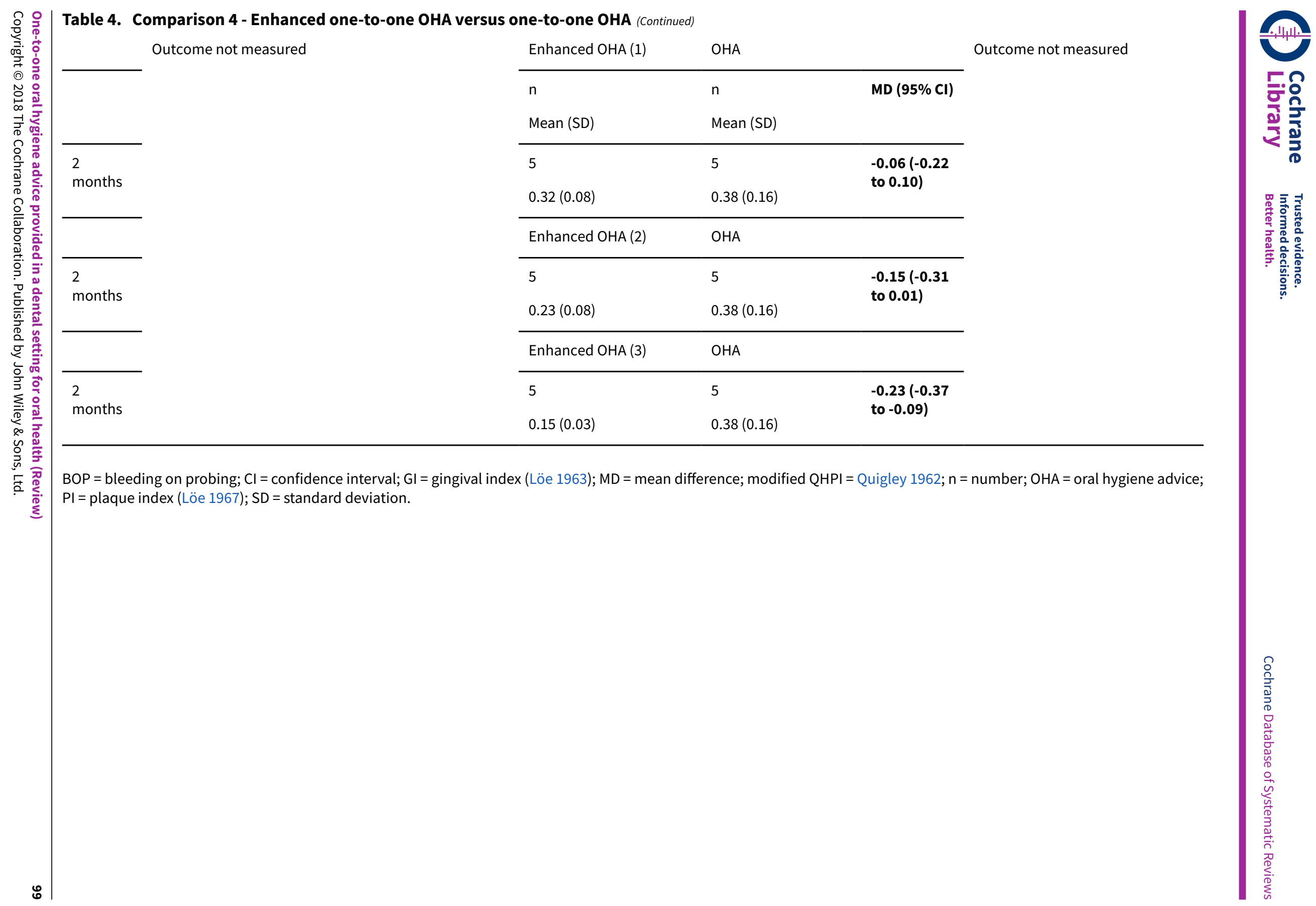




\section{AP PEN DICES}

\section{Appendix 1. Cochrane Oral Health's Trials Register search strategy}

From October 2012, searches were undertaken on Cochrane Register of Studies using the following search strategy:

\#1 ("dental health education" or "health promotion":TI,AB) AND (INREGISTER)

\#2 (("oral health" AND (instruct ${ }^{\star}$ or advice or advise ${ }^{\star}$ or educat ${ }^{\star}$ or teach* or train ${ }^{\star}$ or demonstrat ${ }^{\star}$ or supervis $\left.\left.{ }^{\star}\right)\right):$ TI,AB) AND (INREGISTER) \#3 (("oral health" AND (behavior* or behaviour* or "patient compliance" or motivat*) AND (change OR changed OR changing or modify OR modified OR modification)) :TI,AB) AND (INREGISTER)

\#4 (attitude* AND "oral health") or (attitude AND "oral care") or (attitude AND "dental health") or (attitude AND "mouth hygiene") or (attitude AND "oral hygiene"):TI,AB) AND (INREGISTER)

\#5 (\#1 or \#2 or \#3 or \#4) AND (INREGISTER)

Previous to October 2012, searches of the trials register were done using Procite software, using the following search strategy:

("dental health education" or "Health promotion" or ("oral health" AND (instruct* or advice or advise* or educat* or teach* or train* or demonstrat $^{\star}$ or supervis $\left.{ }^{\star}\right)$ ) or behavior* or behaviour ${ }^{\star}$ or "patient compliance" or motivat ${ }^{\star}$ or ((behavior ${ }^{\star}$ OR behaviour $\left.{ }^{\star}\right)$ AND (change OR changed OR changing or modify OR modified OR modification)) or "feedback device*" or "feed-back device" or (attitude* AND "oral health") or (attitude AND "oral care") or (attitude AND "dental health") or (attitude AND "mouth hygiene") or (attitude AND "oral hygiene"))

\section{Appendix 2. Cochrane Central Register of Controlled Clinical Trials (CENTRAL) search strategy}

\#1 ORAL HEALTH/

\#2 Exp STOMATOGNATHIC DISEASES/

\#3 Exp HALITOSIS

\#4 ((dental or tooth or teeth or enamel or root $\left.{ }^{\star}\right)$ AND (decay* or caries or carious or white next spot* or plaque or reminerali* or deminerali $\left.{ }^{\star}\right)$ ) \#5 (periodont* or gingivitis or (gingiva* next inflamm*) or (gingiva* next bleed ${ }^{\star}$ ) or (gingival next pocket* ${ }^{\star}$ ) or (periodont ${ }^{\star}$ next pocket $^{\star}$ ) or (periodont ${ }^{\star}$ near attachment) or (gingiva* near attachment)

\#6 stomatitis or (mouth next ulcer ${ }^{\star}$ ) or (oral next ulcer ${ }^{\star}$ ) or (oral next candidi ${ }^{\star}$ ) or (aphthous next ulcer ${ }^{\star}$ ) or (mouth near aphthae) or (oral near aphthae) or (mucositis near oral) or (mucositis near mouth) or xerostomi*

\#7 (oral next health) or (dental next health) or orthodontic*

\#8 ("tooth wear" or ((tooth or dental or teeth or enamel) and (erosion or abrasion)))

\#9 (halitosis or (mouth next odour ${ }^{\star}$ ) or (mouth next odor ${ }^{\star}$ ) or (mouth next malodour ${ }^{\star}$ ) or (mouth next malodor ${ }^{\star}$ ) or (oral next malodour)

OR (oral next malodour) or (breath near malodour $\left.{ }^{\star}\right)$ or (breath near odour $\left.{ }^{\star}\right)$ or (breath near odor $\left.{ }^{\star}\right)$ )

$\# 10$ (bottle next caries) or (nursing next caries) or (bottle next decay $\left.{ }^{\star}\right)$ or ((early next childhood) and (caries or decay $\left.\left.{ }^{\star}\right)\right)$

\#11 MOUTH NEOPLASMS/

\#12 (oral next cancer ${ }^{\star}$ ) or ((gingival or mouth or lip* or tongue or (salivary next gland) or palatal or parotid or sublingual or submandibular) AND (cancer ${ }^{\star}$ or carcinoma* $^{\star}$ or neoplasm ${ }^{\star}$ or tumour ${ }^{\star}$ or tumor $\left.^{\star}\right)$ )

$\# 13$ leukoplaki*

$\# 14$ hairy next tongue

\#15 \#1 OR \#2 OR \#3 OR \#4 OR \#5 OR \#6 OR \#7 OR \#8 OR \#9 OR \#10 OR \#11 OR \#12 OR \#13 OR \#14

\#16 Exp ORAL HYGIENE/

\#17 Exp MOUTHWASHES/

\#18 Exp DENTIFRICES/

\#19 (oral next hygiene) or (mouth near care) or (dental near care) or (care near teeth) or (mouth next hygiene) or (plaque near control ${ }^{\star}$ ) or (plaque near remov*)

\#20 toothbrush* or tooth-brush* or toothpaste* or dentifrice* or mouthwash* or mouth-wash* or mouthrinse* or mouth-rinse* or fluoride* \#21 ((interdental next clean*) or (inter-dental next clean*) or (tooth near clean ${ }^{\star}$ ) or (teeth near clean*) or (denture* near hygiene) or (denture* near clean ${ }^{\star}$ ) or (tongue next scrap*) or (tongue next brush*) or (chewing next stick*) or (chewing next gum ${ }^{\star}$ ) or (orthodontic next appliance near clean*))

\#22 (chewing-gum or sugar-free next gum)

\#23 ((dental or tooth or teeth or interdental ${ }^{\star}$ or inter-dental $\left.{ }^{\star}\right)$ and floss $\left.{ }^{\star}\right)$

\#24 ((dental next plaque next index) or (dental next plaque next indices) or (DMF* next index) or (DMF next indices) or (dmf* next index) or ( $\mathrm{dmf}^{\star}$ next indices) or (periodontal next index) or (periodontal next indices) or (oral next hygiene next index) or (oral next hygiene indices) or (gingival next index))

\#25 \#16 or \#17 OR \#18 OR \#19 OR \#20 OR \#21 OR \#22 OR \#23 or \#24

\#26 Exp HEALTH EDUCATION DENTAL

\#27 Exp HEALTH PROMOTION

\#28 instruct ${ }^{\star}$ or advice or advise ${ }^{\star}$ or educat $^{\star}$ or teach $^{\star}$ or train ${ }^{\star}$

\#29 (((health* near promot*)) and (dental or teeth or mouth or periodont* or gingival* or (oral next health))) 
\#30 ((demonstrat* near toothbrush*) or (demonstrat* near "tooth brush*") or (demonstrat* near tooth-brush $\left.{ }^{\star}\right)$ or (demonstrat* near floss*) or (demonstrat*near "oral hygiene $\left.{ }^{\star} "\right)$ or (demonstrat* near "interdental cleaning") or (demonstrat* near wood-stick* ) or (demonstrat* near "wood stick*") or (demonstrat* near "interdental massag*"))

\#31 ((supervis* near toothbrush*) or (supervis* near floss") or (supervis* near "oral hygiene") or (supervis* near "interdental cleaning") or (supervis ${ }^{\star}$ near wood-stick*) or (supervis" near "wood stick*") or (supervis* near "interdental massag*"))

$\# 32 \# 26$ or \#27 or \#28 or \#29 or \#30 or \#31

\#33 HEALTH BEHAVIOR/

\#34 PATIENT COMPLIANCE/

\#35 ADOLESCENT BEHAVIOR/

\#36 MOTIVATION/

\#37 ((behavior ${ }^{\star}$ OR behaviour ${ }^{\star}$ ) AND (change OR changed OR changing or modify OR modified OR modification))

\#38 "feed back device"” or "feedback device*"

\#39 (attitude* near (oral next health)) or (attitude near (oral next care)) or (attitude near (dental next health)) or (attitude near "mouth hygiene") or (attitude near "oral hygiene")

\#40 (((oral next hygiene) near improv*) or ("oral health" near improv*) or ("gingival health" near improv*) or ("periodontal health" near improv*) or ("periodontal condition" near improv*) or (caries near reduc $\left.\left.{ }^{\star}\right)\right)$

$\# 41 \# 33$ or \#34 or \#35 or \#36 or \#37 or \#38 or \#39 or \#40

\#42 ((\#15 OR \#25) AND (\#32 OR \#41))

\section{Appendix 3. MEDLINE Ovid search strategy}

1. ORAL HEALTH/

2. exp Stomatognathic Diseases/

3. exp HALITOSIS/

4. ((dental or tooth or teeth or enamel or root\$) and (decay\$ or caries or carious or white spot $\$$ or plaque or reminerali\$ or deminerali\$)).mp. 5. (periodont\$ or gingivitis or "gingival\$ inflamm\$" or "gingival\$ bleed\$" or "gingival pocket\$" or "periodont\$ pocket\$" or (periodont\$ adj3 attachment) or (gingival\$ adj3 attachment)).mp.

6. (stomatitis or "mouth ulcer\$" or "oral ulcer\$" or "oral candidi\$" or "aphthous ulcer\$" or (mouth adj3 aphthae) or (oral adj3 aphthae) or (mucositis adj3 oral) or (mucositis adj3 mouth)).mp.

7. ("oral health" or "dental health" or orthodontic\$).mp.

8. ("tooth wear" or ((tooth or dental or teeth or enamel) and (erosion or abrasion))).mp.

9. (halitosis or "mouth odour\$" or "mouth odor\$" or "mouth malodour\$" or "mouth malodor\$" or "oral malodour\$" or "oral malodour" or (breath adj3 malodour\$) or (breath adj3 odour\$) or (breath adj3 odor\$)).mp.

10. (("bottle caries" or "nursing caries" or "bottle decay\$" or "early childhood") and (caries or decay\$)).mp.

11. exp Mouth Neoplasms/

12. (("oral cancer\$" or ((gingival or mouth or lip\$ or tongue or salivary) adj (gland or palatal or parotid or sublingual or submandibular))) and (cancer\$ or carcinoma\$ or neoplasm\$ or tumour\$ or tumor\$)).mp.

13. leukoplaki\$.mp.

14. hairy tongue.mp.

15. or/1-14

16. exp ORAL HYGIENE/

17. $\exp$ MOUTHWASHES/

18. exp DENTIFRICES/

19. ("oral hygiene" or (mouth adj3 care) or (dental adj3 care) or (care adj3 teeth) or (mouth adj3 hygiene) or (plaque adj4 control\$) or (plaque adj4 remov\$)).mp.

20. (toothbrush\$ or tooth-brush\$ or toothpaste\$ or dentifrice\$ or mouthwash\$ or mouth-wash\$ or mouthrinse\$ or mouth-rinse\$ or fluoride\$).mp.

21. ("interdental clean\$" or "inter-dental clean\$" or (tooth adj4 clean\$) or (teeth adj4 clean\$) or (denture\$ adj4 hygiene) or (denture\$ adj4 clean\$) or "tongue scrap\$" or (tongue adj3 brush\$) or "chewing stick\$" or "chewing gum\$" or ("orthodontic appliance\$" adj3 clean\$)).mp.

22. (chewing-gum or "sugar-free gum").mp.

23. ((dental or tooth or teeth or interdental\$ or inter-dental\$) and floss\$).mp.

24. ("dental plaque index" or "dental plaque indices" or "DMF? index" or "DMF? indices" or "periodontal index" or "periodontal indices" or "oral hygiene index" or "oral hygiene indices" or "gingival index").mp.

25. or/16-24

26. Health Education, Dental/

27. exp Health Promotion/

28. (instruct $\$$ or advice or advise $\$$ or educat $\$$ or teach\$ or train\$).mp.

29. ((health\$ adj3 promot\$) and (dental or teeth or mouth or periodont\$ or gingival\$ or "oral health")).mp.

30. ((demonstrate\$ adj4 toothbrush\$) or (demonstrate\$ adj4 "tooth brush\$") or (demonstrat\$ adj3 tooth-brush\$) or (demonstrate\$ adj3 floss\$) or (demonstrate\$ adj3 "oral hygiene\$") or (demonstrat\$ adj3 "interdental cleaning") or (demonstrate\$ adj3 wood-stick\$) or (demonstrate\$ adj3 "wood stick\$") or (demonstrate\$ adj3 "interdental massage\$")).mp. 
31. ((supervise $\$$ adj3 toothbrush\$) or (supervise\$ adj3 floss\$) or (supervise\$ adj3 "oral hygiene") or (supervise\$ adj3 "interdental cleaning") or (supervise\$ adj3 wood-stick\$) or (supervise\$ adj3 "wood stick\$") or (supervise\$ adj3 "interdental massage\$")).mp.

32. or/26-31

33. HEALTH BEHAVIOR/

34. PATIENT COMPLIANCE/

35. ADOLESCENT BEHAVIOR/

36. MOTIVATION/

37. ((behavior\$ or behaviour\$) and (change or changed or changing or modify or modified or modification)).mp.

38. ("feed back device\$" or "feedback device\$").mp.

39. ((attitude\$ adj3 "oral health") or (attitude adj3 "oral care") or (attitude adj3 "dental health") or (attitude adj3 "mouth hygiene") or (attitude adj3 "oral hygiene")).mp.

40. (("oral hygiene" adj3 improv\$) or ("oral health" adj3 improv\$) or ("gingival health" adj3 improv\$) or ("periodontal health" adj3 improv \$) or ("periodontal condition" adj3 improv\$) or (caries adj3 reduc\$)).mp.

41. or $/ 33-40$

42. (15 or 25$)$ and (32 or 41$)$

This subject search was linked to the Cochrane Highly Sensitive Search Strategy (CHSSS) for identifying randomised trials (RCTs) in MEDLINE: sensitivity-maximising version (2008 revision) as referenced in Chapter 6.4.11.1 and detailed in box 6.4.c of theCochrane Handbook for Systematic Reviews of Interventions Version 5.1.0 (updated March 2011) (Lefebvre 2011).

1. randomized controlled trial.pt.

2. controlled clinical trial.pt.

3. randomized.ab.

4. placebo.ab.

5. drug therapy.fs.

6. randomly.ab.

7. trial.ab.

8. groups.ab.

9. or/1-8

10. exp animals/ not humans.sh.

11.9 not 10

\section{Appendix 4. Embase Ovid search strategy}

1 "oral health"

2 Exp MOUTH DISEASE/

3 HALITOSIS/

4 ((dental or tooth or teeth or enamel or root\$) AND (decay\$ or caries or carious or "white spot\$" or plaque or reminerali\$ or deminerali\$)) 5 (periodont\$ or gingivitis or "gingival\$ inflamm\$" or "gingival\$ bleed\$" or "gingival pocket\$ or "periodont\$ pocket\$ or (periodont\$ adj3 attachment) or (gingival\$ adj3 attachment))

6 stomatitis or "mouth ulcer\$ or "oral ulcer\$ or "oral candidi\$ or "aphthous ulcer\$" or (mouth adj3 aphthae) or (oral adj3 aphthae) or (mucositis adj3 oral) or (mucositis adj3 mouth) or xerostomi\$

7 "oral health" or "dental health" or orthodontic\$

8 ("tooth wear" or ((tooth or dental or teeth or enamel) and (erosion or abrasion)))

9 (halitosis or "mouth odour\$" or "mouth odor\$" or "mouth malodour\$ or "mouth malodor\$ or "oral malodour\$" OR "oral malodour" or (breath adj3 malodour\$) or (breath adj3 odour\$) or (breath adj3 odor\$))

10 "bottle caries" or "nursing caries" or "bottle decay\$" or ("early childhood") and (caries or decay\$))

11 MOUTH TUMOR/

12 (((oral next cancer\$) or (gingival or mouth or lip\$ or tongue or (salivary next gland) or palatal or parotid or sublingual or submandibular) AND (cancer\$ or carcinoma\$ or neoplasm\$ or tumour\$ or tumor\$))

13 leukoplaki\$

14 "hairy tongue"

$15 \mathrm{OR} / 1-14$

16 "Mouth hygiene"

17 mouthwash\$

18 TOOTHPASTE/

19 "oral hygiene" or (mouth adj3 care) or (dental adj3 care) or (care adj3 teeth) or (mouth adj3 hygiene) or (plaque adj4 control\$) or (plaque adj4 remov\$)

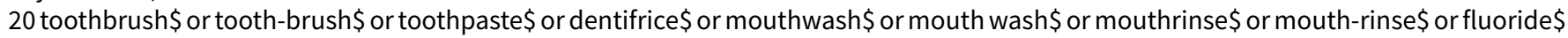
21 ("interdental clean\$" or "inter-dental clean\$ or (tooth adj4 clean\$) or (teeth adj4 clean\$) or (denture\$ near hygiene) or (denture\$ adj4 clean\$) or "tongue scrap\$" or (tongue adj3 brush\$) or "chewing stick\$” or "chewing gum\$” or ("orthodontic appliance\$” adj3 clean\$))

22 (chewing-gum or sugar-free next gum)

23 ((dental or tooth or teeth or interdental\$ or inter-dental\$) and floss\$) 
24 ("dental plaque index" or "dental plaque indices" or "DMF\$ index" or "DMF indices" or "dmf* index" or "dmf4 indices" or "periodontal index" or "periodontal indices" or "oral hygiene index" or ("oral hygiene indices") or "gingival index"))

25 OR/16-24

26 DENTAL HEALTH EDUCATION/

27 HEALTH PROMOTION/

28 instruct $\$$ or advice or advise or educat\$ or teach\$ or train\$

29 (((health\$ adj3 promot\$)) and (dental or teeth or mouth or periodont\$ or gingival\$ or "oral health"))

30 ((demonstrate\$ adj4 toothbrush\$) or (demonstrate\$ "tooth brush\$") or (demonstrat\$ adj3 tooth-brush\$) or (demonstrate\$ adj3 floss\$) or (demonstrate\$ adj3 "oral hygiene\$") or (demonstrat\$ adj3 "interdental cleaning") or (demonstrate\$ adj3 woodstick\$) or (demonstrate $\$$ adj3 "wood stick\$") or (demonstrate\$ near "interdental massage\$"))

31 ((supervise\$ adj3 toothbrush\$) or (supervise\$ adj3 floss\$) or (supervise\$ adj3 "oral hygiene") or (supervise\$ adj3 "interdental cleaning") or (supervise\$ adj3 wood-stick\$) or (supervise\$ adj3 "wood stick\$") or (supervise\$ adj3 "interdental massage\$"))

32 OR/26-31

33 HEALTH BEHAVIOR/

34 PATIENT COMPLIANCE/

35 (adolescen\$ adj3 (behavior or behaviour))

36 MOTIVATION/

37 ((behavior\$ OR behaviour\$) AND (change OR changed OR changing or modify OR modified OR modification))

38 "feed back device\$" or "feedback device\$"

39 ((attitude\$ adj3 "oral health") or (attitude adj3 "oral care”) or (attitude adj3 “dental health") or (attitude adj3 "mouth hygiene”) or (attitude adj3 "oral hygiene")

40 (("oral hygiene" adj3 improv\$) or ("oral health” adj3 improv\$) or ("gingival health" adj3 improv\$) or ("periodontal health" adj3 improv \$) or ("periodontal condition" adj3 improv\$) or (caries adj3 reduc\$))

41 OR/33-40

42 ((15 OR 25) AND (32 OR 41))

This subject search was linked to an adapted version of the Cochrane Centralised Search Project filter for identifying RCTs in Embase Ovid (see www.cochranelibrary.com/help/central-creation-details.html for information).

1. Randomized controlled trial/

2. Controlled clinical study/

3. Random\$.ti,ab.

4. randomization/

5. intermethod comparison/

6. placebo.ti,ab.

7. (compare or compared or comparison).ti.

8. ((evaluated or evaluate or evaluating or assessed or assess) and (compare or compared or comparing or comparison)).ab.

9. (open adj label).ti,ab.

10. ((double or single or doubly or singly) adj (blind or blinded or blindly)).ti,ab.

11. double blind procedure/

12. parallel group $\$ 1 . t i, a b$.

13. (crossover or cross over).ti,ab.

14. ((assign\$ or match or matched or allocation) adj5 (alternate or group\$1 or intervention\$1 or patient $\$ 1$ or subject $\$ 1$ or participant

\$1)).ti,ab.

15. (assigned or allocated).ti,ab.

16. (controlled adj7 (study or design or trial)).ti,ab.

17. (volunteer or volunteers).ti,ab.

18. trial.ti.

19. or/1-18

20. (exp animal/ or animal.hw. or nonhuman/) not (exp human/ or human cell/ or (human or humans).ti.)

21. 19 not 20

Appendix 5. US National Institutes of Health Ongoing Trials Register (ClinicalTrials.gov) search strategy

oral hygiene and advice

oral hygiene and promotion

\section{Appendix 6. World Health Organization International Clinical Trials Registry Platform search strategy}

"oral hygiene" and advice

"oral health" and advice

"oral hygiene" and promotion

"oral health" and promotion 


\section{CONTRIBUTIONS OF AUTHORS}

Janet E Clarkson (JC) conceived the idea for the review. JC, Francesca A Soldani (FS), Linda Young (LY), Kate Jones (KJ), and Tanya Walsh (TW) wrote the protocol. JC, FS, LY, KJ and Thomas Lamont (TL) designed the final review. FS co-ordinated the review. FS, TL, KJ and LY screened abstracts. FS, TL, Rizwana Lala (RL) and KJ carried out data extraction. TL and FS compiled the characteristics of included studies tables. FS, TL, RL and KJ assessed the risk of bias for the included studies. TW provided statistical data advice. TL, FS and KJ drafted the background section. FS and TL drafted the body of the review. TW, KJ, RL, LY and JC commented on and edited the draft review.

\section{DECLARATIONS OF INTEREST}

Janet E Clarkson, Linda Young and Thomas Lamont were all authors of Ramsay 2018. They were not involved in the data extraction or risk of bias assessment of this trial.

Janet E Clarkson is also Co-ordinating Editor of Cochrane Oral Health.

Francesca A Soldani: none known.

Kate Jones: none known.

Tanya Walsh: none known. Tanya Walsh is an Editor with Cochrane Oral Health.

Rizwana Lala: none known.

\section{SOURCES OF SUPPORT}

\section{Internal sources}

- No sources of support supplied

\section{External sources}

- National Institute for Health Research (NIHR), UK.

This project was supported by the NIHR, via Cochrane Infrastructure funding to Cochrane Oral Health. The views and opinions expressed herein are those of the authors and do not necessarily reflect those of the Systematic Reviews Programme, NIHR, NHS or the Department of Health.

- Cochrane Oral Health Global Alliance, Other.

The production of Cochrane Oral Health reviews has been supported financially by our Global Alliance since 2011 (oralhealth.cochrane.org/partnerships-alliances). Contributors over the past year have been the American Association of Public Health Dentistry, USA; AS-Akademie, Germany; the British Association for the Study of Community Dentistry, UK; the British Society of Paediatric Dentistry, UK; the Canadian Dental Hygienists Association, Canada; the Centre for Dental Education and Research at All India Institute of Medical Sciences, India; the National Center for Dental Hygiene Research \& Practice, USA; New York University College of Dentistry, USA; and the Swiss Society for Endodontology, Switzerland.

\section{DIFFERENCES BETWEEN PROTOCOLANDREVIEW}

We made the following amendments to the review.

- Controlled clinical trials were not included as per Cochrane Handbook for Systematic Reviews of Interventions 5.1.0 (Higgins 2011).

- Objective changed from 'To determine the benefits and harms of one-to-one oral hygiene ...' to 'To assess the effects of one-to-one oral hygiene...'.

- Oral infection removed from primary outcome clinical status factors.

- Periodontal health primary outcome clinical status factor to include plaque levels.

- Secondary outcomes patient-centred factors compressed to:

- $\circ$ patient-reported behaviour changes (e.g. toothbrushing/flossing/mouthwash use),

- patient satisfaction with advice provided,

- patient-reported changes in knowledge, attitudes and quality of life.

- Additional databases searched:

- o ClinicalTrials.gov (to November 2017),

- World Health Organization International Clinical Trials Registry Platform (to November 2017).

- Quality assessment completed as per Cochrane Handbook for Systematic Reviews of Interventions 5.1.0 (Higgins 2011).

- Data analysis guided by the Cochrane Handbook for Systematic Reviews of Interventions 5.1.0 (Higgins 2011). 


\section{N D EX TERMS}

\section{Medical Subject Headings (MeSH)}

${ }^{\star}$ Oral Health; Dental Care; Dental Caries [*prevention \& control]; Dental Offices; Dental Plaque [* prevention \& control]; Gingivitis [ ${ }^{\star}$ prevention \& control]; Oral Hygiene [*education] [methods]; Randomized Controlled Trials as Topic; Self Care

\section{MeSH check words}

Adult; Child; Humans 